University of Louisville

ThinkIR: The University of Louisville's Institutional Repository

8-2015

\title{
The being of art and the art of being : hermeneutic ontology in Gadamer and Woolf.
}

Adam Noland,

University of Louisville

Follow this and additional works at: https://ir.library.louisville.edu/etd

Part of the English Language and Literature Commons, and the Philosophy Commons

\section{Recommended Citation}

Noland,, Adam, "The being of art and the art of being : hermeneutic ontology in Gadamer and Woolf." (2015). Electronic Theses and Dissertations. Paper 2249.

https://doi.org/10.18297/etd/2249

This Doctoral Dissertation is brought to you for free and open access by ThinkIR: The University of Louisville's Institutional Repository. It has been accepted for inclusion in Electronic Theses and Dissertations by an authorized administrator of ThinkIR: The University of Louisville's Institutional Repository. This title appears here courtesy of the author, who has retained all other copyrights. For more information, please contact thinkir@louisville.edu. 
THE BEING OF ART AND THE ART OF BEING: HERMENEUTIC ONTOLOGY IN GADAMER AND WOOLF

\author{
By \\ Adam Noland \\ B.A., Earlham College, 2005 \\ M.A., University of Louisville, 2007

\begin{abstract}
A Dissertation
Submitted to the Faculty of the

College of Arts and Sciences of the University of Louisville

in Partial Fulfillment of the Requirements

For the Degree of
\end{abstract}

Doctor of Philosophy in Humanities

Department of Humanities

University of Louisville

Louisville, Kentucky

August 2015 

THE BEING OF ART AND THE ART OF BEING: HERMENEUTIC ONTOLOGY IN GADAMER AND WOOLF

By

Adam Noland

B.A., Earlham College, 2005

M.A., University of Louisville,

A Dissertation Approved on

August 3, 2015

By the following Dissertation Committee:

Annette Allen

Osborne Wiggins

Mark Blum

David Owen 


\begin{abstract}
THE BEING OF ART AND THE ART OF BEING: HERMENEUTIC ONTOLOGY IN GADAMER AND WOOLF
\end{abstract}

August 3, 2015

Overall, the point of this project is to plumb the affinities between Gadamer's notion of hermeneutic ontology and Virginia Woolf's novels — how these affinities illuminate and contribute to an improved understanding of Gadamer's philosophical hermeneutics and Woolf's novels. For their part, Gadamer and Woolf belong to a similar cultural and historical milieu, each, in one way or another, a participant in the intellectual and artistic movement known as Modernism. This movement arose in response to the encroaching impersonality of scientific objectivity: both Woolf and Gadamer recognized the pitfalls of this objectivity, as it necessarily discounts the interpretive opportunity and responsibility of the individual. In Virginia Woolf's novels, we witness an intensification and enactment of one's interpretive imperative. In their structure and thematics, we encounter narratives that emphasize interpretive experiences and concepts - in them there is a heavy accent on those experiences that are binding, those experiences that shape consciousness and determine one's interpretive horizon. Hans-Georg Gadamer's philosophical outlook is especially useful for an analysis of these novels because his philosophy concerns the interpretation of day to day existence as it relates to the interpretation of a literary text. 
For its part, this philosophical framework hinges on the primacy of language - its universality and our unconsciousness of it — our belongingness to art — its ability to engage the meaningfulness of our perceptions and alter them too- and the dialogical situation in which all language use occurs - every utterance belongs to an occasion, its meaning only understandable as it relates to its context. Woolf's novels, for their part, highlight and emphasize these hermeneutic and ontological precepts. In these narratives, we encounter characters who interpret their existence; this interpretive dynamic — and the philosophical precepts that undergird them-are decisive for the significance and impact of these novels; interpretation and meaning are, in fact, the primary subject matter. I will argue that - as others have noted - a philosophical approach is useful for understanding these novels in their full scope, that there is a philosophical undercurrent that runs through these narratives, but that the philosophical scholarship on Woolf fails to fully appreciate the hermeneutic and ontological underpinnings that are decisive for their meaning. Instead of reading these novels through a lens of radical interpretation and questionability, the present scholarship relies on static concepts such as world, self, and reality. My argument is that these concepts are not static, that they are in movement as the individual engages with language, with art, and with others. In many ways, these novels are defined by this movement-how one's understanding and horizon is shaped by this engagement - and the consequences and implications therein. In relating Woolf's novels to Gadamer's philosophical hermeneutics, the reader acquires an improved sense for the reference of the words that populate her novels, words that determine the meaning of a world and the characters who inhabit it: these narratives include characters who strive to understand, who either fail or succeed based on their willingness to privilege and 
engage with experiences of language, of art, or dialogue with others. Now, in relating Gadamer's philosophical hermeneutics to Woolf's novels, the reader encounters an enactment of Gadamer's philosophical outlook: interpretation is inescapable-whether reading or living an average day, the world and its meaning are forever in motion and it is up to the individual to respond in kind. 


\section{TABLE OF CONTENTS}

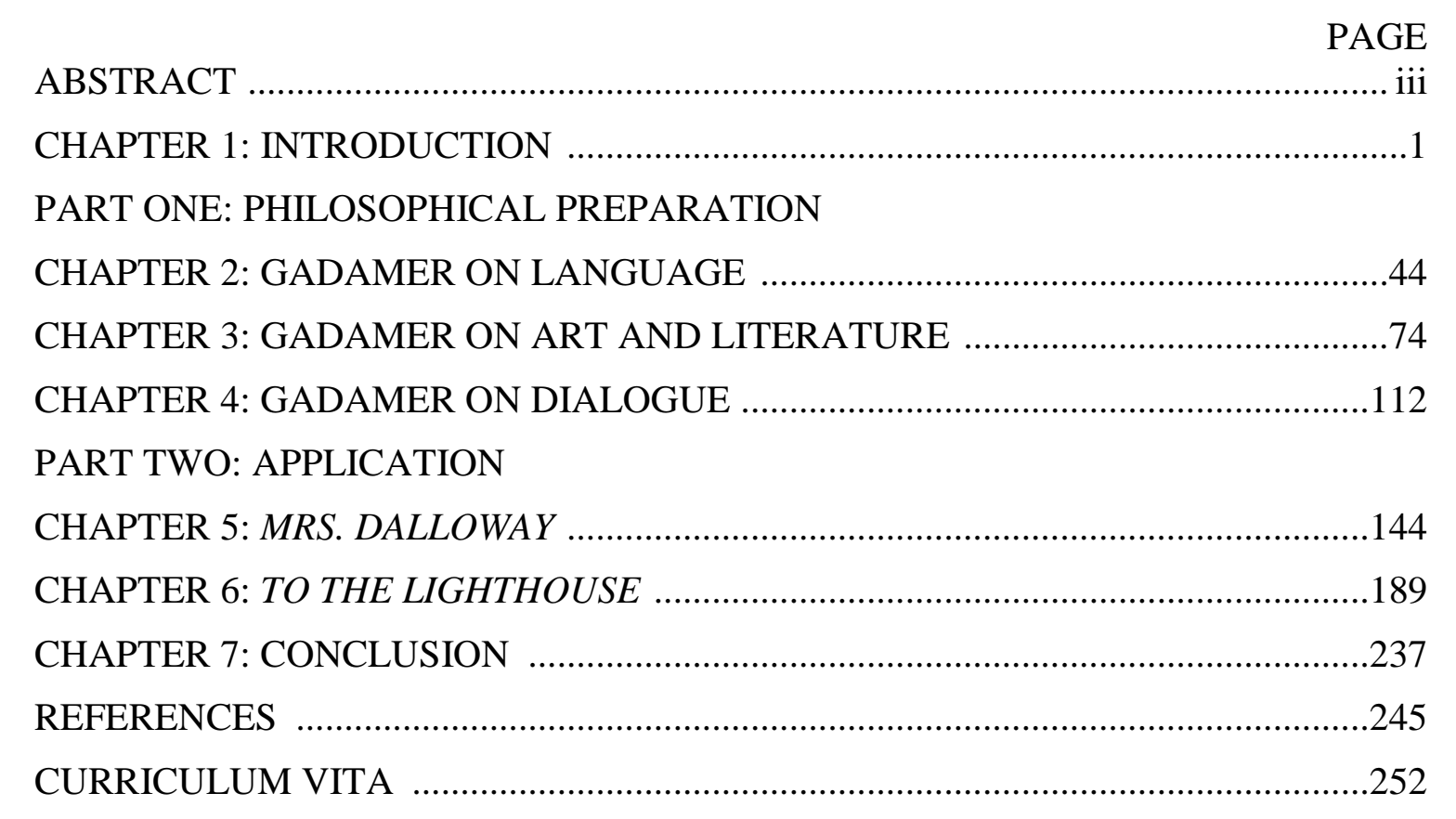




\section{CHAPTER 1}

\section{INTRODUCTION}

There are many ways to interpret Virginia Woolf's novels, but, up until now, no one has chosen to organize his or her interpretive effort around Hans-Georg Gadamer's hermeneutic ontology. For its part, hermeneutic ontology concerns how people interpret at all: the world is meaningless until it is presented. For Gadamer, the originary presentation is language. Language is the means by which people acquire a world (Truth and Method 440). Nevertheless, language is occasional: it belongs to an overall meaning while never fully able to express that totality. People, then, are tuned to engage with presentation, as a part of their/our linguisticality. We make and engage with art to enact our interpretive project: artworks are always what they are meant to be, but that meaning is inexhaustible. Undoubtedly, artworks do compel: through art we gain knowledge that we would have in no other way. As examples of art that take place in language, Woolf's novels provoke the reader: what is language? What is art? What does it mean to be? The answers, of course, are contained within the novels and are central to their interpretation; some of them will be fleshed out, too, in the following pages.

In particular, I will be interpreting two of Woolf's novels: Mrs. Dalloway, and To the Lighthouse. For their part, these novels are lyrical texts that explore language, art, and the wonder of being human. In all three, there is an interpenetration and codeterminacy: 
as one's relationship to language, art, or being changes, the other two morph also. In her novels, she tells the stories of characters who are presented as people — but with an emphasis on how the stories are told; the narrator takes center stage: the exact meaning or nature of these characters is not known; all views and portraits are productive, and lacking at the same time, in tension; who and what people are does vary, but each does have an identity that depends on assertion — each has to be someone or something, whoever or whatever it may be. Here the narrator describes and presents by way of language; the identity of these characters depends on that description; the only way that the reader knows these characters - the only way that they are anything at all. This particular aspect of the narrative reminds the reader: we are by way of language. Of course, Woolf's novels are not just reminders of the indeterminacy of identity and the neediness of language, they call attention to the text as text - the concept of text—and to art as art—its concept too. That is, Woolf's novels are about characters who interpret and negotiate existence, but they are also about novels and how they can mean. Certainly, Woolf plays with form; she makes a kind of argument: the meaning of a story depends much more on its narrative posture than its action. These novels jar the reader: part of their identity is to demand interpretive awareness; that is, the ubiquity of interpretation and its vital importance.

Like Woolf, Gadamer recognizes that human being and interpretation are inseparable. In his case, though, he is not an artist. He writes about art. As for Woolf, because she is a novelist, her commentary on art or the novel is embedded in the text itself: hers is not a direct commentary; instead she takes the path of inference. As an instantiation of art, her novels create the terms of their identity: what they mean and how 
they mean are determined by the particulars of each novel; each changes the identity of the genre and the identity of art. This particular nature of art and the novel is considered by Gadamer. The meaning of art and novels depends on what has come before: each new artistic creation is in dialogue with the past; in the moment of creation, though, its aim is to engage with the particulars of the present moment; to create something new; to gain insight. So it is that change, openness, newness - all are part of the identity of art. But it is not only art that Gadamer confronts: he also takes aim at the concept of language and the idea of the human being as he or she relates to the world. Gadamer's starting point is the concept of text and its proper interpretation. He argues that a text is contemporaneous with all of its readers and that part of its identity is to endure; texts stem from the need for posterity, the urge to carve out a stance on the present moment that nevertheless remains understandable and open to future application ("Text and Interpretation" 34).

Furthermore, texts are written because they assert themselves: the words are always the same even if the meaning changes with the reader or the cultural moment. In texts, there is a self-legitimacy and self-attestation. There is intentionality too: it is what it is meant to be. The reader faces this dynamic of the text and wants to do it justice: he or she is pushed to think about what the words mean; the reader is caught between two poles - that of his or her own world and that of the text. When confronted with a literary text, interpretation is inescapable. The meaning of the text, though, does not lie directly with the text or with the reader, it lies somewhere in between. It lies in the basic function of language, of the recognition of the true world.

The reader's task is to recognize the world for what it is. Individuality demands that the world be different for each person, but, at the same time, language is the product 
of a shared context; in all cases, language is so intimately bound with what it means to be human that any and all language is potentially understandable, for each manifestation is a testimony of the human being's relationship to the world. It is this relationship that the concept of text provokes. A text stakes a claim and makes an assertion: this is what the world means. Of course, a text too is an answer to a question and also makes its own query to the reader (Gadamer, Truth and Method 367). This process never ends. So when a reader faces a text, the reader is reminded of his or her own opinion of the world, for the language of a text is always alien and different: the reader's task is to make sense of the world now that his or her horizon has been disrupted - a task of assimilation.

Indeed, Gadamer's starting point for his philosophy is the proper interpretation of texts, but his concerns are not straightforward. Like Woolf demonstrates in her novels, Gadamer argues that human being, language, and art are part of the same fabric, each impinging the one on the other (Hans-Georg Gadamer on Education, Poetry, and History 90). In order to properly interpret a literary text, it is first necessary to understand the role of language in human being and the role of art in human being. In other words, the literary text is not just an object; its meaning depends on language and history and presentation - just like we do; something about how we understand the world and what it means to us; we are implicated every time we read. This dynamic will guide my dissertation as I move forward.

Before further entering into the particulars of this project, it is worth outlining the pillars of this interpretive approach. To begin with, Virginia Woolf's novels are literary texts that engage the meaningfulness of the world. This meaning, though, depends on the participation of the reader and his or her enactment of the text. The words are forever the 
same, but their meaning will change with each reader. Each reader belongs to his or her own world, and this world is perceived and understood within language. This is the case for all people, in fact. This interaction between the individual and the world is primary, decisive for all interpretation. Gadamer organizes his entire interpretive structure based on this interaction. His interpretive approach might be summarized in the following manner:

1) To be human is to have language. Before we even realize it, we already use and understand language. The world is meaningful and reality is understandable because of language.

2) More can always be said. As we live in language, and language is necessarily meaningful and interpretive, we forever strive to reach a correspondence between all that the world might be and all that we proclaim it to be. However, as we describe the world, this act of description belongs to the occasion of its utterance; the identity of the world becomes something else as it is described. The potential meanings of the world forever outpace our engagement with these meanings.

3) All interpretation is perspectival. We always belong to a situation, and this situation necessarily demands interpretation. In all, we interpret because each of us brings a unique perspective and it is our task to account for this perspective, so that we might approach a correspondence between the meaning of the world and our understanding of this meaning. This effort, though, is always an approximation, never completing itself.

4) All interpretation is dialogical. Texts provoke the reader: they demand that we share in an overall meaning, a meaning which envelops both the reader and the 
text. It is only within the context of this overall significance that the text has meaning and the reader understands. When someone is about to read a text, he or she cannot but anticipate its content, its meaning. It is only as an answer to a question that the text can mean anything. At the same time, the text will necessarily disrupt the presuppositions of the question, the text itself becoming the questioner, forcing the reader to answer. This dialogue is made possible because both the reader and the text belong to an overall meaning, with neither possessing a monopoly on this meaning, each with an equal share. This sense of an overall meaning is forever present, but the particulars change with the passage of time.

5) The historicity of meaning. In general, possibility is shaped by the historical moment. It is necessary to account for historical difference, to acknowledge one's historical moment and that of the text. In doing so, one might avoid anachronistic falsehood. Time comprehends change: there is always difference but, at the same time, this difference is shaped by a shared ontology — each of us has a world and it is this belongingness that determines historical difference.

6) A fusion of horizons between text and reader. All interaction between text and reader is a matter of mediating identity and difference: the worlds of the text and reader are both the same and different. In the end, a new meaning emerges each time a text is read, a meaning that accounts for this tension between sameness and difference. 
Overall, the point of this project is to plumb the affinities between Gadamer's notion of hermeneutic ontology and Virginia Woolf's novels—-how these affinities illuminate and contribute to an improved understanding of Gadamer's philosophical hermeneutics and Woolf's novels. For their part, Gadamer and Woolf belong to a similar cultural and historical milieu, each, in one way or another, a participant in the intellectual and artistic movement known as Modernism. This movement arose in response to the encroaching impersonality of scientific objectivity: both Woolf and Gadamer recognized the pitfalls of this objectivity, as it necessarily discounts the interpretive opportunity and responsibility of the individual. In Virginia Woolf's novels, we witness an intensification and enactment of one's interpretive imperative. In their structure and thematics, we encounter narratives that emphasize interpretive experiences and concepts-in them there is a heavy accent on those experiences that are binding, those experiences that shape consciousness and determine one's interpretive horizon. Hans-Georg Gadamer's philosophical outlook is especially useful for an analysis of these novels because his philosophy concerns the interpretation of day to day existence as it relates to the interpretation of a literary text. For its part, this philosophical framework hinges on the primacy of language — its universality and our unconsciousness of it—our belongingness to art - its ability to engage the meaningfulness of our perceptions and alter them tooand the dialogical situation in which all language use occurs - every utterance belongs to an occasion, its meaning only understandable as it relates to its context. Woolf's novels, for their part, highlight and emphasize these hermeneutic and ontological precepts. In these narratives, we encounter characters who interpret their existence; this interpretive dynamic — and the philosophical precepts that undergird them — are decisive for the 
significance and impact of these novels; interpretation and meaning are, in fact, the primary subject matter. I will argue that —as others have noted — a philosophical approach is useful for understanding these novels in their full scope, that there is a philosophical undercurrent that runs through these narratives, but that the philosophical scholarship on Woolf fails to fully appreciate the hermeneutic and ontological underpinnings that are decisive for their meaning. Instead of reading these novels through a lens of radical interpretation and questionability, the present scholarship relies on static concepts such as world, self, and reality. My argument is that these concepts are not static, that they are in movement as the individual engages with language, with art, and with others. In many ways, these novels are defined by this movement—how one's understanding and horizon is shaped by this engagement — and the consequences and implications therein. In relating Woolf's novels to Gadamer's philosophical hermeneutics, the reader acquires an improved sense for the reference of the words that populate her novels, words that determine the meaning of a world and the characters who inhabit it: these narratives include characters who strive to understand, who either fail or succeed based on their willingness to privilege and engage with experiences of language, of art, or dialogue with others. Now, in relating Gadamer's philosophical hermeneutics to Woolf's novels, the reader encounters an enactment of Gadamer's philosophical outlook: interpretation is inescapable - whether reading or living an average day, the world and its meaning are forever in motion and it is up to the individual to respond in kind.

\section{Gadamer on Language}


As has already been mentioned, Gadamer's starting point is the concept of text. For him, the text is the hermeneutic object par excellence. A text demands that the reader become aware of his or her relationship to language and to history; the words of a text belong to a historical situation and are a result of history, too; these words confront the reader, whose own situation is unique also. A text, then, makes a claim that the reader cannot discount. Necessarily, the reader grows from this encounter: the texture of his or her being has become more intricate, stronger. In this process there is a doubling back: as the reader wonders about the meaning of the words in the text, he or she wonders about the meaning of words in general, about their role in deciphering what the world means. For Gadamer, "the midworld of language has proven itself to be the true dimension of that which is given" ("Text and Interpretation" 29). A text transports the reader into this mindset: that the world is only understandable when it is presented, when it comes into language. The reader is reminded of his or her relationships, of his or her process, of those conditions and situations that have yielded the self-presentation of being. The reader is reminded to honor and privilege language, for there is no world unless it is named: "To come into language does not mean that a second being is acquired. Rather, what something presents itself as belongs to its own being" (Truth and Method 470). When reading a text, the participant is drawn into this dynamic: the world appears different every day, is different, but it is not necessarily alien and strange; it can be appropriated, even understood — the world belongs to its presentation.

Each view, though, each presentation of the world, is always deficient, never complete. For Gadamer, part of the identity of language is that it is occasional; it belongs to the occasion, never able to fully name the whole, the unity; each particular instance is 
new and different, contextualized by the whole, even changing it, but never complete and entire:

But there is another dialectic of the word, which accords to every word an inner dimension of multiplication: every word breaks forth as if from a center and is related to a whole, through which alone it is a word. Every word causes the whole of language to which it belongs to resonate and the whole world-view that underlies it to appear. Thus every word, as the event of a moment, carries with it the unsaid, to which it is related by responding and summoning. The occasionality of human speech is not a casual imperfection of its expressive power; it is, rather, the logical expression of the living virtuality of speech that brings a totality of meaning into play, without being able to express it totally. All human speaking is finite in such a way that there is laid up within it an infinity of meaning to be explicated and laid out. That is why the hermeneutical phenomenon also can be illuminated only in light of the fundamental finitude of being, which is wholly verbal in character (Truth and Method 454).

That is, we all have a vague sense of the world and its truth, and we are always moving towards some sort of confirmation or complete understanding, but language is discursive and situational: it unfolds through time and it changes with each new moment; because of this, we only acquire an aspect or view of the way things are. This nature of language is both productive and frustrating: it leads us to continuously search and try; it also means that we will never reach our goal. Nevertheless, we engage with texts and language for this very reason: as a reminder of our humanity and its potential.

\section{Gadamer on Art and Literature}

If language is the means by which we have a world, one wonders how art fits into this estimation. Language is the original self-presentation of being; art takes notice of this situation and reminds us that all meaning must first be presented; there is no 
interpretation if there is no appearance. Gadamer states this dynamic directly: "The world that appears in the play of presentation does not stand like a copy next to the real world, but is that world in the heightened truth of its being" (Truth and Method 132). Language is the originary presentation, but art mines this dynamic, playing with our natural receptiveness to engage with presentation. So, when we encounter an artwork we are reminded of ourselves; we are reminded that the world depends on its presentation. Each presentation, though, is new and different and always intentional. An artwork is always more than what we make of it-its interpretive possibilities are inexhaustible: yet all artistic production "intend[s] what it produces to be what it is" (The Relevance of the Beautiful 25). Because art is a self-enclosed, internally coherent world that hinges on its self-fulfillment, the artistic product creates the terms of its own interpretation: the task of the interpreter is to do justice to those terms.

Gadamer makes the argument that art is arresting: part of the nature of art is to captivate; so much so that the participant forgets about him or herself, for a moment at least. In that captivation, the participant notices nothing else but the appearance itself: "In the apparent particularity of sensuous appearance, which we always attempt to relate to the universal, there is something in our experience of the beautiful that arrests us and compels us to dwell upon the individual appearance itself" (The Relevance of the Beautiful 16). This concept of the beautiful is important to Gadamer's hermeneutics. He argues that beauty closes the gap between the appearance of something and its true identity. Therefore, when we encounter beauty in art we encounter the thing for what it is and nothing else. For this reason, because it allows us to encounter the world for what it is, the experience of art signifies "an increase in being" (The Relevance of the Beautiful 
15). Of course, like being, a work of art comprehends the fundamental tension between revealment and concealedness. ("The Truth of the Work of Art" 107). We never fully know the meaning of existence or of art, but we are always aware that there is this tension. Part of the accomplishment of art is to face this tension and seek some sort of resolution: "The only relevant thing is whether we encounter a spiritual and ordering energy in the work $[\ldots]$ a new order of unity in tension" ("Art and Imitation" 103). Art encourages us to embrace the ambiguities, doubts and insights that we all experience, giving us a sense for their complementary position in our lives.

For its part, literature and the poetic word are examples of art that depend on language. In literature there is "a counterplay between the intended meaning and the selfpresentation of the language (Gadamer in Conversation 74). Unconsciousness of language is our natural state: when we speak and converse it does not occur to us that we are using language and that language is, or can be, undependable. When we speak, our concern is to reach an agreement about matters of fact, to recognize the way things are. And of course, when we read literature, there is a meaning that is conveyed through the language; we want to understand this meaning and that is our main focus; but, in literature, we become aware of the variability of language, of its indeterminacy and fecundity — we notice that the language itself is in the foreground: the language is new and different, creative too; this language describes a world heretofore unknown.

With this dynamic in mind, we can say that poetic language fulfills itself ("On the Contribution of Poetry to the Search for Truth" 111-2). It does not seek any verification outside of itself. Poetic language does not depend on anything else besides its presentation. The poetic word is always about something but it is always about itself too: 
it is about the accomplishment of language and its role in our life. Gadamer describes the principal accomplishment of language in the following manner: "what the word evokes is there" ("On the Contribution of Poetry to the Search for Truth" 113). Because of language we have a world: the poetic word proves insightful because it challenges us to recognize our own creative mandate - the world can be rich or bland, full or empty, depending on its description.

Language provides the fundamental articulations that guide our understanding of the world. Language is co-existent with our growth; our familiarity with the world too. It is a process of 'making ourselves at home': "The word of the poet does not simply continue this process [...] Instead it stands over against this process like a mirror held up to it. But what appears in the mirror is not the world, nor this or that thing in the world, rather this nearness or familiarity itself in which we stand for a while" ("On the Contribution of Poetry to the Search for Truth" 114-15). We enter into the poetic text and we encounter language that, up to a point, describes the world as we know it, while at the same time it illuminates the world in new and different ways; the words take on a complete naturalness, as if they were always meant to be there, as if each word belonged precisely to its place: there is nothing contrived about these words, just like our first experience with language — everything belongs.

\section{Gadamer on Dialogue}

Dialogue is a useful concept for a variety of reasons. Overall, it will enable me to bring together my cogitations on language and art: both concepts will now dwell in this chapter, illuminated from several different angles. Also, of course, dialogue is central to my interpretive project: I will be in dialogue with Virginia Woolf's novels and dialogue 
is a principal thematic concern in Woolf's novels. According to Gadamer, interpretation itself is defined by dialogue. In its entirety, dialogue is the source of language and art and meaning. There is no such thing as an individual language: "Language is a we, in that we are assigned our place in relation to each other, and in which the individual has no fixed borders [...] we all must overstep our own personal boundaries/limits of understanding to understand" (Gadamer in Conversation 56). We are social creatures and all meaning depends on that socialization: our relationships happen to be our greatest source of fulfillment. Looking ahead to Woolf's novels, we can certainly notice a heavy emphasis placed on the limits and borders between people; people need each other and depend on each other, each a source of conflict and resolution. As Gadamer says, in dialogue "world is disclosed" (Truth and Method 443). In all cases, for every person, the mandate is to recognize the world for what it is. Dialogue has its own energy; it sweeps the participants along: each individual perspective is limited and temporary; in dialogue, though, we test our understanding and our one-sidedness, now pushed to see the thing from another angle. Dialogue yields insight. In dialogue, different aspects of the world appear.

Overall, language and meaning depend on dialogue: "Are we not always answering when we venture a word, by which I mean are we not trying to respond to the other, to the occasion, to the issue, to the causa" ("Culture and the Word" 5). Language and meaning are defined by movement, change: the answers and questions always alter because the hermeneutical situation consistently shifts. Virginia Woolf engages with this dynamic in her fiction and it dominates the interpretation of texts, too. The hermeneutical imagination hinges on the following point: "a sense of the questionableness of something and what this requires of us" (Gadamer in Conversation 42). We ask questions of 
something to open it up: it can either be this way or that way. Then we answer the question and a new question appears: the answer, of course, has its own indeterminacyit too can go one way or another. This series of questions and answers leads to a path: interpretation "implies pointing in a particular direction" ("Composition and Interpretation" 68). What that direction is, or what it should be, is hard to say, but the goal is to recognize the thing for what it is: of course, that thing is going to change because we change. Nevertheless, sincere engagement with the object is the most productive path towards truth:

The hermeneutical experience also has its own rigor: that of uninterrupted listening. A thing does not present itself to the hermeneutical experience without an effort special to it, namely that of 'being negative toward itself.' A person who is trying to understand a text has to keep something at a distance - namely everything that suggests itself, on the basis of his own prejudices, as the meaning expected-as soon as it is rejected by the sense of the text itself (Truth and Method 461).

This approach described here applies to the interpretation of texts and the interpretation of existence as we experience the world. It is a kind of dialogue: here there is an assertion, then there is a response; each assertion disrupts the horizon of the interpreterhere he or she realizes that his or her expectations were not entirely accurate; here, then, he or she adjusts expectations; his or her view is now in harmony with the presentation of the world.

\section{Literature Review}

At this point, I would like to begin by looking at those studies that most closely resemble my own. In this manner I might show how my own approach is part of a more general discussion and prove that it provides insight to that discussion. That is, Mark 
Hussey's book The Singing of the Real World, and A.O. Frank's book The Philosophy of Virginia Woolf's Fiction clearly indicate that Virginia Woolf's novels and philosophy belong together. The question, though, is what kind of philosophy and what kind of analysis. Before going into a more detailed presentation of my own approach, I would like to discuss these two works and by doing so, by way of contrast, my own approach. Hussey's study states his intent directly: "The primary focus of this study is Woolf's record of a 'reality' that she apprehended in the actual world, but that transcends it" (xix). The key terms in this statement are reality, actual world, and transcendence. Here, Hussey's mistake is that he relies on terms that he allows to be static. He places reality and the actual world on one side and transcendence on the other. Whereas, I contend, reality and transcendence belong together-a statement supported by Woolf's novels, I would argue. In other words, one might say that reality includes its very transcendence as part of its identity. How is this so? How can reality go beyond itself and still be real? The answer has to do with language and art. That is, reality depends on its being named and pictured—so, reality is provisional and in process. Reality, in and of itself, is defined by change, a moving further and beyond, by transcendence of itself. There is no way to avoid language and art, but the yield can be less or more, depending on the degree of participation and adaptation to circumstance.

Hussey's approach to Woolf's writing also chooses to focus on such concepts as knowledge, the self and being: "Virginia Woolf's novels are concerned with knowledge of others, and knowledge of the world. The question of the nature of the self is at the heart of her thinking, and, I believe, is the dynamic of her fiction. Her novels uncover what Georges Poulet has called 'the essentially religious nature of human centrality' $[\ldots]$ 
Her point of departure is always a simple, but radical wonder in the face of being at all (what Heidegger called Thaumazein)" (xv). His analysis is appropriate, but, once again, it depends on static concepts that do not reflect the depth and searing insight of Woolf's thought. Her writing points to a need for a radical openness, an impulse to question everything. To talk about knowledge or the self is useful, but derivative of being in and of itself - the disclosure and withdrawal that point us toward ways of knowing and identity construction. In my mind, Woolf challenges the usefulness and dependability of using such concepts. To Hussey's credit—and in support of my own argument—he does recognize that Woolf's thought does point to an ontological concern (the mystery and wonder of being at all), but his own argument, up to a point, undermines this recognition. In contrast with Hussey's analysis, the goal of A.O. Frank's study of Virginia Woolf's fiction is to provide the philosophical associations which Woolf's fiction provokes. Frank focuses on central ideas in Woolf's novels and then elaborates on those ideas as they manifest themselves in philosophy. Unlike mine, Frank's project is not defined by interpretation or hermeneutics as the central philosophical concept. She, of course, does interpret the novels, but only inasmuch as her interpretations support the philosophical concepts and vice versa. She mines the continental philosophical tradition and even cites Gadamer as an inspiration, but ignores him when it comes time to actually apply her interpretive framework. Overall, though, Frank's effort does suggest that my own ideas are not in isolation; rather, they belong to an extensive field which acknowledges that philosophy and literature ask and answer similar questions; even more, more specifically, that Gadamer and Woolf ask and answer similar questions: "The aesthetic turn in modern philosophy as it is described by Gadamer in Truth and Method, 
whereby art offers an appropriate medium of understanding for problems that discursive, methodical philosophy of the Socratic-Cartesian paradigm has failed to answer, offers a position which comes much closer to a description of Woolf's own intellectual stance" (21-2). I agree with this statement, and my own project would be unnecessary if Frank had chosen to analyze Woolf's novels by way of Gadamer's ideas, but she did not.

Up until now, it has not been very popular to link Gadamer and Woolf. Frank's study is an exception and so is Linda O'Neill's article, "Gadamer meets Woolf in a Room of One's Own'. O'Neill wrote her article in the context of education, but it is still useful to mention because it affirms the relevancy of my own study and also the importance of language and art in human development. She says: "Woolf brings to life through literature what Gadamer affirms through philosophical hermeneutics: that the primordial lived experiences, in and outside of schools, cannot be understood without careful attention to accessible traditions, embodied language, and potential transcendence in pursuit of intellectual freedom and practical wisdom” (337). Here O’Neill suggests that Woolf and Gadamer point in the same direction - that analysis and knowledge should have "primordial lived experiences" as a starting point. Instead of relying on one-sizefits-all methods and constructions, one should recognize that these sort of approaches stem from the same material that we all possess: in our relationships to each other, to language, to art, and to the world. To interpret is to recognize the questionableness of something and it is to share in the general ontological relationship of human being to the world. By way of participation, different aspects of the thing itself appears. O’Neill recognizes this emphasis that Gadamer and Woolf place on participation in tradition. In participation, she would note, one can develop a greater sense of meaning: the truth of 
being in the world. And, of course, it is a meaning that is individualized, unique to one's particular history and place in the world.

Yes, a handful of critics have connected Virginia Woolf and Hans-Georg Gadamer. Others, also, have noted a connection between Woolf and Gadamer's teacher, Martin Heidegger. Heidegger's life work was defined by a need to go beyond or to destroy metaphysics. He did not believe that there was a static world—out there—which was the real and true world and that all attempts at knowing or understanding were just attempts at approximating or approaching this true reality. Rather, he argued that being and understanding are co-existent; the world and the perception of it are co-existent; to belong in the world is already to understand it. Humans understand something and are on the way towards understanding more; furthermore, this understanding includes a fundamental tension between disclosure and withdrawal: the world is on a swivel and its meaning too. If this is the case, if reality itself is in flux, then interpretation takes on an even greater role: that which is to be understood is to be questioned; to find the right question is to participate in meaning. In her essay, "Heidegger in Woolf's Clothing", Heidi Storl recognizes Heidegger's impulse as seen in Woolf's writing: "Virginia Woolf's work reveals a deep understanding of, as well as an appreciation for, sustained meditation on that-which-is" (1). I agree with Storl's estimation and would say that literature is the ideal medium for just such a consideration. Literature takes place in language and places language as the medium of its existence; the appearance of language is its very truth - here there is no gap between what the language says and what it is. However, the meaning of such language is indeterminate: interpretation is included in its 
identity. Woolf's novels play with this dynamic and present characters and storylines that wrestle with it too: what is the world and how are we to understand it?

There are some other studies of Virginia Woolf and her fiction I would like to examine. I have chosen to mention these studies because they recognize the philosophical undertones of her work. In general, these studies focus on what is held in common between people and what is constitutive of how people find that common ground - that which shapes knowledge and understanding at all. Jane Duran's article "Virginia Woolf, Time, and the Real" is just one such example. She says: "Woolf's writing forces us to look closely at what is constitutive of the real in our lives. In this sense, Woolf's novels are philosophical. They pose questions driven by wonder, and they answer those questions by depicting those very moments, few though they may be, when a striking sense of the urgently real breaks through our ruminations, and makes itself felt in an unmistakable way" (6). This article is useful for this proposal because it reinforces the direction which I have chosen to take: she too says that Woolf's novels are philosophical and also that they examine reality. The real, of course, is hard to pin down but the merit of this article lies in its suggestion that the real is something that happens to us. The real and the true appear when people engage with the world; the world and its nature makes itself felt precisely because we belong to it.

In Howard Harper's book-length study, Between Language and Silence: The Novels of Virginia Woolf, we see a similar focus, but with a greater emphasis on effort and the role of the subject: here it is the subject's task to find meaning, one that requires tremendous effort and work. In this scene, the world is separate, waiting to be interpreted: "Meaning is not something inherent, or at least self-evident, in the given world; rather, it 
is something to be discovered, achieved, wrested from the struggle with the protean, phenomenal world. The discovery of transcendent meaning becomes the great mythic theme of this drama of intentionality" (3). In this passage we get the flip-side of the coin: instead of meaning as something that happens to us, it is something that we make happen. This assertion is a half-truth. It is necessary to engage with the world and, at times, to be stubborn in that engagement (to not give up), but we are only able to find new ways of being and more coherent meaning because the world already means something to us; it is not always a struggle, sometimes, instead, we glide, propelled by our own momentum, the truth of the world and its self-disclosure deeply resonant.

Virginia Woolf and her novels promote the idea that there is no one fixed, immovable world; the world to be understood is up for debate; to say that things are one way or another is to accept the unquestioned assumptions that have led to subjugation and inequality. Instead, Woolf aimed to present a world that varies, depending on perspective, a world that is never truly, really known. Even Woolf's narrators are unsure about the world—all is conjecture, possibility, as James Hafley notes in his essay, "Virginia Woolf's Narrators and the "Art of Life"”: "Woolf's narrators are creators and not reporters real or supposed; they do not tell the stories as much as the stories tell them; it is they who are the central drama, the central fiction. The abstract and general, the objective and true, are in this art to be located only in the concrete, specific, subjective and invented. Reality is invention [...]" (31). That is, Woolf's novels focus on the manner in which the story is told — the attitude of the narrator towards the story; the content of any story depends on the way it is told. By extension, one might say that reality depends on how it is narrated. 
Now, at this point, I would like to take my summary of Woolf studies in a new direction. This direction is united by a thread that goes through them: what all people share, what is held in common. Gillian Beer's study, Virginia Woolf: The Common Ground, is one such attempt. Although the following passage is specifically about Woolf's novel, The Waves, its tenor is accurate in its description of her novels as a whole:

Like the waves, the person and people come together, then sink 'into one of those silences which are now and again broken by a few words, as if a fin rose in the wastes of silence'. The pressure of 'I' and 'we' have here formed a work at standing water, without tides. The Waves is dense on the page, intensely verbal and articulate, but it searches endlessly, through its rhythms of recounting, for a way of giving utterance to all that is unpossessed by writing. Virginia Woolf is not here creating simply an exploration of individualism; she seeks what is held in common - and as commonly lost (71-2).

To understand Beer's point, it is worth mentioning this tension between I and We that Beer discusses. This tension might be related to Gadamer's concept of dialogue. In all cases there is no completely autonomous I or self. The I is unique and individual but it is also dependent on others. Growth depends on other people and so does language. It is this tension that we hold in common and it is also our need for language, a need that is never entirely satisfied. That is, Virginia Woolf gives voice to the feeling that our voice is deficient; that the I is always searching for something that is never found.

So it is that Virginia Woolf presents characters who do not know, but still have an idea. These characters recognize the mystery and accept it; they build on this mystery and incorporate it into their sense of meaning. Eric Auerbach's famous essay, "The Brown Stocking", recognizes as much: "And here, furthermore, one comes upon the order and the interpretation of life which arises from life itself" (31). Life from life, a circular and 
solipsistic way of thinking, but still true: here the aim is to avoid false thinking or to be diligent in analysis; there is never a completely right way of thinking, but it can be buoyed by uninterrupted listening and a willingness to ask questions. Through participation, one might come closer to a sense of how things are. And, of course, all people have this in common: the interpretation of life from life. Auerbach suggests that Woolf contributes to understanding because her fiction spotlights random moments and random thoughts - this is how people experience life: as a series of moments that provoke thoughts that are not sequential or tied into a neat narrative; instead, the thoughts appear and disappear, without our willing or doing. This is what it means to be human: "The more numerous, varied, and simple the people are who appear as subjects of such random moments, the more effectively must what they have in common shine forth" (33). Instead of focusing on what is commonly thought to be big, Woolf privileges what is commonly thought to be small. We all have perceptions of the world and these perceptions are forever valid - they seize us before we even opt to honor them.

Central to my thesis is the idea that art is a part of life and life is a part of art; art is always present, part of how we perceive and understand. This is a dynamic felt by Woolf and one that she weaved into her novels. Critics, too, have noticed this situation. Penelope Ingram's article, “'One Drifts Apart': To the Lighthouse as Art of Response,” is a strong example : "I see the relationship between art and life in To the Lighthouse as an organic unity, in a relation of part to whole. Art is realized through life as life is realized through art” (“"One Drifts Apart': To the Lighthouse as art of response” 4). Art demands interpretation and it stakes a claim: despite all attempts to dismiss its validity, it remains because presence is part of its identity - it is there, just like humans are here, a token of 
order and vision. To engage with art is to engage with life; it is to ask, who am I, what is this, and how can it be?

Other essays approach these considerations also. Alice van Buren Kelley's collection, To the Lighthouse: The Marriage of Life and Art is just one example. This study argues that artistic sensibility is vital to understanding and meaning. That is, the artist is willing to go beyond accepted forms of thought; the artist asks what it is that makes understanding and meaning possible in the first place; a sense for the basic material that is molded into hard and fast reality and a willingness to remold that reality into one that fits the individual. Van Buren Kelley states her position: "So life is not chaotic, threatening, destructive, but ordered and whole, if only we can see it. If we can uncover the pattern, reveal the balance that keeps all oppositions in equilibrium, we shall see what the artist sees, and what is really there: the fact that life is a work of art" (74). Through art, then, one can create the terms of one's reality; one can see that paradox and opposition and tension are part of being and instead of trying to ignore them one can incorporate them into one's understanding; no longer subversive and subterranean, now included, now in balance.

Numerous critics have thought about Woolf's work and have attempted to interpret her novels; each has engaged with the texts and tried to put in words his or her particular understanding: each critic has his or her own particular history, language, and way of thinking; the novels, then, when interpreted, are restated, reassembled, assimilated; a mediation occurs. Here there is a paradox: in order for the novel to remain the same, to be itself, it must be put into a new language; a language that fits the interpreter and resonates, so that the meaning is maximized; all approach an originary 
meaning, one that is stated and restated. It is this particular dynamic that Gadamer explores in his philosophy - the nature of interpretation. His philosophy is multi-layered and many-sided. Overall, it is based on two, complementary ideas, which exert a backpressure, the one on the other; when one changes, so does the other. First, and most importantly, is human being's relationship to the world; the world in and of itself means something, is to be interpreted. The second idea is how to interpret a text: to consider the identity of a text. When one confronts a text, there is a fixed meaning that nevertheless varies depending on the interpreter. Here the reader is reminded of language; the role of language in interpretation. Whatever a text means has to do with what the world means. Although no critic has chosen to use Gadamer's philosophical outlook to frame his or her interpretation of literature, many critics have considered his philosophy, its impact and implications. In fact, many critics have approached this idea that different and new facets of the world appear when we engage with it. Jens Kertscher's essay "“We Understand Differently, If We Understand at All': Gadamer's Ontology of Language Reconsidered" is one such example. This essay hinges on the following point: "Rather than a matter of grasping an objective meaning, understanding becomes, therefore, a matter of the taking up of a meaning that has already been revealed" (149). Because we have language, we always have a picture of the way things are, but the picture is always and forever incomplete. However, the more we participate, the more we feel in tune with the world, uniquely, and for us.

Gunter Figal's analysis, “The Doing of the Thing Itself: Gadamer's Hermeneutic Ontology of Language" is another essay that presents similar themes. Here the reader is reminded of the idea that language speaks us instead of we speak language. That is, by 
way of language, the world presents itself. The impulse to use language is the impetus to be at one with the world, to belong. When we use language, there is always an undercurrent of possibility — what is right and what is appropriate is never truly known, but the language itself is nevertheless valid and legitimate in its own right; this legitimacy leads to further clarification, to an openness for more, a foundation for asking questions and gaining insight: "What already has been, for example a text, is as an event, because it addresses one with a question. And the interpretation happens as the saying again and the further saying of the said" (111). The need to use language is the need to answer a question; all language both answers a question and asks a question: the world becomes, simultaneously, both more understandable and more mysterious. Mystery, though, becomes less antagonistic and less of a saboteur, acquiring an element of productivity, an avenue to truth.

For its part, understanding is an important concept in Gadamer's philosophical hermeneutics. Understanding is an idea that we all relate to in our own, individual way; it is not a technical term; furthermore it is a term that allows for more technical, scientific approaches to even be possible. In a way, Gadamer's concept of understanding depends on this sense of understanding - that it is non-technical and that all rely on understanding and participate in understanding; however, Gadamer shapes an entire philosophical outlook based on this very concept: understanding is primordial and it is valuable. To this end, Jean Grondin has written an essay to clarify the concept: it is titled "Gadamer's Basic Understanding of Understanding". In the essay, Grondin divides understanding into several different categories: understanding can imply and relate rather variously. On the other hand, Grondin also attempts to abstract and enfold the various categories into one 
overarching approach: "The understanding that he characterizes, following Heidegger, is the "original form of the realization of our existence" (36). To be is to understand; how, of course, and in what way and to what end — these are considerations that demand further clarification, a delicate ecosystem that also demands revision, adjustment and readjustment.

Engagement, one might say, is the path to self-fulfillment. For Gadamer, engagement inheres the notion of linguisticality, the need to put into words. Words are the primordial and original way that any human being has a world. People forget about words, though; part of why they mean so much has to do with the power of their very presence; in the end, they can never be discarded or discounted - precisely because they are forever forgotten. Words allow the world to appear and it is in their appearance that the world is understandable; to submit to language, to commit and to enact — Grondin highlights just such a notion as central in Gadamer's thought: "The important idea for Gadamer's notion of interpretation and its inherent linguisticality is that the listener be taken up by what he seeks to understand, that he responds, interprets, searches for words or articulation and thus understands" (42). One might say that meaning is a wave that carries the participant to new places; having arrived, then, the new is to be mediated by what has come before; the means for doing this is language: now the world is different but, if named, more understandable.

Because the seconds pass and the world is different with each one, because language is never stable and meaning changes with each moment, individuals are provoked and pushed to find a momentary stability: we speak, we write and the words are a testimony. The words are a fortress, a defense against the void, nothingness. The 
appearance of words mediates a curious tension: on one side, they are never entirely accurate (more can always be said); on the other, they are self-legitimating - their appearance is their meaning. This tension leads to the idea that all language use is a kind of translation and that the practice of translation helps the participant to become aware of this dynamic. Translation reminds the interpreter that there is an original meaning; that this meaning is related to the human being's relationship to the world. This idea guides John Sallis' essay “The Hermeneutics of Translation”. This essay might be summarized in the following manner: "Because the manifold of discourse as such is produced by translation, each fold is a likeness or symbol of that back upon which it is folded. This multiple folding, this manifold that translation produces in and as discourse as such, is the originary complication" (68). Put in other words, one might say that any time language is used it is a kind of translation. Each application of language, each particular situation, is always different: up to that point, the words have appeared to describe something elsenow they are to be used (translated) for the new situation. Translation, as such, is a hermeneutical guidepost, a reminder of the interpretive demand that we all experience when pushed to use language.

Gadamer's hermeneutics has to do with the concept of truth and it also has to do with (what he calls) the human sciences as they contrast with natural sciences. Overall, in general, the concept of science might be thought about as a kind of construction that depends on methodology, rigor, discipline, constraint, and many other factors.

Furthermore, the natural sciences hinge on distanciation—so that the scientist's prejudices do not cloud his or her results. Many humanists decided to adopt this model and study their object as if the object studied were a thing in and of itself, independent of 
the interpreter and his or her prejudices. Gadamer rejected this model, instead arguing that the identity of the object belongs to and is part of the identity of the interpreter. The two cannot be separated. He therefore chose to favor the model of participation, as Weisheimer points out in his forward to Gadamer's late collection, In Praise of Theory: "The belonging endemic to the human sciences hardly proves that, not being susceptible of method, these sciences are not rational—indeed not sciences. Quite the contrary, the human sciences represent a kind of 'reason incarnate in existence', a kind of knowledge - Gadamer calls it practical knowledge - that comes from participation rather than distanciation" (ix). When studying philosophy or history or literature, the student belongs to the thing studied: the object studied is articulated in language, something the interpreter possesses also; the object studied takes place in history, something the interpreter is a part of - the interpreter is conditioned by history to such an extent that the historical object is filtered through the present moment. To recognize this conditionedness can yield a greater sense of truth.

Indeed, the human sciences are essential for the revelation of truth. In his introduction to the book, Gadamer in Conversation, Richard E. Palmer clarifies Gadamer's understanding of truth:

For Gadamer, following Heidegger, [the disclosure of truth] is not a disclosure of some eternal, changeless essence; rather, for Gadamer it yields an existential sense that 'this is the way things are'. In the presence of great art, says Gadamer, one says to oneself, 'so ist es!' (yes, that's how things are!) [...] The ontological word 'is' is deeply implicated with truth. It is not an essentialist but an existential truth; it is not an infinite but a finite, fallible truth, emerging in an experiential, lived encounter (12). 
Once again, readers are led back to the ideas of participation and engagement. It is in human being's nature to understand and to have a world; to engage with art or language is to experience an increase in being. It is in the encounter when the interpreter is put to the test: his or her sense of truth, of the way things are, is put to the test; to pass the test, the interpreter has no choice but to revise and incorporate; truth is dependent on this revision, in fact.

In existence, unless something is presented the world is amorphous and undefined. Until presented, there is nothing to interpret; once presented, we are drawn to interpretation. What something means, though, belongs to that presentation; to engage with presentation is to engage with life, with meaning. Ontologically, a presentation is the outpouring of the thing itself; the appearance of the thing itself. In David E. Linge's introduction to Gadamer's collection of essays, Philosophical Hermeneutics, we note this dynamic: "Like the game, the text or artwork lives in its presentations. They are not alien or secondary to it but are its very being, as possibilities that flow from it and are included in it as facets of its own disclosure. The variety of performances or interpretations are not simply subject variations of a meaning locked in subjectivity, but belong instead to the ontological possibility of the work" (xxvi). It is common to think about a symphony or a dramatic play as examples. A symphony is nothing unless it is presented. Every time it is presented it is going to be different yet it is still going to be the same symphony; each performance is an interpretation of the symphony. A text is a little different but it still has the same basic identity. There are several ways of thinking about the presentation or performance of a text. For one, a text can be read out loud; in that reading, the reader infuses meaning into the text and it becomes alive; it will never be read or understood in 
that exact manner ever again; the performance belongs to the circumstance of the reading. Silent reading is a little different, but still uncannily similar. Like everything else, the text is nothing until it is experienced; in that experience the reader is challenged and pushed; the language is necessarily different than that of the interpreter. The interpreter is faced with the task of assimilating the meaning: to do this he or she must find a language that fits his or her outlook and way of being. Overall, then, the performance or the presentation is the only way that the world can appear meaningfully. In the presentation, we are prompted to dwell on the appearance, to ask what the appearance means; for its part, the meaning is both self-evident and self-legitimating and self-different at the same time; each time the thing is presented or performed it is both different and the same.

In his book Philosophical Hermeneutics and Literary Theory Joel Weisheimer approaches these considerations. In this book Weisheimer looks at the implications of philosophical hermeneutics as they relate to literary theory. His basic argument is that language should be looked at as an enactment of being: basically what the word says and what the word is are one and the same; to engage with language is to know the world. Weisheimer makes his point: "The world is as indivisible from its coming to language, and the meaning of a word is as indivisible from its utterance, as is a symphony from its performance and an image from the thing it reflects" (107). In literature we are reminded that the world depends on its presentation, like a book depends on its being read; the language in literature cannot be parsed—it has no exact meaning, the language falls back upon itself; its appearance is its meaning. Furthermore, in each presentation, the thing presented acquires a new identity; now it is seen differently, from a different angle; all presentation is a kind of interpretation: "A picture is an interpretation of what it pictures" 
(109). For his part, Gadamer likes to use landscape art as an example. He notes that the Swiss Alps were seen as menacing and even ugly until artists began to paint the Alps; then, once they were pictured, they were seen as beautiful and majestic - they were seen in a new way.

Gerald Bruns, in his essay "The Hermeneutical Anarchist: Phronesis, Rhetoric, and the Experience of Art," makes a similar point. He too argues that the only way for the world to be understandable is for it to presented or performed: "Performance is not something added to the work or a rendition or a version of it; it is the appearance of the thing itself. The point to grasp is that the thing itself exists in no other way. Its mode of appearance is its mode of being" (61). Bruns' explanation of Gadamer's philosophy hits the mark; it is for this reason that Gadamer prioritizes art to such an extent. Of course, Gadamer's starting point is language, but art and language are intimately bound together: in all cases the appearance of the world is irrefutable; the appearance is the truth.

For Gadamer, art is ordered and whole; in it there is a continuity that we do not find in existence. We are drawn to art because it affords us the possibility of finding order; this order makes the world understandable. In his introduction to Gadamer's work, The Relevance of the Beautiful, Robert Bernasconi notes this aspect of art: "The challenge that Gadamer issues to the idea of art as a special magical realm is carried through by showing the continuity between the world of art and our everyday world. 'We sublate (Aufheben) the discontinuous punctuality of experience (Erlebnis) in the continuity of our existence (Dasein) $(T M, 86)$ " (xvi). That is, part of the identity of art is that it possesses continuity; if the parts do not relate to each other, then it is not art. 
Because of this, we look to art for answers and explanations, with insight as the ultimate yield.

These considerations our approached by Nicholas Davey in his encyclopedic entry in Key Writers on Art: $20^{\text {th }}$ Century. He begins his summary with the following heading, "What happens to us in the experience of art?" (130). By doing so, Davey recognizes Gadamer's philosophical claim — that art does not represent a static reality, it "can transform actuality" (131). Art allows the world to appear meaningfully: "Art is no longer subordinate to its conceptual subject but becomes a vehicle of its sensuous appearance" (131). In this case, the subject matter is the world and human being's relationship to it and to others. Davey goes on: "Art does not cloak reality in appearance but allows actuality to reveal itself more extensively" (132). Art is revelatory because it is ordered and whole. In it there is closure and determinacy: "The indeterminacy of existence means tolerating a world in which the things (subject matters) which concern us - meaningfulness, goodness, love - remain uncertain in nature and outcome. The capacity of art to draw unresolved threads of concern into a coherent determinate pictorial or narrative structure allows a clearer vision of what in actuality remained unclear $[\ldots]$ Art often enables us to see clearly what we often only perceive indistinctly" (132). However, the subject matter presented in art is never entirely finished. Each artistic presentation leaves a space for further interpretation: "If a subject matter is always more than can be said or depicted of it, then every time an artwork attempts an interpretation of a Sache, a residual untranslatable space is opened between the subject matter and its rendering. This space, since it involves a residual tension between what has and has not yet been said or shown, is autopoietic in the sense that it drives the attempt of subsequent 
interpretations to close it" (135). Indeed, our interpretive project is never complete, but, as we try, at least, we notice its contours.

Finally, I would like to talk about poetry and what has been said about Gadamer's emphasis on poetry. Gerald Bruns has something to say about this topic also. As an introductory piece for Gadamer's ruminations on the poetry of Paul Celan, Gadamer on Celan: 'Who Am I and Who Are You?' and Other Essays, Bruns penned the essay, "The Remembrance of Language: An Introduction to Gadamer's Poetics”. In it he discusses how Gadamer prioritizes one particular aspect of poetry: that it reminds us of the role of language in our lives. Overall, we can never entirely account for the role of language in our lives. It is impossible. Of course, linguistics, logic and other systems attempt to do so, arguing that we can understand language for what it is. These attempts are useful, but they do not have the last word: any and all attempts to step out of language take place in language. Poetry reminds us that language allows the world to mean at all: "Rather it is that poetry alters our relation to language. Poetry is an event $[\ldots]$ in which language interrupts our attempts to reduce it conceptually or instrumentally; it takes itself out of our hands" (7). In poetry, the meaning of words acquires a new luster: the occasion that prompts the poetic word is one of necessity; the writer needs the words to describe his or her world; once accomplished, the world is seen in a new way.

Dialogue is an important concept for Gadamer and it is crucial for his understanding of the poetic word. He argues that all language is the result of dialogue: in dialogue language appears out of necessity. Language is the appearance of the world, but it belongs neither to you nor to me; instead, it results from the need to recognize the world for what it is. All intimacy and all relationships are productive and combustive, 
drawn towards this tremendous need, where something new appears, where insight is gained. In poetry, too, there is always an 'I' and a 'you'. The 'I' is the 'I' of the narrator, the person prompted to use language; and the 'you' is the 'you' that understands, that follows along, the 'you' every 'I' needs and wants. In the same essay, Bruns considers this unique character of poetry: "But what matters for Gadamer is not the identity of the 'I' or the 'you' but the intimacy between them - an intimacy which is outside the determinacy of meaning, or which is not an intimacy of knowing and being known but an intimacy mediated by strangeness" (27). The impulse to write and read poetry has to do with this need for intimacy, a need to connect: for the language of poetry pertains to who and what we are; it is a language that means something and is understandable; yet it is alien and different; to mediate between the two, to become what is different - that is the appeal of poetry.

\section{Mrs. Dalloway}

Mrs. Dalloway is the story of several different people on a June day in London.

The titular character is, naturally, at the center but the other characters are essential to the impact of the novel, providing a kind of context, a means of framing. That is, in many ways, the book is about one London day in June. Each character gives the reader a sense of the moment, of the meaning of that particular day and that particular place and particular society. Some of the characters are more fleshed out and others barely have an identity, but each character serves a purpose and informs the narrative. Some of the characters serve as examples of the upper class in London and others are more downtrodden. Some are men, and others women. For some, the war touched them deeply and for others, just peripherally, nothing more than an inconvenience. Overall, nearly all 
of these characters are English, with Rezia as the principal exception. All were raised in the same milieu, with varying degrees of homogeneity. These people were conditioned to understand and think the same, to value the same things. Yet, at the same time, they are different. In Mrs. Dalloway, Virginia Woolf explores this intermediate space. Overall, then, this novel presents this June day in London as a series of moments which are meaningful yet temporary, moments that change who we are and challenge who we are. However, these are not just moments in time, they are also in space. The characters find themselves in the street, in the park, in shops, at home; and they encounter people at these places also. Each encounter-with people, with places - changes who we are. So, then, one day, one moment - each is part of a larger context: each moment inheres what has already taken place and contains within it an anticipation of the next moment. Our relationships with people comprehend a similar dynamic. We relate to and understand people based on our past relationships. Each new person is different — and should be treated as such—but our expectations, our means for knowing somebody, depend on our other relationships. Here, in this novel, the reader perceives a complex interconnectedness.

This emphasis on interconnectedness can be directly related to Gadamer's philosophical hermeneutics, especially his preference for the concept of dialogue. As Gadamer says, "language is a we" (Gadamer in Conversation 56). Generally, all of these characters speak the same language and belong to the same history-yet, at the same time, this commonality allows them to develop different ideas and different outlooks. That is, they depend on their commonalities in order to be different. Because they have a common ground, they are able to find a language that allows them to interpret and grow 
and discover. Clarissa, too, belongs to this particular London day. She is not especially clever, but she is smart enough to privilege her relationships and to recognize the value and reward of connecting with others. As readers, we get the following point: relationships are productive - the yield is often surprising, unexpected and, often times, insightful. Through our relationships we understand more.

Consider the main character, Clarissa Dalloway, for example. She is an upperclass English woman who has recently turned fifty two years old. By all appearances, she is not a mouthpiece for transcendent meaning or deep insight, yet Woolf chooses to put the spotlight on her, decides to reveal the depth and passion that characterizes her life. Clarissa is, of course, in many ways, conventional. She has married a politician and has no real worries other than hosting parties and fulfilling her role as a good socialite. She is neither daring nor bold. Yet, she is still a person with thoughts and feelings that matter. Her life is equal to the life of anybody else, rich or poor, man or woman. Thoughts, concerns, perceptions: Clarissa experiences them all. Clarissa is alive and she is searching for something. She wants to understand. To this end, Clarissa has built relationships and engaged with others. Woolf presents her as a character who senses that relationships are always more than we know them to be: stemming from the relationship itself, individuals acquire the vocabulary and orientation to relate to others and to see the world a little more clearly. For this reason, Clarissa fixates on her relationships and her past: neither can nor should be discarded, both still crucial to her interpretive project. So, then, when Clarissa returns home from her flower shopping expedition and goes to her attic bedroom, she ruminates on what the bedroom means to her, for she sleeps separate from her husband, Richard. This image of the bed reminds Clarissa that she has never entirely given her 
husband what he wants - or that she is incapable of giving it to him. She lacks something. This something is not laid out in the open, rather it is something intangible; something "central which permeated; something warm which broke up surfaces and rippled the cold contact of man and woman, or of women together" (Mrs. Dalloway 32). It is something that she senses when vulnerable, needy women come to her to confess, or seek absolution, or comfort. Then, when these women come to her, she takes notice of the obscure yet productive nature of relationships:

Only for a moment; but it was enough. It was a sudden revelation, a tinge like a blush which one tried to check and then, as it spread, one yielded to its expansion, and rushed to the farthest verge and there quivered and felt the world come closer, swollen with some astonishing significance, some pressure of rapture, which split its thin skin and gushed and poured with extraordinary alleviation over the cracks and sores! Then, for that moment, she had seen an illumination; a match burning in a crocus; an inner meaning almost expressed. But the close withdrew; the hard softened. It was over - the moment (32).

Here, Clarissa approaches a total meaning, one that comes from how she relates or interacts with people; her main concern is to recognize things for what they are. Overall, the point is that her sense for what she lacks, for that thing that she is missing, includes a sense for meaning, a sense that has to do with the identity of relationships. Clarissa can perceive this shortcoming: she is unable to give in completely, to yield to the influence of the other. Woolf suggests that love is a difficult thing for Clarissa, but that Clarissa knows it is still the only thing that matters.

\section{To the Lighthouse}

To the Lighthouse concerns the Ramsay family and the houseguests that visit their summer home. The patriarch, Mr. Ramsay, is a philosopher on vacation from his 
lectures. The matriarch, Mrs. Ramsay, is, primarily, a mother of eight and wife, but she also invests considerable energy in helping and influencing friends and family. There are other characters in this fictive work, but—besides Mr. and Mrs. Ramsay—Lilly Briscoe is the most important. In its structure, the book points toward a triangular relation among these three characters. Certainly, the story focuses on the transaction that takes place between husband and wife — sometimes dissonant, sometimes resonant, the marriage creates the conditions for the identity and growth of the couple: both learn and understand because of the difference and affinity of the other; each a source of support and a challenge to the status quo. Lilly takes note of this relationship between Mr. and Mrs. Ramsay — its essential nature — and is fascinated by it. Her feelings toward Mr. Ramsay run hot and cold but she knows that she cannot easily dismiss him; for Lilly is enamored with Mrs. Ramsay, a woman who has chosen Mr. Ramsay; he is demanding but because he has such high standards he also is a source of insight — he challenges himself and everybody else. Lilly is drawn toward this attitude but is also repulsed. Mr. Ramsay leans toward doubt and precision while Mrs. Ramsay leans toward sympathy and hope. Each needs the other, depends on the other, to compensate for limitations, to gain a more complete picture. But it is not just the Ramsay couple and Lilly that negotiate; there are other characters, too, who depend on the other, who both relish and reject their companions. For this novel hinges on the space between people: each character makes a claim that cannot be discounted; each is different, after all; each has something to say, the words a challenge. When it comes to hate or love, emotion and feeling, there is a necessary movement, a kind of dialectic: in Woolf's imaginary world or in our daily experience, these feelings only come because we care and each character too; each offers 
something; we feel communion or antipathy because we recognize an opportunity; whether we hate or love, it is because the other challenges us and we can or cannot meet the challenge. It is this dynamic that Woolf explores. When, for example, the Ramsay family and their guests gather around the dinner table, the narrator describes the state of mind of the different characters based on the reflection, the relationship, of the different members around the table. Each character depends on the other, understands because of the other, is because of the other. This dinner scene is exemplary of the narrative posture of the entire novel: no character is presented in a vacuum - the identity of each character swivels, depending on who judges.

In its overall structure, this novel presents its principal thematic concern-people are mysterious and also understandable; no matter how frustrating, the frustration is worth the reward. Gadamer suggests that people have different strategies for coming to terms and each may be valid, depending on the level of attention and engagement; depending, too, on the willingness to take risks. What is the payoff? What risks might people take? To answer, let's look at the tripartite structure of the novel that Woolf creates. Divided into three parts, it consists of, first, The Window, then Time Passes, and finally The Lighthouse. The Window takes place in one day. On this day, the Ramsays discuss if they might go to the lighthouse the next day—a journey yearned for by their youngest son, James. Mr. Ramsay says that there is no chance the weather will permit such a sojourn, while Mrs. Ramsay says that it is possible, the weather difficult to predict. It also includes Mrs. Ramsay sitting at a window with her son James, knitting and then reading to him. But she is not just sitting, she is also modeling for Lilly, who happens to be painting the scene. The day ends with the family and guests gathered around the 
dinner table and then, finally, a moment of intimacy between Mr. and Mrs. Ramsay. The next section is Time Passes. In it, ten years fly by: here, we are reminded that time is indefatigable; no matter our opinion, no matter what we think, time marches on. It does not care about our wants and needs, hopes or desires, unfeeling and impersonal, its dominion remains, forever and always. So people die. So things change: Mrs. Ramsay dies, war happens-young men die in their prime. For Mr. Ramsay and Lilly, these are life-changing events, but in the context of billions of years, just grains of sand-so Woolf's narrative presents these events. Then we reach the other side in the novel, ten years later, another day in the life of the Ramsay family, on vacation once again, hosting guests once again, once again a trip planned to the lighthouse, though this time without Mrs. Ramsay who had died in the intervening years. In this section of the novel, the most notable characters are Mr. Ramsay and his two children, James and Cam; Lilly Briscoe is back also; she who had begun her painting ten years ago and now intends to finish it. Lilly has unfinished business— her painting — and so too James and Mr. Ramsay—-their trip to the lighthouse. Although the day ten years ago was not particularly special, it continues to be vital to these characters: James sitting with his mother, James hoping to go to the lighthouse, Lilly thinking about Mrs. Ramsay, Lilly working on her painting, Mr. Ramsay consorting with his family, connecting with his wife. That day remains, framing this new day. So Lilly decides to finish her painting, so Mr. Ramsay and his children depart for the lighthouse. Each accomplish their goal, in the end - an homage to inspiration, to Mrs. Ramsay. For she unites these disparate characters. Yes, each reach their goal and make the best of the situation. Although life has been hard and family life strained, Mr. Ramsay does not concede, he fights on, fully aware that life does not stop 
and start at his convenience-adaptation or annihilation his only options. In the case of Lilly, the intimate link between life and art commands attention. In her painting, Lilly's goal is to present what she has learned from the Ramsays. Lilly knows that in their relationship there is a clue to a more complete understanding; that Mrs. Ramsay and her relationships were genuine, in those relationships there were contained a kind of truththe world became more real. Lilly, then, paints because she wants to test herself and push herself: the painting, after all, could be anything; it could be anything but it has to be something; in her decisions she asserts a form on the world; the world has now taken shape. Once complete, the painting will always be itself, the deposit of effort, engagement and participation. For years, Lilly had contemplated this painting, had contemplated Mrs. Ramsay and her family_-how does this family, how does this painting relate to the meaning of things? - its completion moving her a little bit closer to the answer.

To explicitly link this novel and Gadamer, it is useful to return to this triangular relationship between husband, wife and artist and the tripartite structure —one day, the passage of ten years, then another day. In husband and wife we notice a good example of dialogue; also, in the transaction between Lilly and Mrs. Ramsay. We are reminded of Gadamer's words: in dialogue, "world is disclosed"” (Truth and Method 443). Each depends on the other for a starting point, for a sense of stability—standing on this level, well-anchored platform, each can take risks, explore, well aware that, after jumping, each will land on level ground. So, then, each has an interlocutor with whom he or she can ask and answer questions; here, Gadamer's words prove fitting: interpretation “implies pointing in a particular direction" (“Composition and Interpretation" 68). Indeed, these 
characters interpret and explore new territory, exposing themselves to the new, to the potential. Woolf's perception of this is apparent in that Lilly, through her art, engages this dynamic. She has always recognized the meaningful heft of this couple, of the family, of Mrs. Ramsay and her son James: in all of them she can sense a clue to help her answer her own enigmas. But, instead of passively ruminating on these implications, she actively engages with them: she creates a painting that presents these interactions in visual language. She tarries with this image, entertaining the unlimited possibilities, but she eventually makes choices, commits herself to a structure. By doing so, she has put into form what was previously shapeless: the day, the family, life_-all have now been interpreted. Once again, Gadamer's philosophy resonates: "The world that appears in the play of presentation does not stand like a copy next to the real world, but is that world in the heightened truth of its being" (Truth and Method 132). 


\section{CHAPTER 2}

\section{GADAMER ON LANGUAGE}

As the topic is hermeneutic ontology, language is the appropriate starting point, for language is the means by which human being interprets and understands itself and the world: prior to any and all knowledge constructions, language, interpretation, and meaning, indivisible in their aims and accomplishments. Language is always present and to recognize its determinative influence is to avoid sabotage. When discounted, when the world is objectified and nothing else, we become victims, the world now one thing and just that; of course, language and its imaging of the world outpace any and all objectification, but in discounting language we are too easily sidetracked. In objectifying the world, one sees it from a point of view that has validity, but it is only valid as just that - a viewpoint. There is more to the picture. To say that it is the whole picture is to invite turmoil and subterfuge: the world and its meaning antagonistic or deficient, always static, obstructing adjustment and revision, lacking attunement. There needs to be a counterbalance. When the world is projected as an immobile entity there is no room for imagination or insight: the world is always one thing and this means that we will never meet it for what it is. In all cases, both negatively and positively, the matter is one of degree. One can ignore language and its influence to a greater or lesser extent; so too one can privilege language more or less. As language is something that we do not possess but instead, more correctly, possesses us, using language is not a matter of conscious effort; 
instead, languages hinges more on engagement and participation. As one engages with language, one learns to follow its trail: flush with hints and possibility, it is a constant balancing act; with nothing certain, we latch onto potentiality and head down a path that leads us in a direction that compels, legitimate because we have listened, but still shrouded in darkness. This is the dynamic: whether or not we choose to recognize it as such, language is our guide and our master; to come to terms with this situation is fundamental because it improves our sense of balance; to truly understand things for what they are there needs to be humility and maximum attention; the world and its meaning are always changing and we need to keep up with this flux.

Language is imminently influential: part of the identity of language is that we never can truly know it for what it is; we can never entirely account for its sway. As Gadamer puts it, language intends content and never can be altogether self-reflexive: "Language intends the other person and the other thing, and not itself. That means that the covering over of language as language has its basis in language itself and accords with the human experience of language" ("Towards a Phenomenology of Ritual and Language" 44). Language is determinative: any attempt to use language is already shaped by language; to say otherwise is to stunt understanding and invite distortion. Language always intends content and that content concerns matters of fact; what is; the way things are; meaning; that we perceive something as something: "Language is not just one of man's possessions in the world; rather, on it depends the fact that man has a world at all" (Gadamer, Truth and Method 440). So, then, methodologically speaking, language and world are one and the same. The world and its understanding are primordial: from there, having a sense for the meaning of the world, one can further define its identity and 
nature. To do so is natural but is also prey to abuse: things become settled and defined and we too easily forget that the very definitions depend on the questions we ask; we forget that identity can also be variable if our questioning is imaginative and incisive. Sure, it is natural to construct objects, but the appropriate and correct application of this construction hinges on the idea that these constructions do not have the final say. They belong to an ontological background that shapes their identity and usefulness: "Our verbal experience of the world is prior to everything that is recognized and addressed as existing. That language and world are related in a fundamental way does not mean, then, that world becomes the object of language. Rather, the object of knowledge and statements is always already enclosed within the world horizon of language" (Gadamer, Truth and Method 447).

Indeed, language is always already present. To listen to language and to use language is our fundamental means of confronting ourselves and the world. It is the most meaningful record that we have. With this element of language in mind, Gadamer makes the following statement: "Being that can be understood is language. The hermeneutical phenomenon here projects its own universality back onto the ontological constitution of what is understood, determining it in a universal sense as language and determining its own relation to beings as interpretation. Thus we speak not only of a language of art but also of a language of nature-in short, of any language that things have" (Truth and Method 470). Here, language and understanding fall back on one another: to understand one needs language and to use language one has already understood-understanding fulfills itself in the verbal act. Being, too, is part of this equation: Gadamer argues for the non-distinction between interpretation, understanding, language and human being. We 
are always trying to understand and it is language that is the true medium for that comprehension: when something has a language, it is understandable and lends itself to further understanding.

Language and the world are inseparable; the appearance of language and its interpretive content too; a subject matter is always in question, a process of elaboration and identification. In language there is identity: something is what we proclaim it to be. That identity, though, is provisional — the subject matter-whatever it may be — has acquired a stability in language, but temporality and our discursiveness present the new and unexpected: we return to language, at this point, to appropriate the moment - and language grows in its connotations, complexity and power-its naming power not diminished, but increased. Here there appears to be a contradiction: language stabilizes the world yet also shapes it. How does Gadamer reconcile this tension? He places language within the context of conversation: "we are endeavoring to approach the mystery of language from the conversation that we ourselves are" (Truth and Method 370). All statements and assertions, all language use in general, have an addressee, however definite or indefinite he or she may be. The point is that this language is understandable and is presented in just that way: the difference and individuality of the interlocutor requires that we accommodate our language, that it represent a point of mutual contact and a mutual world, an accommodation of development. It is this dynamic of dialogue, of addresser and addressee, that shapes the development of language: in the very presence or anticipation of the other, in his or her look or his or her words, the individual receives a challenge, a blow of awareness that the world is more than we know it to be. 
This dynamic of dialogue is primary, over and above the consciousness of either member in the conversation; language does not belong to either member - it instead lies in the give and take, in the relation itself, a back and forth that never stops. That is, language and conversation have their own spirit and energy, a kind of buoyancy that envelops the interlocutors: "Understanding or its failure is like an event that happens to us. Thus we can say that something was a good conversation or that it was ill-fated. All this shows that a conversation has a spirit of its own, and that the language in which it is conducted bears its own truth within it - i.e., that it allows something to 'emerge' which henceforth exists" (Gadamer, Truth and Method 385). Certainly, one can confirm this statement by recalling the emphasis that people place on personal relationships: the people in our lives are our greatest source of fulfillment. Without them the world would shrink; so vital precisely because each mediates this tension between stability and change. They occupy an important place in our lives because we share something with them and also because they compel - something in them demands that we take notice of their claim, a persistent challenge to become more.

By locating language within the dynamic of dialogue, Gadamer transcends the subjectivity that one typically associates with language - the I that understands and the thing that is to be understood. In doing so, language acquires its true breadth — as a medium in which truth occurs even when — or because - it is unexpected: neither member knows where the conversation is going or what will come of it. This nature of language is important: the world and its truth assert themselves in language but do not ever settle, both provisional and in search of greater articulation. There is no final version: language 
is a provocation. This places language on firm ground: as the articulation of its identity and meaningfulness, the world appears in language and becomes what it is—something else and something more, incompletable in its completedness.

To further explain the priority placed on language as ontologically determinative — prior to any subjective intention — Gadamer turns to the concept of play. Play is useful because it is a structure that binds the player while enabling a kind of free movement that is not tied down to any particular goal: it is "a form of restraint and freedom at one and the same time" (Gadamer, "The Play of Art" 130). Gadamer contends that play is pervasive and fundamental to how one interacts with the world: in our embeddedness in the world we are already under way towards play. Our interactions with the world are never entirely open — the world cannot be everything — and in everything we do there is transformation: the world gains identity while still remaining open for more. For Gadamer, language belongs to the world of play: "Play is the process that bridges the gap between a not yet semantically articulated form of communication and word communication. Play appears to me to be a type of pre-linguistic dialogue. It is already in the play of the infant with its own fingers and movements, and especially in the play that includes others" ("Boundaries of Language" 14). Language is a kind of play in which the movements of the players (the interlocutors) are determined by the play itself (the conversation), a never-ending back and forth:

When do we speak of play and what is implied when we do? Surely the first thing is the to and fro of constantly repeated movement - we only have to think of certain expressions like 'the play of light' and the 'play of the waves' where we have such a constant coming and going, a movement that is not tied down to any goal. Clearly what characterizes this movement back and forth is that neither 
pole of the movement represents the goal in which it would come to rest (Gadamer, The Relevance of the Beautiful 22).

As in play, in a dialogue the words spoken are determined by the subject matter, a movement that takes place in language, a movement that never rests

This back and forth action — unbound and self-propulsive — helps explain why Gadamer would say that language and understanding are an event of being and not a willful act of consciousness: "Understanding too cannot be grasped as a simple activity of the consciousness that understands, but is itself a mode of the event of being. To put it in purely formal terms, the primacy that language and understanding have in Heidegger's thought indicates the priority of the 'relation' over against its relational members- the I who understands and that which is understood" ("On the Problem of Self-Understanding" 50). Language bounces back and forth between two interlocutors like a ping pong ball; as it does, the truth of the subject matter asserts itself. This dialogue and movement does not necessarily need to take place between people directly speaking with one another. It also happens when we read texts. In texts there is an I that understands and something to be understood. When someone reads a text there is language that refers to something, something that both the writer and reader share: a common world. As the world appears in language, the reader is provoked: the content of the words are understandable yet they are new and different; the reader asks questions and the text volleys back answers; the text asks questions and the reader answers; the meaning of the words and the meaning of the world in concert.

In any dialogue, whether between two people who speak to each other or between a reader and a text, the shared content, the disputed content, is the meaning of the world. 
This meaning does not lie in any one person. It lies in the anticipation of the other and the response of the other. The temptation to use language is the temptation to address someone - so that the world is understood and so that it can be further understood: "To speak means to speak to someone. The word should be the right word" (Gadamer, "Man and Language" 65). Put in different terms, the desire to use language is a desire for more: the world does not belong to any single person, so it is only by way of question and response that we approach the true nature of the world, a being that we all vaguely understand but can never entirely possess. In our orientation to the world we have a diffuse sense for the nature of things, but because language is infinite and variable, there is never a final answer; in language the world is defined but it is a definition that belongs to a larger context, the context depending on the definition and the definition depending on the context: "Communication takes place when the other person takes part in what is imparted to him — and in such a way that he does not, as it were, only receive in part what is communicated, but shares in this knowledge of the whole matter that is fully possessed by both of them" (Gadamer, "The Play of Art" 128). In language use, then, one is pushed to modulate and recalibrate: as the world is defined in language the very act demands reassessment, for in the effort one recognizes truth, an irrefutable event that includes possibility within itself.

As two interlocutors converse- - whether it is a conversation between a reader and a text or face to face - the meaning of the world is disclosed. In this interaction, there is an impulse that is out of the control of either member: the subject matter asserts itself and both are pushed to respond. But why are we pushed to respond? What is the accomplishment of language? Essentially, one can say that the world changes as it is 
named and its meaning too. Language appears because it is our way of confronting the world and recognizing it for what it is: "To come into language does not mean that a second being is acquired. Rather, what something presents itself as belongs to its own being" (Gadamer, Truth and Method 457). Here, language comprehends simply everything, everything that has a name. Something only has meaning when it is there to be evaluated and something can only be evaluated when it is there in the first place. Language is our way of entering into the concrete and the definite. The world is diffuse and self-concealing, but in its appearance in language it is there and it is distinct. Language clears a path and points in a direction. Yes, there is an unrestricted freedom in language, but the possibilities of expression are limited by the current moment: everything is not possible at any time. A path has already been cleared and we cannot go backwards.

The world already means something and it is only by engaging with that meaning can one coax it into something more. As one reads or listens, the complexity and the connotations gain in power. Each new moment is different, thereby demanding new expression; this new articulation changes how one experiences the moment too: "A person who speaks $[\ldots]$ is so oriented toward the particularity of what he is perceiving that everything he says acquires a share in the particularity of the circumstances he is sharing" (Gadamer, Truth and Method 427). The articulation of the subject matterwhether narrow or broad or in-between - alters its very identity: it is now something definite and understandable - it is what it is - yet in the naming there remains a residual space, an opening for further clarification. In their articulation, we know things as they 
are, but those things are never settled, for as they are named the very things shift, belonging themselves to the situation.

Of course, there are innumerable ways of expressing this idea that the world changes as it is named; we belong to the world and the world belongs to us: the world provokes us to respond and as we do so it morphs into something else. The very identity of things depends on one's engagement: "We are simply following an internal necessity of the thing itself if we go beyond the idea of the object and the objectivity of understanding toward the idea that subject and object belong together" (Gadamer, Truth and Method 457). To recognize this oft-concealed nature of language is to parry with the verifiable and the provable; language and its use has its own truth, one that shapes our assertions and one's attempts to prove them. We are reminded of this aspect of language - as an event in which there is no difference between the idea presented and the presentation of the idea- every time we are stopped short and notice the limits of our understanding: every time we realize that we do not know and never will; language and its truth cannot be proven, for it is the medium that shapes the questions we ask and the world we perceive.

Language is ever-present and it is our means of understanding. The world has meaning because of language — but how does language work exactly? Why is it so powerful? What happens when a word is spoken? Gadamer points to language's evocative capacity: "The universal nature of all speech—namely, the fact that what the word evokes is there" ("On the Contribution of Poetry to the Search for Truth" 113). It is a curious paradox: language allows us to commune with the world yet in language use we also acquire a distance from the world. When we ignore language we notice how the 
world impinges on us, as if we lost all ability to shape our future; something overwhelms us because it is unidentified - we cannot see it for what it is. In language, though, the world comes to appearance - it is there for all of us, together; it is not idiosyncratic and particular. As something shared, we receive reassurance by way of language: we trust its possible accomplishment. Language has been vetted, acquiring a body and a presence that coincides with the thing itself: "In the end, the true being of things becomes accessible precisely in their linguistic appearance" (Gadamer, "The Nature of Things and the Language of Things" 77). As we cannot be everywhere at once, nor can we travel to the past or the future, language allows us to engage with everything that is not immediately present: "Speech can present something, place it before us as it is, even when it is not present" (Gadamer, "Boundaries of Language" 10). In this accomplishment, we overcome our provincialism and acquire a sense for the context of our being.

This distance is important because it promotes contemplation: the thing is there as it is; we can therefore take it at its word and work out the implications therein. Gadamer puts it this way: "[I]n naming, things are proclaimed to be what they are for us. It is correct that one recollects them in naming and that endows contemplation" ("Towards a Phenomenology of Ritual and Language" 26). In language there is recognition and affirmation: "In taking up a distance, the word achieves two things for us: recognition of oneself in another, and recognition along with others of what has been affirmed by everyone" (Gadamer, "Culture and the Word" 10). Indeed, language is the product of a shared world - in it, the definite and the real and the true. To engage with language is to enter into a process of understanding, to confront the world as it is: "Learning to speak 
does not mean learning to use a pre-existent tool for designating something somehow already familiar to us; it means acquiring a familiarity and acquaintance with the world itself and how it confronts us" (Gadamer, "Man and Language" 63). In this confrontation there is recognition-something appears and in this appearance we approach the idea.

In language we confront the world and recognize it for what it is: the world and its appearance are one and the same. But what appears? For language is always changing, always variable, never self-same. Language is an attempt to work out the context of one's very being. In language one has a sense for a general idea and as the language is used that general idea changes. In articulation, language is shaping one's sense for the possible: as it is articulated the world gains in presence and body, but this new awareness is provisional, the context having changed. Language itself is interpretive, meaningful: "Language [...] consists in delun (revealing), in making the real states of affairs manifest. That means that we do not merely point to something but also recognize it for what it is. Now this, clearly, is the life-world of language: it is itself an interpretation of the lifeworld" (Gadamer, "The Expressive Force of Language: On the Function of Rhetoric in Gaining Knowledge" 128). The implications of this statement are clear: language can be a guide. If one listens to language and uses language and accepts its force and power and influence, then the world might mean something that truly matters; things might be understandable — instead of alienation, communion.

But it is, indeed, very tempting to see the world as a collection of objects that are meant for consumption and control, or - at the least — verification. In this verifiability there is comfort but there is also potential for abuse. When one downplays the role of interpretation in existence then one becomes subject to a world that terrorizes precisely 
because it cannot change: either we will never truly know it or we think we do and it will disappoint, fraudulent. As we pay attention to language we are reminded that it is the ultimate mediator: "Is the given not in fact the result of an interpretation? It is interpretation that performs the never fully complete mediation between man and world, and to this extent the fact that we understand something as something is the sole actual immediacy and givenness" (Gadamer, “Text and Interpretation” 30). What things are, then, depends on interpretation; interpretation depends on language; one interprets because one has language and one has language because one interprets. In other words: "Language is the universal medium in which understanding occurs. Understanding occurs in interpreting" (Gadamer, Truth and Method 390). For this reason, one does not really feel that one has understood something until one has verbally expressed the idea: it is nothing until it is there to be understood; the expression itself is the understanding; the verbal expression of understanding belongs to the thing being understood: "The verbal explicitness that understanding achieves through interpretation does not create a second sense apart from that which is understood and interpreted" (Gadamer, Truth and Method 399). The verbal act is interpretation manifest, each — interpretation and the verbal actimpossible without the other.

As one searches for the right word and the right expression one is reminded of the essential rightness, appropriateness, and correctness of language. In his or her experience one is prompted to search for words that fit the moment — one has an undeniable feeling that the right word is out there-precisely because one lives in words and these words truly are a testimony of one's engagement with the world, the world and word indivisible; when one finds the right word the world is at rest: 
[I]n the utilization of the linguistic interpretation of the world that finally comes about, something of the productivity of our beginnings remains alive. We are all acquainted with this, for instance, in the attempt to translate, in practical life or in literature or wherever; that is, we are familiar with the strange, uncomfortable, and tortuous feeling we have as long as we do not have the right word. When we have found the right expression [...], when we are certain that we have it, then it 'stands', then something has come to a 'stand'. [...] What I am describing is the mode of the whole human experience of the world. I call this experience hermeneutical, for the process we are describing is repeated continually throughout our familiar experience. There is always a world already interpreted, already organized in its basic relations, into which experience steps as something new, upsetting what has led our expectations and undergoing reorganization itself in the upheaval (Gadamer, "The Universality of the Hermeneutical Problem" 15).

Human experience is hermeneutical, oriented towards meaning and interpretation: the unconsciousness that is part of our beginnings never abandons us. Just as when we first begin to grow up in a language and things acquire expression in our day to day life, this process continues throughout our life. As we grow, the world does acquire a stability, but we also encounter the new and the unexpected; we are pushed to modify and readjust; the words we use confront these changes, but in that confrontation the words are no longer the same: the words bloom and fade-some fall into disuse, others appear unexpectedly and others acquire new shades of meaning as they are combined to fit the new situation.

As we look backwards and forwards, one can see how Gadamer could place "the whole human experience of the world" within the context of linguisticality. To summarize: language is the given —one cannot think without language nor is there meaning without language. Language, for its part, does not belong to any one person: its appearance depends on the addresser and the addressee, but belonging to neither. And 
what appears in language is no different than the thing itself, the thing described; the thing only has identity in language. As this is the case, then language can make things appear even when we are not there, enabling us to acquire a distance from the world and see it for what it is. So, then, as we use language we see things for what they are, but, at the same time, the reference and the referent only acquire a temporary stability, for the passage of time pushes for more. The primary emphasis placed on interpretation becomes evident: language is already an interpretation but that interpretation is necessarily deficient, describing the world of the past and not of the present moment.

Language has already accomplished much of our interpretive work. As we listen to language and use it this interpretive work is harnessed so that it fits the new situation; language is combined so that the world becomes more meaningful; the interpretive work of language is flexible, capable of unexpected combinations:

If a person transfers an expression from one thing to the other, he has in mind something that is common to both of them; but this in no way needs to be generic universality. Rather, he is following his widening experience, which looks for similarities, whether in the appearance of things or in their significance for us. The genius of verbal consciousness consists in being able to express these similarities. This is its fundamental metaphorical nature, and it is important to see that to regard the metaphorical use of a word as not its real sense is the prejudice of a theory of logic that is alien to language (Gadamer, Truth and Method 428).

Gadamer emphasizes the fundamental metaphoricity of language. All language and all meaning depend on each other; a hall of mirrors, as the angle of the reflection changes so too the image; as the words are combined the meaning of each word shifts—-but only 
because of how the words are combined and their reference: these combinations lead to an ever-widening understanding of possibility and possibility of understanding.

This is a circular argument—and intentionally so. In the realm of language and understanding, there is no first principal: "The hermeneutic circle says that in the domain of understanding there can be absolutely no derivation of one from the other, so that there the logical fallacy of circularity does not represent a mistake in procedure, but the most appropriate description of the structure of understanding" (Gadamer, "Text and Interpretation" 30). In other words, that which we understand depends on our understanding and our understanding depends on that which we understand. Each attempt to understand is accidental, occasional and finite, yet language itself belongs to an overall context that envelops anything and everything we do: that we have language at all shapes what we do with language in the particular moment. Our fundamental linguisticality is bound to our sense of the possible: there is a push to inhabit the space that language opens up, but that space can never entirely be filled, as it shifts and expands with our movement. As language appears, then, we acquire a more definite sense for our place, bound by what has been said, and an even greater sense for what has not been said—all that might be said in order to correctly understand everything. This is a never-ending process, for we will never correctly understand everything; we are bound to the moment and finite; in this sense, everything said is a provocation for more:

"But there is another dialectic of the word, which accords to every word an inner dimension of multiplication: every word breaks forth as if from a center and is related to a whole, through which alone it is a word. Every word causes the whole of language to which it belongs to resonate and the whole world-view that underlies it to appear. Thus every word, as the event of a moment, carries with it the 
unsaid, to which it is related by responding and summoning. The occasionality of human speech is not a casual imperfection of its expressive power; it is, rather, the logical expression of the living virtuality of speech that brings a totality of meaning into play, without being able to express it totally. All human speaking is finite in such a way that there is laid up within it an infinity of meaning to be explicated and laid out. That is why the hermeneutical phenomenon also can be illuminated only in light of the fundamental finitude of being, which is wholly verbal in character" (Gadamer, Truth and Method 454).

Language mediates the infinite and the finite. Language is finite because it is in a process of development, changing as it is applied to each moment. It is infinite because what we mean to say is never entirely exhausted in we what actually say: more can always be said and there are infinite ways to express what we mean. Gadamer puts it this way: "Now the true nature of speaking is such that what is meant constantly goes beyond what is said" ("Reflections on My Philosophical Journey" 52). With each expression, a claim is made - this is how things are — but such a claim does not exhaust the potential for future claims: the very identity of future assertions depends on what has come beforepossibility is now something else.

We are always trying to find the right words - so that what we mean to say and what we actually say are one and the same. This is - for the sake of freedomimpossible. Otherwise we would have nothing to work towards - the matter would be settled, and then what? Instead, one's sense for the possible changes as one engages with the concrete. The use of language itself is a means of gaining insight: one's sense for the way things are and how they appear are united. Each articulation, then, is manifest: but there is never one approach — each attempt has its merits and its deficiencies, pointing in a direction that carves out a space but also seals up a concurrent opening: "Self-bestowal 
and self-withdrawal - such a dialectic of uncovering and withdrawal seems to hold sway in the mystery of language" (Gadamer, "From Word to Concept: The Task of Hermeneutics as Philosophy” 139). For this reason, we make conjectures, test out possibilities and play with language: we never know what will be revealed. Each attempt brings the world to language in a new and unique way: "For man language is variable not only in the sense that there are foreign languages that one can learn but also variable in itself, for it contains various possibilities for saying the same thing" (Gadamer, Truth and Method 442). There are other ways of describing this dynamic - that the world is more understandable when one engages with it, yet this understanding is directional; it leads us on a path that reveals truth but obscures insights that we might have gained otherwise. To understand that we are pointed in a direction and what this entails of us can assist us in our attempt to illuminate the truth and value of that orientation:

"Explicating the whole of meaning towards which understanding is directed forces us to make interpretive conjectures and take them back again. The self-cancellation of the interpretation makes it possible for the thing itselfthe meaning of the text-to assert itself. The movement of the interpretation is dialectical [...because] the word that interpretively fits the meaning of the text expresses the whole of this meaning-i.e., allows an infinity of meaning to be represented within it in a finite way" (Gadamer, Truth and Method 461).

In this commentary, Gadamer points to the idea that the interpretive word should include everything that is not said in what is said and should be understood as such. By keeping in mind possibility - the whole of meaning - then the interpretation can place itself on firm ground: where it does not fit into this overarching context, it does not belong; it only means anything because of its placement within the context. Of course, here Gadamer is 
speaking of the interpretation of texts, but the division between the interpretation of texts and interpretation in general is not really a division: the interpretation of texts is fundamentally related to interpretation of experience and vice versa-we engage with texts because they are foundational to our interpretive project.

We can never, of course, completely articulate this entirety, this whole—instead it envelops us and surrounds us: "It is a way of language that holds itself open to the whole of being. [...] Totality is never an object but rather a world-horizon which encloses us and within which we live our lives" (Gadamer, "Reflections on My Philosophical Journey" 37). Any attempt to engage with meaning, to understand, is an entry into the particular, the concrete, the moment. In all cases, it is a mediation between unity and difference: "Being is visible not only as the one but also, and just as originally, as the other and as the multiplicity of differences, and as the identity and difference that comes into language" (Gadamer, "Towards a Phenomenology of Ritual and Language" 44). It is a mediation that is never complete. The task of language is to put into words the manner in which things fit together and how things are connected. But it is also the nature of language that those connections vary, including the very meaning of the words, as the words are applied to the situation. Once again, careful consideration of this back and forth can yield hermeneutical fruit: "Hermeneutics has the task of revealing a totality of meanings in all its relations. The individuality of the sense intended corresponds to the totality of definitions" (Truth and Method 467).

As we experience the passage of time, we encounter the new and unexpected. We try to interpret the moment, but there are so many possibilities, with no guarantee as to which is right. Somehow, though, we have a sense for what might work and we try to 
follow that scent, making sure that the conditions are right, with no distractions and an adequate level of volume, that we are tuned to the right frequency, a message worth our maximum attention. Then, when we feel we have listened, we make a statement that interpretively fits — or so we hope: the only verification that is possible depends on the very means of that which is being verified. Always, though, we have to commit: "To be this and not that constitutes the determinacy of all beings" (Gadamer, Truth and Method 442). With each manifestation, there is no return. Sure one can revise and amend, but every new assertion depends on what has been said before: the very shape of possibility morphs. We are not in a position to reject the hermeneutical situation to which we belong: we can only move forward. To incorporate our situation, to recognize that we belong to it, promotes clarity, a diminishing of distortion. We see things as provisional and recognize them as such — instead of flawed, enabling: so that our individuality matters, so that our viewpoint provides insight, capable of inspiring. Each view has its own truth: "The infinite perfectibility of the human experience of the world means that, whatever language we use, we never succeed in seeing anything but an ever more extended aspect, a 'view' of the world” (Gadamer, Truth and Method 444).

Language and its use point us in a direction: one that is valid but also one that requires that we recognize it as just that — an interpretation and not the final word. Through language, one can expand and extend one's horizon: one's possibilities of knowledge and understanding can and do grow. How is language able to accomplish this expansion? Here, Gadamer's words prove helpful: "Where the word fulfills itself and becomes language, we must take it at its word" ("From Word to Concept: The Task of Hermeneutics as Philosophy 139). That is, when the word means something, when we 
enter into the discourse and forget about how something is said and only have before us the content of what is said, when the words refer backwards and forwards, self-verifying and self-legitimating, then the word is entirely convincing and altogether valid. This nature of the word - that it is self-verifying — is of special note. A word, as a genuine expression of meaning, can never be false. It is there as a word and this presence is irrefutable: the appearance of the word and its meaning are one and the same. Gadamer puts it this way: "It would no longer be a word if it could be false as a word. A discourse formed of words can be false or true only if its expressed opinion concerning a state of affairs is in question" ("On the Truth of the Word" 135). The word, language in and of itself, is what allows for things to be true or false in the first place. Words and one's impulse to use them inhere a legitimacy that cannot be refuted: before one can challenge the sovereignty of language, it has already asserted its influence.

There are other ways of talking about this situation: for example, by way of the metaphysics of light and of the beautiful. Light is important because it allows what is there to be seen. Without it, all would be indistinguishable. Words contain within them a similar quality, allowing what is there to be understood — to be what it is: "The light that causes everything to emerge in such a way that it is evident and comprehensible in itself is the light of the word" (Gadamer, Truth and Method 478). So, until the words are used to name the thing, the thing has no identity, undefined and incomprehensible; once named, it is itself, truly what it is. Now, the concept of the beautiful is important for similar reasons: in beauty there is radiance - the idea of the beautiful belongs to the appearance of beauty, emanating. In the appearance of the thing in words, there is a similar sensation of emanation and radiance: the distance between the idea of the thing 
and its appearance is dissolved. There is no difference between the words and what is said in the words: "All coming into language [...] has about it something of this quality of self-attestation [...] In using words what is given to the senses is not put at our disposal as an individual case of the universal; it is itself made present in what is saidjust as the idea of the beautiful is present in what is beautiful" (Gadamer, Truth and Method 483). The very attempt to describe one's perceptions and one's sense for the meaning of those perceptions belong together. Words are there to say something and whatever they say will be put to task, with no choice but to define and contrast themselves based on other words. The words acquire a validity when they are challenged but remain strong; they are not empty, capable of expressing something that matters: "To be a word means to be saying [...] In order to find those words that are the most saying from among the infinite variety of possible words, we must remember what truly characterizes 'a word': that it stands and one stands by it. This clearly already implies that the word lays claim to an enduring validity through what it says or sayingly does" (Gadamer, "On the Truth of the Word" 138-9).

Now, up until now I have been focusing on language as it appears in conversation. But, as I have already mentioned, there is more to consider. Texts are important too: the identity of texts depends on the identity of language and the identity of language depends on the identity of texts. As we look at the nature of texts, we will see that much of what has been discussed will now appear with greater clarity. Texts intensify and emphasize understanding and the identity of language. In texts the character of language appears in bold relief, the nature of language more noticeable because there is nothing but language in texts. In texts, there are advantages and there are challenges; they have a definite 
identity, are repeatable, and are entirely intentional — the writer is aware that the reader has nothing but the text to understand what is there. Indeed, part of the identity of language is that in its development the words become fixed, the meaning of each word shared, more and more there. The script, for its part, is the culmination and intensification of this fixation - the words, then, immutable: "How the words are developed that one needs, and one learns the correct words, and so learns how one learns things, that is not conscious learning and practicing. Nevertheless this process of linguistic exchange accomplishes the solidification of the use of language. To that extent the fixation by means of script is anticipated in the developmental history of every language" (Gadamer, "Towards a Phenomenology of Ritual and Language" 33). The movement towards script is a movement towards interpretation. It is a recognition that the words mean something and that such a meaning should be preserved. By doing so the words make a claim: these words matter and will always matter, their very meaning dependent on nothing but themselves. Gadamer describes this nature of the text: "The verbal expression of what is meant in the text must be constructed in such a way that, without any help of voice and gesture, the text articulates itself and actually 'presents' what is meant by it. [...] This distinctive feature of writing enables and limits the text to the pure transmission of sense" ("The Eminent Text and Its Truth" 5). In a text, the reader is forced to confront this claim: if the words are intentionally there and will forever be there, then the reader has the responsibility to do the words justice; however, the exact meaning of the text is always different for each reader and every time someone reads; to listen to the text and understand it for what it is, the reader will interpret each time, for the hermeneutical situation demands adjustment. 
Part of the identity of a text is that it demands interpretation. It is the task of the writer to recognize this dynamic and to construct the text in such a manner that the meaning is clear and understandable. The text should be identifiable and repeatable - the meaning should reside in the text and nowhere else; the text should be a witness to itself-but precisely because the text is so transparent, the reader notices his or her interpretive responsibility to an even greater degree: the words are understandable and they are there, but their exact meaning is still disputable. Here the writer pushes the reader to understand something — what is there in the text — but the very meaning of the words are not stagnant — the reader completes the meaning, a completion that changes as the process takes place. The writer has a double task: to be as transparent as possible in presenting the ambiguity, fecundity and dynamism of language. Here, Gadamer's words are helpful:

What prescribes to all reifications in writing their task is precisely that this thing being announced should be understood. The printed text should fix the original announcement $[\ldots]$ in such a way that its sense is unequivocally understandable [...] The task of interpretation always poses itself when the meaning content of the printed word is disputable and it is a matter of attaining the correct understanding of what is being announced [...] Accordingly, we must say that a text is not simply a given object but a phase in the execution of the communicative event ("Text and Interpretation" 35).

The words need to be presented in such a way that they are understandable yet incomplete; the reader has no choice but to interpret, to bring his or her own perspective and horizon to the interaction: when something is read, the words are the same yet different for every reader. It is the writer's task to recognize this dynamic and to include all possible interpretations within the very identity of the text: the text includes potential 
interpretations within itself and is presented in this manner. In writing, there is anticipation: "Writing is more than a repetition in print of something spoken. To be sure, everything that is fixed in writing refers back to what was originally said, but it must equally as much look forward; for all that is said is already directed towards understanding and includes the other in itself" (Gadamer, "Text and Interpretation" 34).

All writing includes the reader within itself: its purpose is to guide and lead the reader. In the concept of text there is an intimate connection between writer and reader: both comprehend understanding and interpretation. The text is so vital because it demands that the individual include the other within itself. When reading a text, each is forced to ponder the meaning of words: the meaning is different for the writer and the reader yet there is a point of contact; the world as it appears in language is in a process of transition. By way of text, the reader engages with this movement- the meaning understandable but also questionable: "Only on the basis of the concept of interpretation does the concept of the text come to constitute a central concept in the structure of linguisticality; indeed, what characterized the concept of text is that it presents itself only in connection with interpretation and from the point of view of interpretation, as the authentic given that is to be understood" (Gadamer, "Text and Interpretation" 30). That is, we use language to interpret and understand the world but we rarely become aware of this interpretive process: language already includes interpretation within itself. But when confronted with a text, where there is nothing but language and that language is permanent, we are prompted to consider how we understand and interpret in the first place: the text resounds only when the words already mean something, when they truly 
matter. Writing, reading, and the text are "[a] fruitful model for all experience" (Gadamer, "Towards a Phenomenology of Ritual and Language" 34).

In the same breath, one might talk about the book of nature and "[t]he readability of the world" (Gadamer, "Towards a Phenomenology of Ritual and Language" 34). Reading is a fruitful model because the words only mean something when the reader anticipates the meaning and follows through with this anticipation as he or she reads. That is, the anticipation of content and the act of reading are one and the same yet also include adjustment and revision within the very same act. In the same way, in our experiences we expect things to be a certain way and these expectations shape the very identity of the experiences while also undergoing revision as our expectations are thwarted. For this very reason, we place such a heavy emphasis on texts and the act of reading — as an enactment and intensification of our interpretive process-from reading we learn lessons. Gadamer notes that reading aloud highlights the true nature of reading: "Reading aloud demonstrates quite clearly, I think, that reading is a completion-ofmeaning which is one's own and is fulfilled within itself in the same act of fulfillment" ("Reflections on My Philosophical Journey" 51). Reading is such a dynamic process that it is impossible to parse the different elements that form it: the meaning of the text, one's own meaning, anticipation and realization - all feed off each other and grow from one another.

As one interprets and as one lives, one understands to a greater or lesser degree. Yes, we already understand, but to what to extent one can harness this understanding and enact its truth depends on one's level of attention and one's willingness to listen even when one does not know — to move further and beyond. As one reads, he or she is 
reminded and drawn into this dynamic of knowing and not knowing. For something to mean anything at all, it already has to mean something; but this does not suggest that meaning is ever exhausted - it is a process that takes place in phases; when something is understood, more is to be understood: "What we call reading means to read with understanding. So reading itself is already an interpretation of what is meant. And thus reading is the basic structure to all carrying out, all realization, of meaning. [...] It therefore also holds that for the text about to be read, the reader who gives the work its full presentness will experience an increase in being" (Gadamer, "Reflections on My Philosophical Journey" 53). This idea that the reader experiences an increase in being is central. As we read a text, its various words and sentences respond to one another and combine and re-combine, a process of regression and progression: the possibilities of meaning fluctuate, moving towards harmony, never entirely reaching it, demanding that the reader participate and keep the words in balance - each moment, each word, a task in itself. The attentive reader, then, makes this effort and in doing so becomes more-more able, more aware, more understanding, of his or her burden and what this entails: that we project our world and respond to our world, its meaning both a question and an answer.

The text, for its part, can make such a demand because it is removed from all contingencies. It is pure meaning, pure sense. For this reason, the reader knows that the text could have something to say: its potential truth cannot be refuted. The reader's aim, then, is to engage with this potential - to confirm and expand what is known:

Thus, precisely because it entirely detaches the sense of what is said from the person saying it, the written word makes the understanding reader the arbiter of its claim to truth. The reader experiences what is addressed to him and what he understands in all its validity. What he understands 
is always more than an unfamiliar opinion: it is always possible truth. This is what emerges from detaching what is spoken from the speaker and from the permanence that writing bestows (Gadamer, Truth and Method 396).

Sure, the text may not necessarily be true but the reader does not know until the text has been read and even then truth is not verifiable or provable. It is the reader's job to make his or her own conclusions: to test hypotheses and find resonance. Where there is inspiration, the text has succeeded.

As a text is always possible truth and truth is variable, occasional and of the moment, then its permanence is of special importance: the reader can always return to the text. Here are Gadamer's words on the subject: "A text is not to be understood as an expression of life but with respect to what it says. Writing is the abstract ideality of language. Hence the meaning of something written is fundamentally identifiable and repeatable" (Truth and Method 392). The text has a definite identity and this places demands on the reader. The text should be understood with respect to what it says but the content of these words only counts when the reader brings them into his or her own viewpoint and own understanding, when the identity of the words remains valid while still occupying a position of change and difference; where the reader respects the words by asking what they mean: "When one brings a text to speak through reading, even if such reading be without any audible articulation, one takes up the meaning that resides in the line of meaning that the text has and builds it into the universe of meaning which the reader himself or herself has already opened up" (Gadamer, "Reflections on My Philosophical Journey” 52). 
As has been alluded to throughout this discussion, the reader finds him or herself in a kind of dialogue with the text. The text has something definite and precise to say, yet the exact meaning depends on the horizon of the reader. Each word means differently for each person. What the text has to say, exactly, depends on the questions that the reader poses to the text:

To understand a text is to come to understand oneself in a kind of dialogue. This contention is confirmed by the fact that the concrete dealing with a text yields understanding only when what is said in the text begins to find expression in the interpreter's own language. Interpretation belongs to the essential unity of understanding. One must take up into himself what is said in such a fashion that it speaks and finds an answer in the words of his own language (Gadamer, "On the Problem of Self-Understanding" 57).

The text answers and subsequently poses more questions - the answers leading to new, previously unconsidered consequences and implications. Only when the words truly mean something and only when they truly provoke will the reader incorporate the meaning of the text into his or her understanding: here the context of being and language shape both the reader and the text. What is being said and why does it matter? The answer is always a personal one, depending on the circumstances of the individual, meant to be weighed, thought through, a journey of excursion and return.

Yes, something is shared by the two partners, the text and the reader. In this case it is a common subject matter. Here the writer has articulated the subject matter, has attempted to place it within a context and make it real. The presence and body of the text, then, entrances the reader: the words matter and the reader responds because they apply to his or her own life - the words illuminate and enlighten, unique and personal yet belonging to a shared world: "Only through [the interpreter] are the written marks 
changed back into meaning. Nevertheless, in being changed back by understanding, the subject matter of which the text speaks itself finds expression. It is like a real conversation in that the common subject matter is what binds the two partners, the text and the interpreter, to each other" (Gadamer, Truth and Method 389). We really are bound by a common subject matter, but it is a subject matter that is questionable. We are pushed to interpret texts because their resonance and implications are variable. Texts themselves are defined by their complexity, their overarching structure that is selflegitimating, each word supporting every other; as we encounter texts, there is clarity and obfuscation — the message is right there, but the implications are infinite: "We find the hermeneutical relationship involved in our concept of text whenever we encounter resistance to our primordial assumption of the meaningfulness of the given" (Gadamer, "Text and Interpretation" 31). Indeed, when we do not know, we ask questions - in them, a world of hope and doubt. 


\section{CHAPTER 3}

\section{GADAMER ON ART AND LITERATURE}

As we enter into this discussion of art and literature, it is first necessary to reestablish the identity of language, for its nature is decisive. Language is the means by which we have a world. As we grow up in the world, language appears: in language, things become what they are; without language, things have no identity, meaningless. The only way we know the world, though, is as something; before we ever question the names of things and their meaning, the linguisticality of the world has already asserted itself: something has already been understood. Nevertheless, identity and meaning do evolve, for each are up for debate. That is, the temptation to use language is an urge to understand more: in each utterance, the words become more concrete, the referent more and more defined, but also exposed to the individuality of the other. Here, the interlocutor or addressee demands an accommodation - that the language mediates the difference of each. In this mediation there is reassurance - these words are meaningful and they matter, in them inspiration and provocation: in this process, too, the words gain in presence and body - more and more real, more and more true. This movement never ends. The passage of time requires change and so does the individuality of each and everyone. As the world is articulated, some things are brought to the fore and others remain in the background. It is a constant effort to find the right balance: to include all that we do not know right along 
with what we do know and to be understood as such. Art, for its part, belongs to this process of understanding.

In art, something-comes-to-being. That is, in art, something is presented as something and is understood as such; identity, presentation, performance and representation conflate-become one. What is presented, though, belongs to itself yet is different. In other words, in the attempt to foreground presentation and representation, meaning, coherence, balance, and unity have already asserted themselves, for they belong to the nature of the world and our perception of it; yet, each performance, each encounter with art is accidental, of the moment, necessarily unique. As time passes, loose ends, uncertainty and incoherence arise unchecked — and unavoidably so — but we are concurrently equipped to confront these challenges. Art is a part of this effort. So, then, art appears and we engage with it because it promotes a greater sense of balance- - things are in order, at least temporarily. But it is not only because coherence is part of its identity that art is so central to our interpretive project, its importance also lies in the fact that the artwork is different each time it is presented, yet it is the same. The artwork places demands on the participant. The meaning of the artwork belongs to itself, yet it is also mediated by all who experience the artwork. In each encounter, the artwork asks questions of the participant and the participant asks questions of the artwork. In this back and forth, a movement of integration occurs. Mediated by the present moment and all who participate, the artwork must change to remain itself-in this there is interpretive gold: a challenge to adapt that belongs to one's very concept of understanding and truth.

Definitively, language is the starting point, as meaning and the world cannot be separated, but what we see and what we understand is not static. Our hermeneutic 
responsibility can never be denied. In art, there is an echoing of this linguisticality: a representation of the world is presented and in this presentation we are reminded of the (possible) representation(s) of the world. With each artwork, then, representation is the main topic and theme. As we make and engage with artworks we are confronted with how we perceive and understand. Artworks only mean anything because they belong to our experience of the world: so tantalizing, so seductive, so true-because they reflect our engagement with the world and each other-in this, greater awareness. As an artwork is a self-enclosed whole that admits no outside verification, we turn to art as a means of understanding our own lives, for we aim to make our lives just like that — as self-enclosed wholes in which all of the parts fit together. Of course, such a task is never entirely possible but to say so does not deny the essential orientation towards integration. For an artwork demands that we relate its content to our own lives, and in the process we see what otherwise may have remained dim:

Language signifies memory. Mnemosyne is, however, the mother of all the muses and so the patron of art. Artwhether picture, word, sound, song, or whatever its origin was or its present social function may be-means, in the final analysis, a way of confronting ourselves in which we become mindful of ourselves. In word as in picture, in petroglyph as in the song, and still in the refined and mediated forms of later literature, the world as a wholethe whole of our world experience-has become present. And even the most silent forms of modern painting, which radiate a brooding silence, evoke in us the 'you are that.' Such an experience of the whole, in which we confront ourselves, occurs through the continual new-awakening of the echoing of art. In this lies the actual distinguishing characteristic of humans (Gadamer, Hans-Georg Gadamer on Education, Poetry, and History 90). 
When we encounter art we are reminded of how we perceive and what we perceive and how we understand and what we understand; the answers, though, are never certain and torturously ephemeral, but the artwork is solid and there, a token of stability and insight, an anchor amid the flow of time.

Compellingly, Gadamer contends that it is through the echoing of art that we recognize things for what they are. Of course, it is hard to parse cause and effect, but certainly the picturing of the world does change its identity. Each time the world is presented in art, it is no longer the same, now something new. In this context, Gadamer discusses the ontological valence of the picture: "In it we can see without any doubt that a picture is not a copy of a copied being, but is in ontological communion with what is copied. It is clear from this example that art, as a whole and in a universal sense, increases the picturability of being. Word and image are not mere imitative illustrations but allow what they present to be for the first time fully what it is" (Truth and Method 137). To say that we would not know the world without art is an unwieldy contention, but to say that the world is more understandable, more true and more compelling as a result of art seems justified. Each time the world is (re)presented more and more of its layers and nuances are revealed. Each time the world is (re)presented differently, we see it and understand it from a unique angle, as itself and as something more. Part of art's responsibility is to prompt us to see and understand creatively; the thing represented - the content - might be the same in several different artworks, but the way it is presented constitutes the value and truth of the artwork: "the picture itself is what is meant insofar as the important thing is how the thing represented is presented in it" (Gadamer, Truth and Method 134). In an artwork there is a dynamic interaction between the content and 
the manner in which it is presented: the aim, in all cases, is to present the subject matter in a way that reveals its truth, so that we know it for what it is. Of course, something can be presented in many different ways, but each successful presentation already belongs to the identity of the content:

That the picture has its own reality means the reverse for what is pictured, namely that it comes to presentation in the representation. It presents itself there. It does not follow that it is dependent on this particular representation in order to appear. It can also present itself as what it is in other ways. But if it presents itself in this way, this is no longer any incidental event but belongs to its own being. Every such presentation is an ontological event and occupies the same ontological level as what is represented. By being presented it experiences, as it were, an increase in being. The content of the picture itself is defined as an emanation of the original (Gadamer, Truth and Method 135).

In this statement, certainly, we can discern the value of art and the impetus to engage with art. In the experience, the participant becomes more because the world becomes more. In each encounter, different aspects of the world spring forth.

In its representation in art, then, the world is seen differently and is recognized for what it is. But this recognition is not static; part of the identity of art is that it conceals itself as it reveals itself; its depths are unfathomable: what people recognize and what they understand includes ambiguity within itself. Something is presented that cannot be denied, but belonging to the very identity of the artwork is its own variability: it means something but what it means includes difference within itself-in each encounter, the participant must interpret. In this context, Gadamer discusses the concept of play.

Play is essential to Gadamer's hermeneutic ontology. In his exposition of art and language, Gadamer emphasizes play because play envelops the players and shapes the 
movements of the players. Before making any conscious choices, play has already asserted itself: "Here the primacy of play over the consciousness of the player is fundamentally acknowledged [...]. Play clearly represents an order in which the to-andfro motion of play follows of itself. It is part of play that the movement is not only without goal or purpose but also without effort. It happens, as it were, by itself" (Gadamer, Truth and Method 105). Once the participants commit to the play, the movements and decisions of the players belong to the nature of the play and constitute the self-presentation of the play. In this respect, the identity of the play is of utmost importance, for once someone has committed to the play, then the play itself is decisive and not the player: "The players are not the subjects of play; instead play merely reaches presentation (Darstellung) through the players" (Gadamer, Truth and Method 103).

According to Gadamer, art is a kind of play. In art there is a movement back and forth between the artwork and anyone who experiences the artwork. The artwork, in fact, is created in anticipation of the person who experiences it. Each time the play of art takes place, it reaches presentation. But why is art a kind of play? Why does it demand this never-ending movement? Art is a kind of play because play is regulated movement; it is not just unfettered movement; it is free movement within a binding structure: "The function of the representation of play is ultimately to establish, not just any movement whatsoever, but rather the movement of play determined in a specific way. In the end, play is thus the self-representation of its own movement" (Gadamer, The Relevance of the Beautiful 23). Art, then, is a kind of play because the movement between the artwork and the participant is a kind of regulated movement; the artwork makes demands and the participant is drawn to respect those demands. The artwork has its own structure that is 
binding, yet belonging to this structure is variability. What is understood changes with each encounter, yet it is still the same artwork:

We started from the position that the work of art is playi.e., that its actual being cannot be detached from its presentation and that in this presentation the unity and identity of a structure emerge. To be dependent on selfpresentation belongs to what it is. This means that however much it is transformed and distorted in being presented, it still remains itself. This constitutes the obligation of every presentation: that it contain a relation to the structure itself and submit itself to the criterion of correctness that derives from it (Gadamer, Truth and Method 120).

The artwork has an identity. It is itself. But what is presented in the artwork is a content that includes our understanding of the world and our perception of it. Something is presented. The thing that is presented is there and it is intended: "“Acting as if" seems a particular possibility wherever the activity in question is simply a case of instinctual behavior, but one that 'intends' something" ("The Play of Art" 124-5). Something is intended and it is a representation, but the meaning and identity of the representation does not belong to anybody; what is there, exactly, is the subject of the play, for what we understand and recognize is never self-same, always different.

Indeed, play is a kind of structure that determines the movements of the players, but the movements, as such, are variable and free within this structure. The creation of an artwork, then, is a kind of play: a structure is created that determines the movements of the participants but the structure includes variability within itself. It is only in the performance, the experience, that the artwork is present at all; in each encounter, the aim is to engage with the artwork so that it remains the same and to do this the performance 
has no choice but to adapt to the present situation. Each encounter with art is an attempt to allow it to be what it is:

I call this change, in which human play comes to its true consummation in being art, transformation into structure. Only through this change does play achieve ideality, so that it can be intended and understood as play. Only now does it emerge as detached from the representing activity of the players and consist in the pure appearance (Erscheinung) of what they are playing. As such, the play-even the unforeseen elements of improvisation-is in principle repeatable and hence permanent (Gadamer, Truth and Method 110).

This concept of transformation into structure is important because it is only as a structure that the artwork has an identity. The only way that anybody can access an artwork is through its performance and each performance is different; nevertheless, all participants have a sense for the identity of the artwork: the play is an attempt to bring to appearance the structure of the artwork, an attempt that can never be more than an approximation.

Yes, an artwork is a structure. It is not something that can be planned and created on a step by step, methodical basis. It is something that has its own unity and grows out of itself. With this in mind, certain elements can be added or taken away, and it can still remain itself. All performance and engagement with this structure is an attempt to realize its ideality, when it is at its most coherent and most self-legitimating. Gadamer describes this organic aspect of structure, or "Gebilde", in the following manner:

The general meaning of 'Gebilde' suggests something not understood from the vantage point of a preplanned finished state one knows in advance but rather something that has developed its own pattern from within and thus is perhaps to be grasped in further formations [Bildung]. To understand this idea is, in itself, an important task. The task is to build up and establish what a Gebilde [shaped form, structure] is; to construe something that is not 
'constructed' - and that means that all efforts at construction are withdrawn ("Text and Interpretation" 49).

This concept of structure, then, privileges attentiveness and process. It is in the engagement and participation that the structure emerges; our fundamental orientation to meaning shapes this engagement, a back and forth process that strives for unity and coherence.

As we engage with art we engage with a structure - and this structure fundamentally inheres insight because something emerges that we would not have noticed otherwise. Something emerges that is understandable and complete: what once was inchoate is now entire - all of the parts fit together. The structure is the only measure - it depends on itself to validate itself. In the artwork everything belongs and everything is in balance. There is no incongruence: everything appears as if it had no choice but to be there. All that appears in the artwork is what is meant; the appearance and the idea are one: "Thus the concept of transformation characterizes the independent and superior mode of being of what we called structure. From this viewpoint 'reality' is defined as what is untransformed, and art as the raising up (Aufhebung) of this reality into its truth" (Gadamer, Truth and Method 112). Art allows us to see things for what they are. Something is identified as what it is and this identification is legitimate because it belongs to a context that depends on nothing but itself, a context that has emerged out of itself:

Transformation into structure is not simply transposition into another world. Certainly the play takes place in another, closed world. But inasmuch as it is a structure, it is, so to speak, its own measure and measures itself by nothing outside it. [...] It no longer permits of any comparison with reality as the secret measure of all 
verisimilitude. It is raised above all such comparison - and hence also above the question whether it is all realbecause a superior truth speaks from it (Gadamer, Truth and Method 111-2).

As the artwork is so coherent and so understandable — as the idea and the appearance merge into one - the artwork yields insight—we relate the meaning of the artwork to the meaning of life: "The transformation is a transformation into the true. It is not enchantment in the sense of a bewitchment that waits for the redeeming word that will transform things back to what they were; rather, it is itself redemption and transformation into true being. In being presented in play, what is emerges. It produces and brings to light what is otherwise constantly hidden and withdrawn" (Gadamer, Truth and Method 112). In art something is presented and we dwell on that appearance: we ask what it means and why it is there. We are prompted to enter into the artwork more and more profoundly. In doing so, we do not reach a final answer and then discard the question. We continue to ask questions and in the questioning the complexity and depth of the artwork — its very meaning and identity_-demand that we consider and take into account all of the contributing variables, a slew of factors that stem from one's experience of the world, an accounting and confrontation that would not happen if it were not for the artwork.

Art echoes one's experience of the world and it is in this echoing that one understands more and better; in art, the world appears as we would not otherwise have seen it. For this reason, art is everywhere and it is unavoidable. Art belongs to our very process of understanding the world; we are tuned to engage with it. But some people choose to seek it out and engage with it in a conscientious manner. In doing so, there is 
even greater yield, a more acute sense of communion, a clearer path to truth. It is the case, in fact, that art reminds us of our plight: that time passes inexorably, that we appear out of nowhere and belong to a world not of our choosing —all of this shapes us and determines our actions. Before we make any decisions, the possibility of that decision has already been molded. To come to terms with this lack of control and to harness the influence that we do have belongs to our experience of art. Our engagement with art is like this: something is there that places demands; we are not free to see or understand whatever we choose; yet there is freedom and necessarily so-in order for the artwork to be what it is, it must be adapted to the current hemeneutical situation. In the encounter with the artwork, there is a reflexive movement: one's place in the world and one's interpretation of the world is the whole that envelops each and every one of us; at the same time, the artwork is its own whole, undeniable in its presence. There is, then, a back and forth movement between the interpretation of experience and the interpretation of the artwork. In this movement, one relates the whole of one's experience to the artwork and one relates the whole of the artwork to one's experience: "Amidst the variety of art, this same message of the whole addresses us over and over again. Indeed, this seems to provide a more precise answer concerning the significance of art and beauty. This means that in any encounter with art, it is not the particular, but rather the totality of the experienceable world, man's ontological place in it, and above all his finitude before that which transcends him, that is brought to experience" (Gadamer, The Relevance of the Beautiful 32-3). In art there is a contemporaneity and a timelessness because it, in fact, engages those experiences that shape our sense of time and our historicality. An artwork belongs to a cultural moment and is a testimony of that moment. However, it is precisely 
this sense that the artwork is a part of history that is timeless and universal. In all encounter with artwork, then, the participant is reminded of history and change. Yet, in the mediation between the past and the present, the participant takes note of a meaning that belongs to both: the past belongs to the present and the present belongs to the past. Furthermore, the experience of art is one that takes place through time. As one actively engages with an artwork, the significance and meaning of each moment is uncertain; yet the parts do fit together to make a meaningful whole, however indeterminate the meaning may be. This construal requires active participation, a restless back and forth energy; an action that never entirely settles but does approach completion, even if it never gets there. These experiences of time are important and are reflected in how we experience time in our daily lives.

The work of art is useful because it is a whole that strives for completion; a sense of fulfillment that we aim for in each performance and each encounter, a whole that we can never entirely enact; nevertheless, it is in the attempt, in the possibility, that we attain insight. For in each performance there is a possibility of correctness that shapes the experience; some aspects might be ignored and others might be emphasized, but it is only the identity of the artwork that places such constrictions; its identity belongs to the performance, which necessarily is filtered through the present moment, shaping the performance. It is this striving for correctness that constitutes the appeal of art. For in the attempt to respect the artwork, we also learn to respect and engage with the identity of our very existence:

In as much as the verse and art are themselves such a whole, they incorporate us in themselves. They are, philosophically speaking, reflections in themselves. We are 
ourselves encompassed by the whole, which we are and which is in us; but not encompassed in such a manner that the whole would be present for us as the whole. We encounter it rather as the totality and vastness, wherein everything is, only through adhering to what has been allotted us, ie., the nómos, whatever it may be (Gadamer, Hans-Georg Gadamer on Education, Poetry, and History 91).

By way of art, we come to realize that each moment is new and makes its own demands: like we do with artwork, we do with life-we place each moment within a larger context, a dynamic interaction that requires attention, engagement and participation. We will never exactly know this larger context for what it truly is because of the nature of change, but to acknowledge that it is there and that each new moment requires revision has its own value, for then we know to pay attention and participate, then we have a better sense for our place in the world.

When we engage with a work of art, it imposes its own structure on the participants, a structure that is only present in the performance. Each performance is different, but, at the same time, the only way that anyone can experience the artwork is through performance. All performances are necessarily deficient—-they do not reach ideality; but it is not incidental to the work of art that it depends on performance-it is part of what it is: "The artistic experience is constituted precisely by the fact that we do not distinguish between the particular way the work is realized and the identity of the work itself. That is not only true of the performing arts and the mediation or reproduction that they imply. It is always true that the work as such speaks to us in an individual way as the same work, even in repeated and different encounters with it" (Gadamer, The Relevance of the Beautiful 29). It is of special importance that the work is always the 
same even as the performances vary. This means that each performance belongs to the identity of the artwork; the identity of the artwork includes difference within itself; each possible interpretation and performance constitute the identity of the work playing itself out. It is in the performance that the artwork achieves absolute presence, a presence that places demands on the participant in which he or she tries to square the performance with the true identity of the artwork; here, though, the performance is all there is - it is only through its performance that the artwork has an identity. This is the special nature of art as play: "Play is structure - this means that despite its dependence on being played it is a meaningful whole which can be repeatedly presented as such and the significance of which can be understood. But structure is also play, because-despite this theoretical unity — it achieves its full being only each time it is played. That both sides of the question belong together is what we have to emphasize against the abstraction of aesthetic differentiation" (Gadamer, Truth and Method 116). As we look at the different mediums in which art can manifest itself, we notice the different ways that each artwork can be performed. Each medium is different, each demanding a different kind of performance. Theater is one example. In theater, each performance is in service of the artwork: so that the performance corresponds most fully with the identity of the work. That identity, of course, never completes itself; in the performance the artwork is never entirely what we imagine it might be. Furthermore, the audience, the actors, the playwright - all have an equal share in the identity and meaning of the play. In the case of the play-wright, he or she has written a play that is a guide for the production of the play: it is only in the performance that the play becomes what it is. In the case of the actors, they are given the task of embodying the play, so that it becomes something definite for 
anybody who experiences it. Here, the actors succeed when the distinction between the presentation and the thing presented is a non-distinction: the actors' only job is to allow the play to be understood for what it is. In this case, the play is presented for an audience: "openness toward the spectator is part of the closedness of the play. The audience only completes what the play as such is" (Gadamer, Truth and method 109). The play is meant for an audience: the identity of the play belongs to the participation of the audience, a situation where neither the actors nor the audience enjoy priority; instead, all who participate have the same burden and opportunity: to engage with the artwork so that it becomes itself. In the experience of the artwork, there is something that lies in between for all who experience it, unpossessed and awaiting appropriation: it is the task of each to accommodate the meaning of the artwork with the meaning of one's own experience. This challenge alters with each encounter because the meaning of an artwork is inexhaustible: it includes difference within itself.

As an example, I would like to highlight Ibsen's drama, The Lady from the Sea. Although written to be performed, his work is widely considered to be literature, also meant to be read. Now, when I read this work there is an interpretive demand that is undeniable. Written in the late nineteenth century, his work is a pre-cursor of Woolf's, inaugurating many of the themes that come to dominate Modernism. In it, Ibsen examines free will, existential determination, and the institution of marriage. As Ibsen sees it, marriage was a poisoned and corrupt institution. As a result, both men and women suffer and human being is stunted. Overall, marriage comprehends our economic, social and existential imperative. At the time, many women had to marry in order to survive: it was not a matter of choice but of necessity. Consequently, many marriages were initiated 
on a slippery foundation: the union turns out to be less than the sum of its parts, each party diminished instead of exalted. In his play, Ibsen emphasizes free will and the continuity and coherence that we all strive for in meaningful existence. To slur over one's past or deny the value of one's history leads to fragmentation, frustration and confusion. One's past should be acknowledged and confronted: only in this manner can one move forward and grow. And it is only in the context of one's past that the decision to marry or not makes sense. Now, I am only able to interpret this play as such because I identify and recognize what it is like to have a personal story, what it is like to interact with people, what it is like to fuse my hopes and dreams with those of another. Of course, the historical and material conditions have changed considerably, but it also true that my personal context includes an awareness of this difference. Despite this difference, people then as now found fulfillment in their relationships and in marriage. In reading this play, I get a better sense for the dynamics of this union and the effort and actions required for it to yield personal fulfillment.

Theater is an example of a reproductive art where performance is foregrounded, but all artworks are made to be performed. This is the case even for the plastic arts or the literary arts. Even a painting hinges on performance. When someone looks at a painting, it is an experience that occurs through time: a scanning process takes place. A painting is made to be viewed, and in this viewing something is understood, but that something is not the final answer; we return to the painting because there is something in it that compels, the nuances and relations in movement. Pablo Picasso's Guernica is an example of a painting that emphasizes this sense of movement. Of course, we experience this kinetic energy with all paintings, but, to a considerable degree, the subject matter of 
Guernica is this movement itself. Fiero describes the Cubist image in these terms: "The Cubist image, conceived as if one were moving around, above, and below the subject and even perceiving it from within, appropriated the fourth dimension-time itself" (6: 6). Produced in response to the bombing of the Spanish town Guernica, "the world's first aerial bombardment of a civilian target", Picasso's aim was to represent the horror of this event. But, instead of representing it realistically, Picasso chose to represent it as a Cubist image. In many ways, Picasso's Cubism is a refutation of the impersonality of violent technology. Each image can be seen from several different viewpoints and requires a scanning process that never completes itself. As one scans, the nuances and relations shift and change. It emphasizes the variability of the perceiving consciousness, the inexhaustibility of perception: the perception of each individual is of value and worth, contributing to our collective sense of truth and meaning.

Overall, the painter has created the painting because it provides answers but also because it asks questions; queries and responses that depend on each encounter, forever vibrant:

A dialectic of question and answer does not here come to a stop. On the contrary, the work of art distinguishes itself in that one never completely understands it. That is to say, when one approaches it questioningly, one never obtains a final answer that one now 'knows.' Nor does one take from it relevant information, and that takes care of that! One can never fully harvest that which resides in an artwork so that it is, so to speak, consumed. Apprehending a poetic work, whether it comes to us through the real ear or only through a reader listening with an inner ear, presents itself basically as a circular movement in which answers strike back as questions and provoke new answers. This is what moves us to tarry with a work of art, of whatever kind it may be. To be tarrying [Verweilen] is clearly the distinguishing mark of the experience of art. An artwork is never exhausted. It 
never becomes empty" (Gadamer, "Reflections on My Philosophical Journey" 43-4).

An artwork is created with the experience in mind, one in which the participant encounters something that is true and understandable, yet variable and of the moment: a reflexive movement occurs - in order to understand what is there, the participant has no choice but to relate this new present to past experience. It is part of the identity of the artwork that the participant should feel challenged and also feel the need to face the challenge.

Once created, the artwork belongs to no one, not even the artist-he or she confronts the artwork just like anyone else: as something that reveals itself in its abundance but also reposes in itself; the artwork has its own special identity that is autonomous and self-sufficient; the artwork is meant to be performed and in the performance it is both different and the same each time. This is part of its identity, in fact — that it encounters each participant as a thing that changes the participant: the artwork is always created in anticipation of the performance. The artwork only has an identity when it is performed: "The concept of play was introduced precisely to show that everyone involved in play is a participant. It should also be true of the play of art that there is in principle no radical separation between the work of art and the person who experiences it" (Gadamer, The Relevance of the Beautiful 28). The work of art is created in anticipation of its experience and this experience mandates that the participant recognize what it is that is being presented. In order to understand what is being presented, the participant looks at his or her own life, relates what appears in the artwork to his or her own understanding and experience. In this, there is a horizon of possibility 
that envelops and surrounds the participant: the artwork belongs to this horizon and asks that the participant reassess his or her place in the horizon because it has presented something that has never even been considered; once seen, the participant feels the urge to integrate. In this context, Gadamer's words prove apt: "The play of art as appearance is played out between us. The one takes the creation simply as a creation, just as the other does. Communication takes place when the other person takes part in what is imparted to him - and in such a way that he does not, as it were, only receive in part what is communicated to him, but shares in this knowledge of the whole matter that is fully possessed by both of them" ("The Play of Art" 128). Yes, in art something is presented that appears and we relate this appearance to absolutely everything; everything, in fact, has an appearance. To come to terms with the appearance of everything, to try to square appearance with truth — this is the nature of hermeneutic ontology.

The artist, then, creates an artwork so that all who experience it participates in the same effort: so that one might see and understand the world for what it is. Like an artwork, the world, too, has an identity and we each feel the need to commune with this identity. Art belongs to this process of fulfillment:

What gives the work its identity as a work? What makes this what we call a hermeneutic identity? Obviously, this further formation means that its identity consists precisely in there being something to 'understand,' that it asks to be understood in what it 'says' or 'intends.' The work issues a challenge which expects to be met. It requires an answeran answer that can only be given by someone who accepted the challenge. And that must be his own, and given actively. The participant belongs to the play (Gadamer, The Relevance of the Beautiful 49). 
The artwork issues a challenge and we are drawn to this challenge because, instead of engaging with the diffuse gauze of an undifferentiated world, we encounter something that is definite, concrete, and complete. Yet, because the artwork never reveals all of its answers, because it must be performed to be at all, the work changes with each encounter. This meeting with difference is appealing because of our own experience of time: change is unavoidable and we are better off if we face it, if we too are fluid. It is a trial of adaptation and integration: "It is a question, therefore, of allowing what is to be. But this 'letting be' does not mean the repetition of something we already know. We let the past be for us as we are now, not by repeated experience of it, but through an encounter with it" (Gadamer, The Relevance of the Beautiful 49). The artwork is different for each person who experiences it and in each moment that one encounters it. In all, the artwork paves its own path, but it depends on the participant to follow the guideposts and to be able to read them; in order to do so, the participant has to accommodate his or her outlook and language in such a manner that he or she might decipher the hieroglyphics of the artwork. Yet, the artwork is created in such a way that it anticipates difference: it is made to be understood uniquely, depending on who encounters it - even as it remains itself. Gadamer puts it this way: "All artistic creation challenges each of us to listen to the language in which the work of art speaks and to make it our own. It remains true in every case that a shared or potentially shared achievement is at issue" (The Relevance of the Beautiful 39). The artist creates the artwork to be experienced, but it is not until this happens that the artwork is what it is supposed to be. In this encounter, the participant is changed and the artwork is more truly itself, a means of mediation. 
The artwork is meant to be experienced and because of this the artwork includes the other within itself. In the same manner, the participant chooses to experience the artwork so that he or she might do the same-encounter the other so that he or she is more oneself. As one grows in the world, one tries to find one's place in it and to understand it; it is an anxious question with no final answer, but there are moments of illumination and continuity. Art contributes to this effort:

Self-understanding always occurs through understanding something other than the self, and includes the unity and integrity of the other. Since we meet the artwork in the world and encounter a world in the individual artwork, the work of art is not some alien universe in which we are magically transported for a time. Rather, we learn to understand ourselves in and through it, and this means that we sublate (aufheben) the discontinuity and atomism of isolated experiences in the continuity of our own existence (Gadamer, Truth and Method 83).

An artwork is always new and different, yet its materials are the same as those that belong to one's interpretive effort; the artwork is immediately accessible, requiring no effort other than a willingness to pay attention; in this encounter the world appears transformed and this transformation is so compelling and so true that we relate it to our own world, so that it too might be understood for what it is.

An artwork is created in anticipation of its performance and each performance strives to present the artwork as it is. But what is the content of the artwork? Why does it belong to our understanding of the world? Well, up to now the answer has been alluded to, but it has not been mentioned explicitly: that an artwork presents something as something and is understood as such. Whatever is presented is intentional and is presented as appearance: "Mimetic imitation [...] does not intend to be 'believed,' but to 
be understood as imitation. Such imitation is not feigned, is not false show, but on the contrary clearly a 'true' showing, 'true' as a show. It is perceived just as it is intended, namely as show, appearance" (Gadamer, “The Play of Art” 127-8). In an artwork something is presented and that something is what it is meant to be. As we follow this line of thought, we might notice that something can only be presented when one knows what it is: in the artwork, something is there as one knows it to be. As one creates an artwork or encounters an artwork, the raw materials that we use to interpret the world are transferred into the artwork and, in this transference, these materials are removed from their contingent circumstances and we acquire a knowledge of the essence: "The concept of imitation can be used to describe the play of art only if one keeps in mind the cognitive import of imitation. The thing presented is there (Das Dargestellte ist da). That is the situation basic to imitation. When a person imitates something, he allows what he knows to exist and to exist in the way that he knows it" (Gadamer, Truth and Method 113). In art something is presented as we know it to be-anybody who encounters the artwork will then recognize what is represented; in the representation, the thing is presented as it is understood; nevertheless, what is understood, precisely, is part of the play, up for debate, agile.

Art is a path into the true because in it there is no difference between the representation and the thing represented; the representation is the only available way for the thing to be understood; the thing is there as we know it: "the work of art does not simply refer to something, because what it refers to is actually there. We could say that the work of art signifies an increase in being" (The Relevance of the Beautiful 35). The work of art does not point away from itself; the reference is included within itself: to 
engage with the representation, one already knows that which is represented. In other words, as one engages with representation, the thing represented is already there in the representation, for one would not be able to represent it if one did not know it: "With regard to knowledge of the true, the being of the representation is more than the being of the thing represented" (Gadamer, Truth and Method 114). Yes, the representation is paramount and shapes how we encounter the thing represented, but, in the same breath, the thing represented is encountered as it is because we recognize it in the representation: "For there is no doubt that the essence of imitation consists precisely in the recognition of the represented in the representation" (Gadamer, "Art and Imitation" 99). In other words, in an artwork, something is always presented as something; the content depends on the presentation and the presentation depends on the content. What, exactly, is represented, though, can vary widely. In its most abstract sense, one can represent the relations between things, their order: "This talk of imitation obviously derives from the fact that the universe itself, the vault of the heavens, and the tonal harmonies we hear, can all be represented in a miraculous way by numerical ratios, especially those between even numbers. [...] Mimesis reveals the miracle of order that we call the kosmos" (Gadamer, “Art and Imitation" 101). For in our experience of the world, we encounter order all around us; it is only natural that we would represent this feeling of order in an artwork; here, an artwork reconciles the relations of things, a correspondence that we sense and strive for, incomplete and temporary yet flush with potential.

When something is represented it is made present; this means that it is there to be encountered and in the confrontation one wonders what it is, exactly, that is there. One wants to recognize the thing that is there: "Recognition confirms and bears witness to the 
fact that mimetic behavior makes something present" (Gadamer, "Art and Imitation" 98).

Recognition is very important. When one recognizes something, one understands the thing for what it is:

When I recognize someone or something, what I see is freed from the contingency of this or that moment of time. It is part of the process of recognition that we see things in terms of what is permanent and essential in them, unencumbered by the contingent circumstances in which they were seen before and are seen again. This is what constitutes recognition and contributes to the joy we take in imitation. For what imitation reveals is precisely the real essence of the thing" (Gadamer, Art and Imitation 99).

Put simply, in art something is represented so that it might be recognized. What is represented is entirely intentional and is meant to be dwelt upon; it is meant to be seen and considered; the representation is meant to matter because it is all that is there: "What is shown is, so to speak, elicited from the flux of manifold reality. Only what is shown is intended and nothing else. As intended, it is held in view, and thus elevated to a kind of ideality. It is no longer just this or that thing that we can see, but it is now shown and designated as something. An act of identification and, consequently, of recognition occurs whenever we see what it is that we are being shown" ("The Play of Art" 129). An artwork allows for unlimited freedom: it can be anything. But an artwork is never everything. The artist has to make choices and in doing so he or she commits to a certain way of understanding and a certain way of seeing. Nevertheless, it is also the artist's prerogative to situate his or her artwork within this paradigm of limitless possibility: by presenting a defined artwork with details, the artist provokes the participant to relate the specific identity of the artwork to the truth of art and all that it entails. In order for this to happen, the participant has no other option than to enter even further into the artwork: it 
is only in the details that the universal appears. An artist presents something that is there - and this something is the only measure. It is the participant's responsibility to engage with what is there and to recognize what is there.

In an artwork something is presented that is intentional, meaningful, and universally relatable. The participant is able to see what is there because each artwork includes the other within itself: it is an attempt to go beyond the individual and identify those experiences that we all share. The more one engages with art, the more one grasps our commonalities. When something is shared, it is no longer idiosyncratic: one now trusts it for what it is. In this activity, there is an experience of growing familiarity: "The joy of recognition is rather the joy of knowing more than is already familiar. In recognition what we know emerges, as if illuminated, from all the contingent and variable circumstances that condition it; it is grasped in its essence. It is known as something" (Gadamer, Truth and Method 113). In our experience of the world, there is a rush of phenomena that we can never entirely trap: there is just too much to process; however, some of it does acquire meaning and some of it is understood, if not completely. In our perception, the world is already understood, at least up to a point. Art is a part of this process: "Recognition always implies that we have come to know something more authentically than we were able to do when caught up in our first encounter with it. Recognition elicits the permanent from the transient. It is the proper function of $[\ldots]$ art in general to accomplish this" (Gadamer, The Relevance of the Beautiful 47). In art, our experiences of the world are reflected: in order to understand what is there in the artwork, we indubitably relate it to our own lives. In this action, the 
contingent elements are removed, no longer depending on the individual situation, now part of a structure that relies on nothing but itself and therefore cannot be false.

An artwork is an avenue to truth because it depends on nothing but itself. It is its own self-enclosed world that creates the terms of its own existence. In an artwork, we recognize the way things are because our own experience of the world is similar: it too is a self-enclosed whole that admits no outside verification. Gadamer describes this character of art in a similar fashion: "art is present whenever a work succeeds in elevating what it is or represents to a new configuration, a new world of its own in miniature, a new order of unity in tension" ("Art and Imitation" 103). We turn to art because it is permanent while still including change within itself: the work of art demands that its experience take place through time and in this undertaking the participant strives to allow the artwork to be what it is; it is an attempt that is always an approximation; the artwork makes a normative claim and we are beholden to this claim, but the exact parameters are never clear and they fluctuate with the passage of time. This balancing act, this mediation between the permanent and the transient, this attempt to accommodate identity and difference - all of this is part of our experience of the world. In art, we get the chance to engage with particulars; instead of something diffuse, we encounter something concrete: it is there and it is intentional and it is self-sufficient. An artwork is self-sufficient when everything belongs, everything is in its right place and in its right order: its truth cannot be refuted. The world of the artwork and the world of lived experience conflate.

In the same breath, Gadamer discusses the symbolic character of art. To discuss the symbolic is similar to discussing the role of recognition in art. Yet, discussing the symbolic can provide its own clues and can yield a more nuanced picture of the nature of 
art. In all cases, the point of art is to recognize the way things are and to become more familiar with the nature of the world; when something is recognized, it is understood for what it is; by engaging with art, one's overall experience of the world is related to the particulars of the artwork, which, by nature, is complete and entire, with no loose ends. When we experience art, this feeling of completeness is transferred to one's own understanding. For a second, the world, in all of its complexity, is unified:

For our experience of the symbolic in general, the particular represents itself as a fragment of being that promises to complete and make whole whatever corresponds to it. Or, indeed, the symbol is that other fragment that has always been sought in order to complete and make whole our own fragmentary life. [...t]he experience of the beautiful, and particularly the beautiful in art, is the invocation of a potentially whole and holy order of things, wherever it may be found (The Relevance of the Beautiful 32).

We turn to art in order to find meaning, so that the different, distinct elements of life might fit together. As we live with art, its truth asserts itself, a declaration that is undeniable and overwhelming; in the experience, we gain insight that we would not gain in any other way. That is, the meaning of the artwork is included within itself, yet that very meaning is only understandable when related to the matrix of possible meanings; furthermore, one could say that the artwork changes the contours of possibility, for it presents something that had, up to that instant, not been considered or recognized:

We typically encounter art as a unique manifestation of truth whose particularity cannot be surpassed. The significance of the symbol and the symbolic lay in this paradoxical kind of reference that embodies and even vouchsafes its meaning. Art is only encountered in a form that resists pure conceptualization. Great art shakes us because we are always unprepared and defenseless when exposed to the overpowering impact of a compelling work. 
Thus the essence of the symbolic lies precisely in the fact that it is not related to an ultimate meaning that could be recuperated in intellectual terms. The symbol preserves its meaning within itself (Gadamer, The Relevance of the Beautiful 37).

By being there at all, the artwork is an impetus for further explanation, for one can never exhaust the particularity of each individual artwork; the artwork both refers to something else and includes its reference within itself.

Art is a medium of truth, insight and meaning that is unique and irreplaceable. It is capable of all of these accomplishments because we are tuned to engage with art-it is a part of who we are and how we understand: art and being necessarily belong together, each reflecting the other. So when Gadamer says that art "resists pure conceptualization," this statement should also be applicable to human being. If one thinks about how we understand, then it is easy enough to defend this position: for it is true that everything cannot be understood; when some things are brought to our attention, others are left in the background, unavoidably so. Here, Gadamer's words prove useful: “precisely what is exhibited in the work of art ought to constitute the essence of Being itself. The conflict between revealment and concealment is not the truth of the work of art alone, but the truth of every being, for as unconcealedness, truth is always such an opposition of revealment and concealment. The two belong necessarily together" ("The Truth of the Work of Art" 107). An artwork does present something, but what it is exactly can never be completely determined. In this manner, we are asked to balance and unify, to identify the artwork while admitting that this identity is variable and in flux; in each encounter, the meaning of the artwork shifts because each constituent component only matters as each relates the one to the other, a constellation of meaning that is dynamic and fluid; the 
experience becomes an exercise in revision and unification. In art, there is an indeterminacy that is part of its definition, requiring that the participant interpret: something is there, but that thing includes difference within itself. Life is not so different. In life, we are not sure about the meaning of things either. Yes, truth asserts itself, but as we come to know more, the mystery of things also becomes more apparent: "interpretation seems to be a genuine determination of existence rather than an activity or intention" (Gadamer, "Composition and Interpretation" 71). In all cases, interpretation is a part of existence and we engage with art to equip ourselves in this effort.

We can never know everything: we already know something and this orientation determines the questions we ask and all that we might consider. In this, we are bound to a moment and a situation. The act of interpretation is a working-out, a consideration of all those factors and elements that are determinative; it is an incompletable process and one with no final answer, for those things that shape our questions and the very act of interpretation can never be entirely accounted for. This is the case for the interpretation of existence and of art. The final truth, the root cause, the source - these will never be grasped: our blind spots, our incessant movement, this whirl that envelops us - these ensure our need for interpretation; this search for balance requires our attention, effort and engagement. As we consider the different elements—of all that is—we come to recognize and understand, a coherence and meaning assert themselves and the relations are further understood in all of their complexity and nuance: in all, the world becomes more. Yet, as the world becomes more the true complexity and mystery of things becomes more noticeable also. For as we understand more, we become more aware of everything that we do not understand. With any assertion, the world is pictured at a 
certain angle: more can and needs to be said in order to account for the one-sidedness of each statement. The meaning of life, then, or of art, is never final. As we engage with life and art, the entire structure - the overall meaning — alters as we enter further into the structure: the whole changes with the parts and the parts change with the whole. In each moment, the meaning is new:

To be sure, correct knowledge is made possible by the openness of the there. The beings that come forth out of unconcealedness present themselves for that which preserves them. Nevertheless, it is not an arbitrary act of revealing, an act of theft, by which something is torn out of concealedness. Rather, this is all made possible only by the fact that revealment and concealedness are an event of Being itself. To understand this fact helps us in our understanding of the nature of the work of art. There is clearly a tension between the emergence and the sheltering that constitute the Being of the work itself. [...] Its truth is not constituted simply by laying bare its meaning, but rather by the unfathomableness and depth of its meaning (Gadamer, "The Truth of the Work of Art" 107).

In life and in art the act of interpretation is required. In each case, the meaning shifts as we know more and differently. Art demands interpretation and it is part of its identity that it changes — becomes itself — as we change.

The interaction between the participant and the artwork is dynamic; related to this dynamism and contributing to it is the manner in which the participant experiences the artwork: instead of moving in one direction until reaching the end, instead of consuming the artwork so that all of its riches are acquired, the artwork requires that the participant encounter it on its own, autonomous time. Concerning the temporal dimension of art, Gadamer has this to say: "the work of art is [...] determined by its own temporal structure rather than by the quantifiable duration of its existence through time" (The Relevance of 
the Beautiful 43). In its occurence, the artwork has its own time, one that contrasts with our pragmatic, practical notion of time: instead of going forward, we tarry. In this case, the artwork suspends our usual sense of time: in the interaction, there is no time other than that of the artwork. The ideal feeling of time in the artwork is never quantifiable; instead, it depends on the structure of the artwork, an attempt to allow the artwork to be what it is at its most ideal; for our experience of time depends on rhythm and contrast; here, once again, it is a question of the relation of parts to whole and whole to parts. The proper tempo, then, depends on context: it is only within the context of the whole that the proper time can be found. This account of time has two parts: for one, there is the tempo of the performance, and for the other, the suspension of temporal duration. The two cannot be parsed. The point here is that the proper tempo depends on the relation of one moment to all of the other moments within the artwork; a sense for this relation, though, depends on a willingness to go backwards and forwards, a recognition that these relations are not fixed, changing in the experience itself. That is, in order to find the tempo appropriate to the artwork, one must first experience the artwork as a whole, an experience that is recursive and anticipatory; in this activity, there is a suspension of durationality and directionality. The more one dwells with the artwork, then, the more it reveals of itself:

The temporal dimension that is bound up with art is, in fact, fundamental. In this tarrying the contrast with the merely pragmatic realms of understanding becomes clear. The Weile [the 'while' in Verweilen, tarrying] has this very temporal structure - a temporal structure of being moved, which one cannot describe merely as duration, because duration means only further movement in a single direction. This is not what is determinative in the experience of art. In it we tarry, we remain with the art 
structure [Kunstgebilde], which as a whole then becomes ever richer and more diverse. The volume increases infinitely - and for this reason we learn from the work of art how to tarry (Gadamer, Gadamer in Conversation 77).

Through the autonomous temporality of the artwork, we learn that meaning cannot be consumed and discarded, nor is there a final answer that we might someday capture; instead, meaning appears in the interaction: the more we occupy the structure the more its truth appears, the more we get a sense for the component parts and their relations. In the experience of art and, more specifically, in the act of tarrying we gather that meaning is inexhaustible and infinitely complex; with each new moment it becomes something else and it is our task to account for this - an act of intent that slips between our fingers but still leaves a trace, renewal and prophecy in tandem.

This temporal experience of art is universal. It applies to all mediums of art. But the specific concern of this project is literature and its identity. When one reads literature, one tarries; the connotations and complexity of meaning in movement also, always demanding more of the reader. But literature is not exactly the same as art either; it is different in that language is the root and measure of literature; of course, art depends on language, too, for art is always an experience of meaning, but other art forms are one step removed from language. Therefore, according to Gadamer, literature occupies a special and privileged position in the pantheon of the arts: instead of engaging perception which then leads to an experience of (in)determinate meaning, literature engages our linguisticality—in it we confront the reference and discourse contained within language —all that language can accomplish. That is, through our linguisticality we proclaim the identity of the world: something comes to being that was never before and 
the world becomes something else as it is described. Literature depends directly on this linguisticality and art too, but art is a result of how we understand the world and define it; literature clears the way for art and is a model for it too: "Heidegger asserts that the essence of art is poeticizing. What he means is that the nature of art does not consist in transforming something that is already formed or in copying something that is already in Being. Rather, art is the projection by which something new comes forth as true. The essence of the event of truth that is present in the work of art is that 'it opens up an open place"" (Gadamer, "The Truth of the Work of Art" 108-9). The commonality between poetry and art is undeniable. Poetry serves as a model for art because it transforms the world: our sense for the identity of the world depends on language and poetry engages this process of definition. Art is like poetry in that it too transforms its subject; even if its medium is not language, it is on its way to language: both art and poetry present something as something, but the exact meaning is never certain; one returns to the artwork again and again, aware that its truth is new each time.

All that has been said about art up to this point also applies to literature. But it is also true that literature belongs to a special category. It belongs to the domain of language. Literature lies at the intersection of art and language. At this point, then, it is worth returning to our analysis of language and what it means that we have language. Put simply, it is impossible to separate meaning from language or understanding from language. That is, we grow up and acquire a language and this is not a conscious effort: before we even notice, the names of things have staked their claim. This is our relationship to language, then: it is unconscious and we are oriented to the content of the discourse instead of the details of grammar or syntax; as we use language, we only notice 
the meaning. The literary work of art engages this aspect of our linguisticality - that in language we come to know the world as it is:

When we grow up in a language, the world is brought close to us and comes to acquire a certain stability. Language always furnishes the fundamental articulations that guide our understanding of the world. It belongs to the nature of familiarity with the world that whenever we exchange words with one another, we share the world. The word of the poet does not simply continue this process of Einhausung, or 'making ourselves at home.' Instead it stands over against this process like a mirror held up to it. But what appears in the mirror is not the world, nor this or that thing in the world, but rather this nearness or familiarity in which we stand for a while. This standing and this nearness find permanence in the language of literature and, most perfectly, in the poem (Gadamer, "On the Contribution of Poetry to the Search for Truth" 115).

Literature is able to promote awareness and insight because it depends on nothing but language. When confronted with a poem or a novel, the reader comprehends that language is all that there is and this pushes the reader to wonder about the identity of language. Why is language so captivating? How is it so self-reliant? A reflexive action occurs: the reader wonders about the meaning of the words in a poem and subsequently relates those words to their meaning in life. Here the reader becomes aware that the world changes as his or her ability to describe it changes; the meaning of the poem depends on language and the meaning of life depends on language: in each, there is no other measure; in engaging with a poem, we engage with it as a coherent whole and attempt to understand some overall meaning - the same too with life. In life, language is decisive, but it has already asserted its dominion before we even notice - the world has already been born. 
The literary work of art means something that matters, but the exact meaning is ambiguous and many-sided; the words vanish into their meaning, but reappear because the meaning includes difference; here we have no option but to return to the words. In the literary work of art each word is unique and irreplaceable, the overall meaning and effect depending on the combination of words, with each word contributing; if one word were substituted, the text would be something else: "In poetry, there is no longer a gap within the act of meaning: what becomes represented in language bears witness to more than mere linguistic mastery. An enigmatic form of the non-distinction between what is said and how it is said gives to art it specific unity and facility and so, too, its own manner of being true" (Gadamer, "The Eminent Text and Its Truth" 10). Each word, then, is vital: each carries its own unique meaning, so unique that we notice how the meaning depends on nothing but itself. We notice that each word bears its own fruit, its own insight, each word reveals something different: in a literary text each word guarantees its own validity. In a literary text language depends on nothing but itself and it is this aspect of its identity that is most decisive for this discussion. A literary text engages our linguisticality - that we have language at all. In a literary text we take notice of how we typically use language: we normally use language to express an idea, while still aware that the same idea can be expressed any number of different ways. Language in a literary text, though, is different. In it, each word resists being taken up into a discourse with a straightforward meaning; in this process, we are reminded of the potential accomplishments of language: language, in and of itself, can shape how we understand. We are reminded of this influence when we encounter literary works of art: "In this kind of text language emerges in its full autonomy. Here language just stands for itself; it 
brings itself to stand before us, whereas normally its words are taken over by the intention in the speech and then after being used are just left behind" (Gadamer, "Reflections on my Philosophical Journey" 39). Here, Gadamer's argument depends on the contrast between how we typically use language (where the meaning is straightforward and seemingly unambiguous) and the status of language as it exists in the literary work of art (where the language resists a straightforward meaning, each word in play with the other, the final meaning never settled). In the literary work of art, each word carves out a space for itself. In language, there is an orientation to meaning and naming that cannot be escaped: as each word appears, the possibility of every other word is shaped; there is a natural progression, an inescapable coherence that shapes both the reader and writer - both strive for the feeling that each word fits, the parts and the whole in harmony. Gadamer expresses this idea in the following manner:

In a literary work, a peculiar tension is generated between the directedness to meaning inherent in discourse and the self-presentation inherent in its appearance. Every part of speech, every member, every individual word that submits to the unity of meaning in the sentence, represents in itself also a kind of unity of meaning insofar as through its meaning something meant is evoked. So far as the word issues forth from the play within its own unity and does not function merely as a means of conveying the meaning of the discourse as a whole [Redesinn], to that extent the multiplicity of meaning within the word's own naming power is allowed to unfold ("Text and Interpretation" 43).

A literary work needs nothing but words and this self-legitimation highlights the accomplishments of words and how we use them. A literary work of art is so important and compelling because, as Gadamer says, "what the word evokes is there" ("On the Contribution of Poetry to the Search for Truth" 113). Each word, then, has its own weight 
and body and presence, demanding to be accounted for. The more the words are valued, the more impactful the literary work of art: as each word is respected, the reader is seduced. With the appearance of the first word, a direction has been chosen, and every other word depends on this beginning. The success of the literary artwork, then, depends on this interplay of words, the ability of the words to relate to one another, so that each word is magnified, felt, only there because of the exact combination: "a word becomes a poetic word [...] because of the power of 'realization"” ("On the Contribution of Poetry to the Search for Truth" 112). A poetic word hinges on the fact that it relies on other words. It is only when the appropriate combination is brought together that the words truly shine and are most truly themselves; it is only in this context that the connotations and complexities of words are at their most productive. Furthermore, it is in literature that the evocative character of language is at its most potent. In literature, we are seduced by the words and the world they create; this world, though, can be new and different, the words themselves the only measure; if they belong, then the world they picture has become what it is.

Yes, the literary work of art depends on nothing but our own experience of language and this event of language cannot be separated from our contact with the world. When we engage with a poem we grapple with the names of things and what it means that things have names. In being named, the world has already been identified for what it is: a poem takes advantage of this situation, using these words that we all know, mining our familiarity with the world, and asks us to reconsider what this familiarity means. Based on this familiarity, we define the world as it is and test and verify its nature. But any perception, any positing at all, has already been shaped by language - in the 
questions asked, there is still mystery. Poetry takes notice of this aspect of language and runs with it. It recognizes that the words are alive and pushes to invigorate them with possibility. In this case the only legitimation required is the corroboration of other words: "It is a saying that says so completely what it is that we do not need to add anything beyond what is said in order to accept it in its reality as language. The word of the poet is autonomous in the sense that it is self-fulfilling. The poetic word is thus a statement in that it bears witness to itself and does not admit anything that might verify it" (Gadamer, "On the Contribution of Poetry to the Search for Truth" 110). To the extent that the words belong, there is insight. Here the words are combined in new and different ways, yet their aim is to express a meaning that is understandable and coherent. Although the words might be unexpected or surprising, they still matter because they congeal to make a completed whole. And this completed whole is a kind of mirror held up to the (in)completed whole of our experience in life, the one reflecting the other. In both, the world is alive and so are its words, nothing verifiable, everything there to be created, all in search of fulfillment. 


\section{CHAPTER 4}

\section{GADAMER ON DIALOGUE}

Up to this point I have discussed the roles of language, art and literature in hermeneutic ontology. Implicit in these concepts and central to their understanding is the concept of dialogue. In each—whether in language, art or literature — a dialogue takes place. It might be between two people or between a person and an artwork or a person and a text. Whatever the case, a mediation occurs and something new comes to be. In all, it is a matter of negotiating the polarities of familiarity and strangeness: there is always a point of contact, a shared world; yet, at the same time, we, each of us, are individuals, particular, different and unique. As each person engages with meaning, that meaning acquires more nuance, in that the meaning applied to the situation adjusts to the moment and alters the very situation itself. The mutual world is the subject matter, up for debate, and this world is dynamic. Each dialogue is an opportunity, a chance to confront the moment and assimilate, an occasion to test one's presuppositions and sort out the true ones from the false. We are all caught in a situation and it is impossible to step outside one's situation, but in encountering the other we might see our circumstance with greater clarity, even if it will always remain a partial view. And in understanding our own point of view we might interpret better, for we belong to that which we interpret; we are participants in the meaning of the world. 
In a dialogue our commonality is the topic, a world to which we each belongone that we know intuitively. The world already means something to us and it is this significance that shapes how and what we understand. Before we are even aware of it the world and its meaning has already been born. It is the linguistically constituted world that is brought into play when in dialogue. Each participant belongs to a shared world and it is only on the basis of this belongingness that the world might be further differentiated. Dialogue rests on a common understanding that includes difference within itself. As it is the same world that seeks further definition, both members submit to its truth, with neither member in possession of it entirely. Each person has his or her particular horizon and is unable to see beyond it. It is this very horizon that determines what we think and know. But this means that it is impossible to know what we know. As a way of testing our horizons and expanding our horizons, as a means of breaking up our narrowness and bias, we enter into dialogue. In doing so our horizon is put to the test: in dialogue it is the law of the subject matter that gains ascendancy. Neither member of the dialogue is in control; both parties submit to the dialogue and no one knows the potential result. The orientation to meaning is so great that the dialogical participants are possessed by it. As each are drawn to the same truth without being able to express it in its totality, both are in a process of movement towards fulfillment, even if it is never entirely attainable. The means of doing so is dialogue. Dialogue is necessarily hermeneutical: the world is interpreted and becomes what it is. The truth of the subject matter asserts itself and seeks further clarification: "The nature of the hermeneutical experience is not that something is outside and desires admission. Rather, we are possessed by something and precisely by means of it we are opened up for the new, the different, the true" (Gadamer, "The 
Universality of the Hermeneutical Problem" 9). In dialogue each member is possessed by the commonality of the world, a belongingness that strives for transcendence. As we cannot escape our orientation to meaning, dialogue inheres a loss of self-possession and self-control:

The basic constitution of the game, to be filled with its spirit - the spirit of buoyancy, freedom and the joy of success - and to fulfill him who is playing, is structurally related to the constitution of the dialogue in which language is a reality. When one enters into dialogue with another person and then is carried along further by the dialogue, it is no longer the will of the individual person, holding itself back or exposing itself, that is determinative. Rather, the law of the subject matter is at issue in the dialogue and elicits statement and counterstatement and in the end plays them into each other. Hence, when a dialogue has succeeded, one is subsequently fulfilled by it (Gadamer, "Man and Language" 66).

In the end, we can either account for this loss of control and include it in our understanding or we can think we are in control and fail in our understanding, undermined. Because we cannot help but understand, dialogue is an opportunity for fulfillment, to become what we might be. As a result, we understand better, for the uniqueness of the other demands that we accommodate his or her individuality, the world now assimilated more fully and with more recognizable contours.

In the dialogical exchange, the participants attempt to overcome the one-sidedness of the other. Each assertion demands a counterbalance. All are embraced by possible truth while unable to express everything that is possible: "Most astonishing about the essence of language and conversation is that I myself am not restricted by what I believe when I speak with others about something, that no one of us embraces the whole truth within his beliefs but that the whole truth can, however, embrace us both in our 
individual beliefs" (Gadamer, "What is Truth?" 46). The whole truth does embrace us despite our individuality: we participate in dialogue in order to overcome our idiosyncrasies and discover the universal. In submitting to dialogue, we do so in an effort to glean what is common; the particularity of each blends into greater understanding: "Neither partner alone constitutes the determining factor; rather, it is the unified form of movement as a whole that unifies the fluid activity of both. We can formulate this idea as a theoretical generalization by saying that the individual self, including his activity and his understanding of himself, is taken up into a higher determination that is really the decisive factor" (Gadamer, "On the Problem of Self Understanding" 54). We are so attuned to the contentions of the other that we respond and reply before we are conscious of it: both members sublate his or her individuality to a greater truth.

As an example of dialogue, I have chosen to highlight my interaction with Virginia Woolf's novels. To begin with, I both belong to the same world as Woolf and our worlds are different. Before making any overt attempt to interpret or overcome difference I already understand her novels (to a certain degree) in a self-evident manner: her world is linguistically constituted and so is mine. It is only on the basis of this unconscious congeniality that I might ask questions and identify the productivity of this dialogue. My aim is to recognize what the words mean, but they only mean anything within the specific context of the present moment. This moment and my individuality will shape what I understand. Of course I might bring in anticipations to the reading that are erroneous. It is only on the basis of the reading process itself that I might notice the falsehood of these anticipations. This mediation of transparency and obscurity leads to an interrogation, a means of confronting what is there in the text: "The real power of 
hermeneutical consciousness is our ability to see what is questionable" (Gadamer, "The Universality of the Hermeneutical Problem" 13). As I probe Woolf's novels something is comprehended but this knowledge will only be made secure when I ask how I understand: one should "try to say how one understands" (Gadamer, Gadamer on Celan 144). When one reads a literary work he or she carries his or her world into the text and this is inescapable: it is the reader's task to recognize this mediation and account for it. But it is only on the basis of the linguistically constituted world that the reader understands anything at all. In order to understand what is there, we must confront our interpretation, our own world. It is, however, only on the basis of the text itself that we confront our presuppositions, our language. And before any attempt to include any supplemental knowledge in the reading it is the language of the literature and of the interpreter that is decisive:

No reader can understand without specialties, and yet every reader only understands when the specialty of the occasion is sublated by the universality of occasionality. This means that the poem does not bring to language a specific, unique occurrence known only to witnesses or those enlightened by the poet directly. It means that every reader can respond to what the language gesture conjures up, as if it were an offer. All readers must supplement what they can perceive in a poem on the basis of their own experience (Gadamer, Gadamer on Celan 134).

Each reader should understand based on the language of the text itself, but this means that the text will be understood differently (because of the reader's particularity) and it is his or her responsibility to account for this friction. And there is a considerable amount of difference. The reference of the language in Woolf's novels and my world are undoubtedly in tension and this variance should be overcome as much as possible. But it 
is only on the basis of the meaning of the text and its demands that I should bring in any supplemental knowledge to my interpretation.

As a male born in Louisville, Kentucky in 1983 I belong to a very different world than that of Virginia Woolf. However, I would contend that (to a considerable extent) mine is an inherited world — in many ways similar to that of Virginia Woolf's: many of the precepts and foundations of my cultural world have their grounding in the epochchanging era of Woolf. A figurehead of British Modernism, Woolf and her fiction engaged many of the same questions with which we still wrestle. Her era and her fiction saw fit to challenge many of the stale notions of the past: in Modernism there was a radical questioning of all that was taken for granted. Interpretation took center stage and many writers, intellectuals and artists sought a new grounding for interpretation. Instead of a static world whose meaning was there to be discovered and mapped out, these thinkers saw that the world and its meaning depended on our interaction with itinterpretation and meaning were dynamic and in movement. There was no certainty and there was no accepted truth. It was up to the individual to ground his or herself and find firm footing. This continues to be our task up to the present day: "the change from Modernism to postmodernism is not a difference in metaphysic so much as a different stage in the digestion of the same metaphysic" (Bell, 9). But what are the precepts of Modernism? What alternative did writers like Virginia Woolf provide? First of all, Modernism was an era of crisis. The thinkers of the era saw that the grounding and foundation of civilization was untenable. The world had descended into violence and chaos, hierarchical, power-hungry and exploitative. There was no solidarity; there was no community; many did not see themselves in each other nor recognize the value of shared 
existence. Woolf belonged to this world: where she was less just because she was a woman; a world of colonial powers exploiting the subjugated in order to amass land, wealth and prestige, an existence far too familiar with the ravages of war. These crises prompted the writers and artists of the day to seek out new language, new formscreations that might promote community and solidarity, an awareness of one's collective plight:

This century had scarcely grown used to its name, before it learned the twentieth would be the epoch of crisis, real and manufactured, physical and metaphysical, material and symbolic. The catastrophe of the First World War, and before that, the labor struggles, the emergence of feminism, the race for empire, these inescapable forces of turbulent social modernization were not simply looming on the outside as the destabilizing context of cultural Modernism; they penetrated the interior of artistic invention (Levenson, 2).

For these artists, there was a sense that the world had been led to crisis because of a lack of imagination; people too easily obeyed orthodoxy: because people did not contribute to their own meaning there was no sense for the power and profundity of what the world might be as a participant in its very creation. In creating new forms, the Modernist artists challenged the populace to think in new ways: "they all knew themselves to be engaged in forms of creative violence. For these figures the aim could never be simply to set the imagination free; it was rather first of all to challenge an unfreedom, the oppressions of journalism, of genteel audiences, of timid readers, of political and religious orthodoxy" (Levenson, 2). In the case of Woolf, who acutely felt the strictures of oppression on a daily basis, she turned to the novel as a weapon of liberation. The novel at this point had enjoyed a long tradition and was generally considered to be an unbiased record of the 
relations between people, straightforward and clear. Novels were generally understood to be transparent, the meaning the same no matter the reader. Woolf herself enjoyed and participated in this tradition, but she came to realize that the traditional novel no longer sufficiently probed the questions of the new era. As a response, Woolf mined this tradition in order to turn it inside out, so that the readers were forced to participate, to engage with meaning and interpret: "The response of [Woolf] to a dominant literary culture lies in breaking with a literary tradition by totally immersing herself within it, at once appropriating it and interrogating it” (Herrmann, 2).

The aim was liberation but this also meant a new freedom and a new responsibility. If people were no longer told what to think, then each had to interpret. In the Modernist era, "the question of interpretation lies at its heart" (Bell, 9). Science itself was even challenged as people came to realize that the conclusions of science are a result of the questions asked, depending on the observer and the conditions of the experiment: "science does not 'explain' the workings of the universe, it merely describes what happens in given conditions" (Bell, 11). The Modernist thinkers recognized that the meaning of the world relies on each one of us and is different for every individual. Even the transparency of history was challenged. History was now seen as an interpretive discipline: the historian no longer merely described what happened in the past, but instead interpreted the past based on the interests of the present moment and the historical pressure that shapes the historical question: "The prestige of historicism was undermined by the questioning of the scientific model, for the word history refers both to the unimaginably vast process of events making up collective human life and to the interpretive discipline through which it is understood" (Bell, 14). 
As the primary grounding of our access to the world, language was given a special priority in the thought of Modernists. They saw language as a "construction within a void" (Bell, 12). One might prioritize engagement with language and as recompense one might feel at home instead of alienated or lost. One could build a world that belongs to the builder, understandable because personal: "rather than describing or reflecting the world, language was now seen to form it" (Bell, 16). But language, of course, is not something that anybody can control, shaping our knowledge, ultimately unfathomable. Language is inseparable from what it means to be. As a way of engaging this self-created world and our interpretive responsibility, art acquired a special role in this matrix. It was considered to be "an intuition of Being" (Bell, 29). Art was a means of engaging our interpretive faculties and confronting our self-created world. Art was there and it was irrefutable, directly engaging our existence and demanding interpretation, part of our perception and understanding of the world. In the pantheon of art, literature was accorded a special category. Literature accomplished everything that art could, but it also directly involved the participant's linguisticality, forcing the reader to confront the role of language in his or her life and to face existential questions that could not be confronted in any other manner: the Modernists placed "an especially primordial philosophical burden upon imaginative literature, [...in it] the active means of questioning and discovering fundamental values, truths, and understandings for which there was no alternative grounding" (Bell, 29). In literature, there was an opportunity to understand the world as it might be, a world in which the reader participated in its very creation.

As a reader of Woolf's novels, I too am a participant in their meaning. This participation is possible because the same truth embraces myself and Woolf (incarnate in 
her novels) even if it is impossible to entirely commune with it. We are oriented to this truth and this orientation defines our very existence. It is in our nature to understand and to seek further understanding. For its part, understanding is realized in language. Now, because of time, language evolves and so does meaning. It is always the same world that is named in language, but each moment is variable, and the language shifts as it describes the world: always inherited, acquiring new resonances, the world becomes something else as it is articulated, looking ahead to the future. When entering into dialogue this orientation to understanding is decisive - it is what shapes the subject matter and the language of the participants:

How is understanding possible? [...U]nderstanding is not just one of the various possible behaviors of the subject but the mode of being of Dasein itself. It is in this sense that the term 'hermeneutics' has been used here. It denotes the basic being-in-motion of Dasein that constitutes its finitude, and hence embraces the whole of its experience of the world. Not caprice, nor even an elaboration of a single aspect, but the nature of the thing itself makes the movement of understanding comprehensive and universal (Gadamer, Truth and Method xxvii).

Because of time and change and individuality, our experience of the world is the foundational concern, shaping all other questions.

We are oriented to understanding and this sense of significance is fluid.

Something is always understood but motion pushes us to revise and adjust, our angle of vision now something else. No matter what, we use language and our words are an interpretation of the world: "Our starting point is that verbally constituted experience of the world expresses not what is present-at-hand, that which is calculated or measured, but what exists, what man recognizes as existent and significant" (Gadamer, Truth and 
Method 452). The raw material that we take to be distinct from our understanding actually belongs to it, for once something is given a name and included in our discourse, it belongs to a context that shapes it while also shaping the context, ensnared in a web of meaning. For our linguistically constituted world defines the nature of something in the first place, belonging to the interpretive concerns of the speaker: "Pure seeing and pure hearing are dogmatic abstractions that artificially reduce phenomena. Perception always includes meaning" (Gadamer, Truth and Method 80). Perception is irreducible from meaning, so that the things of the world belong to its participants; the linguistic understanding of things defines their identity: "Is the given not in fact the result of an interpretation?” (Gadamer, "Text and Interpretation” 30).

We partake in dialogue to test our horizons and expand our horizons. Up to a point, we already understand the world, but this understanding is provisional and is itself the result of an interpretation. We participate in the hermeneutic process to secure our understanding and to define the world a little more clearly. As the world is different with each moment, every instant is an opportunity:

It is the world itself which is communicatively experienced and continuously entrusted (Traditur) to us as an infinitely open task. It is never the world as it was on its first day but as it has come down to us. Always present when we experience something, when unfamiliarity is overcome, where enlightenment, insight, and appropriation succeed, the hermeneutic process takes place in bringing something into words and into the common consciousness" (Gadamer, "Reflections on My Philosophical Journey" 29).

Now, the world itself can never be entirely possessed as it truly is because our own hermeneutic situation is inescapable and this predicament shapes the understanding process. As we read, it is our task to account for our outlook, to recognize that we belong 
to the very meaning of that which is understood. In the hermeneutic encounter, something is understood, which leads to greater assurance and familiarity, and at the same time false presuppositions are refuted because they are repudiated by this new, more complete understanding.

In the encounter with tradition, in dialogue and in the hermeneutic process, we are afforded the chance to have a better sense for the truth of things and our role in the formation of this meaning. In each dialogical meeting we come to know more and to understand better, but as this process occurs the nature and truth of the subject matter morphs also: the more we understand the more want to account for our lack of knowledge; the more that is said the more we notice everything that is unsaid. The act of understanding includes interpretation within itself: as we belong to a situation and cannot step out of our situation, we have the task of interpreting because each situation is different - the interpreter brings his or her foreknowledge and foremeanings to the subject matter and as he or she does so some of them are confirmed and some refuted; that we have a situation at all is essential: the hermeneutic situation implies questions, lack of knowledge and interpretation. To a significant degree, we already understand but it is our opportunity and burden to further secure this understanding and refine it: "In all human knowing of the world and in all orientation within the world the nature of the moment of understanding has to be worked out" (Gadamer, "Reflections on My Philosophical Journey" 28). This attempt, of course, is incompletable. Interpretation is unavoidable: Gadamer points to "the inexhaustibility of the experience of meaning" ("Text and Interpretation" 24). As we try to interpret the world certain aspects are 
highlighted and others fade into the background, unnoticed; and as we recognize certain aspects this movement alters their meanings, as each relates the one to the other:

Interpretation shares in the discursiveness of the human mind, which is able to conceive the unity of the object only in successiveness. Thus interpretation has the dialectical structure of all finite, historical being, insofar as every interpretation seeks to supersede the one-sidedness which that inevitably produces. [...H] ermeneuetics has the task of revealing a totality of meaning in all its relations. The individuality of the sense intended corresponds to the totality of all definitions (Gadamer, Truth and Method 476).

Every interpretation has to start somewhere and at a certain moment in time: this means that each interpretation is limited in its own way. The success of an interpretation depends on the interpreter's ability to assimilate, include and account for this shortcoming. In doing so, the accidental nature of interpretation might become a positive. Each time we interpret, we have to adapt to the exact situation - which is always different —if we hope to succeed: this means recognizing the situation and how it relates to the subject matter and the overall meaning.

In every hermeneutic encounter we bring our own foremeanings, presuppositions and prejudices into the process. And until we engage with the hermeneutic object we have no way of sorting out the true, enabling prejudices from the false, distorting ones. But once we become involved we begin to foreground our horizon against that of the interpreted subject matter, to account for and overcome difference:

Let us consider what this idea of foregrounding involves. It is always reciprocal. Whatever is being foregrounded must be foregrounded from something else, which, in turn, must be foregrounded from it. Thus all foregrounding also makes visible that from which something is foregrounded. We have described this above as the way prejudices are brought 
into play. We started by saying that a hermeneutical situation is determined by the prejudices we bring with us. They constitute, then, the horizon of a particular present, for they represent that beyond which it is impossible to see (Gadamer, Truth and Method 304-5).

We do not become aware of our own horizon until we encounter the horizon of the other and in this meeting we acquire a more complete view, even if it remains partial.

There is no such thing as an objective interpretation; the world interpreted always includes the concerns and horizon of the interpreter. The interpreter belongs to understood meaning: "In all understanding an application occurs, such that the person who is understanding is himself or herself right there in the understood meaning. He or she belongs to the subject matter that he or she is understanding" (Gadamer, Gadamer in Conversation 47). Whether we recognize it or not, something only means anything at all because it means something to us. If we ignore our own role in interpretation then that reading will come off as arid, stale, and lifeless. But if we include ourselves and account for our role then the interpretation has the potential to be exciting, vigorous, insightful.

There are many occasions for dialogue; the most important and most basic circumstance is conversation - the result of two individuals who share a world and yet are different: when brought together each relies on a common ground on which more might be understood. Another occasion for dialogue is the historical artifact. When one encounters a historical artifact one is confronted with the task of interpreting it within the entire narrative of history, to explain its place in the secuence. The historical artifact is always the same but its meaning will change based on the interpreter. The historian brings his or her own interests, concerns, points of view, and historical moment into the interpretation. The interpreter cannot do otherwise. It is the interpreter's job to account 
for the historical moment and his or her individuality and include it in the interpretation; the past impinges on the present and the present impinges on the past. The interpreter cannot move beyond history; it is only because of history that we understand anything at all or have anything to say:

In fact history does not belong to us; we belong to it. Long before we understand ourselves through the process of selfexamination, we understand ourselves in a self-evident way in the family, society, and state in which we live. The focus of subjectivity is a distorting mirror. The self-awareness of the individual is only a flickering in the closed circuits of historical life. That is why the prejudices of the individual, far more than his judgments, constitute the historical reality of his being (Gadamer, Truth and Method 278).

In choosing to interpret history one is granted an opportunity: one might better understand the context of being. That is, we inherit a moment and this point in time is the result of a long tradition. This heritage — whether custom, artwork, language or text - has been passed down through time: in some cases, like language, the tradition evolves and changes; in others, it remains solid and permanent, as in an artwork or text. In the case of custom or language, history has shaped its present iteration, always in process, adapting to the moment. But in encountering history we might better understand where we come from and how we might participate in our evolution. There is value in studying history: the past decides who we are and in its study we might confront this formation instead of accepting it unquestioningly.

Before we even realize it we already understand. When someone speaks to us we understand. When we read a book we understand. When we view an artwork we understand. We understand because it is always the same world that is presented, even though its particulars change with the passage of time. So, too, when we study history we 
understand. But this meaning can be made secure. We can confront this significance and try to think about what is being understood and how and why it is understood. In doing so we might place this interpretation on firmer ground. This means that, more than anything, the study of history is an attempt to comprehend the present moment, for history informs the present moment and the present moment shapes how we understand history: "History is only present to us in light of our futurity. Here we have all learned from Heidegger, for he exhibited precisely the primacy of futurity for our possible recollection and retention, and for the whole of our history" (Gadamer, "The Universality of the Hermeneutical Problem" 9). And the future is only accessible in light of our past. In the two, the future and the past, there is a continuity: "Historical knowledge can be gained only by seeing past in its continuity with the present" (Gadamer, Truth and Method 325). For its part, this continuity is always an open question. The historian cannot go beyond his or her historical situation and this means that there is always a mediation that the historian ought to recognize. Each attempt to interpret history should be understood as a mediation: "The truth is that historical understanding always implies that the tradition reaching us speaks into the present and must be understood in this mediation-indeed, as this mediation" (Gadamer, Truth and Method 325).

Historical interpretation implies a mediation between the interpreter and the historical object and so too the interaction between the interpreter and an artwork. Art, belongs under the rubric of dialogue or play; in it there is a loss of subjectivity in which the subject matter gains ascendancy and determines the movements of the participants. When we experience an artwork we lose control and the truth of the subject matter asserts itself: "When a work of art truly takes hold of us, it is not an object that stands opposite 
us which we look at in hopes of seeing through it to an intended conceptual meaning. Just the reverse. The work is an Ereignis - an event that 'appropriates us' into itself. It jolts us, it knocks us over, and sets up a world of its own, into which we are drawn, as it were" (Gadamer, Gadamer in Conversation 71). Before we even know what we know the artwork has already made its claim to truth. We are not in a position to possess the meaning of an artwork before it has been experienced: if the experience of an artwork is genuine then it will always surprise us and take us on a journey; in the artwork there is an indeterminacy that provokes the participant, asking us to reevaluate our interpretive process and overall understanding. We are drawn into the world of the artwork and in this movement we become something else.

Dialogue in and of itself is a matter of mediating identity and difference. Play, for its part, serves the same role. In play there is a regulation of movement that also includes variation. This idea of regulated movement is essential. Once completed, an artwork is self-same, it is there, and it is immutable. An artwork is intentional and it has an identity: "It is clear here, especially in the phenomenon of repetition itself, that identity or selfsameness is intended" (Gadamer, The Relevance of the Beautiful 23). The artwork has a definite identity because it regulates the interaction between itself and the interpreter: "The function of the representation of play is ultimately to establish, not just any movement whatsoever, but rather the movement of play determined in a specific way" (Gadamer, The Relevance of the Beautiful 23). This movement of the play is determined by the artwork, by its structure. An artwork, for its part, is meant to be a completed whole in which each element interlocks. This is the nature of the artwork and part of its identity, but the artwork also has the responsibility of accommodating itself to all potential 
participants, of anticipating the individuality and difference of all who might experience the work. The artwork is made in anticipation of its experience: it engages fundamental categories of perception and understanding, representing an attempt to acknowledge our commonality. This unity, though, splits into individualities and differences as we enter into concrete application and participation: "This definition of the work as the focal point of recognition and understanding also means that such an identity is bound up with variation and difference. Every work leaves the person who responds to it a certain leeway, a space to be filled in by himself' (Gadamer, The Relevance of the Beautiful 26). Our shared world includes a tension within itself that is inescapable. An artwork is a selfenclosed unity with no loose ends, yet this fulfillment is only possible because of the person who experiences it. The participant is tasked with the completion of the artwork so that it is unified, but success is only possible if the participant relates the world of the artwork to his or her own world.

An artwork is so compelling because it belongs to our world and we belong to it, but an artwork represents more than a faithful reproduction of reality. It is, instead, the world transformed into a meaningful unity: "The mimetic is and remains a primordial phenomenon in which it is not so much an imitation that occurs as a transformation" (Gadamer, "Poetry and Mimesis" 121). Transformed into a new, coherent whole, the stuff of perception is mined and becomes meaningful. Released from the contingency of circumstance, the meaning of perception is placed within an overarching structure that is intentional, thereby releasing it from the circumstance and allowing it to be there as it is, true because it has found a home within the overall structure and significance of the artwork: "Where something is recognized, it has liberated itself from the uniqueness and 
contingency of the circumstances in which it was encountered. It is a matter neither of there and then, nor of here and now, but it is encountered as the very self-same. Thereby it begins to rise to its permanent essence and is detached from anything like a chance encounter" (Gadamer, "Poetry and Mimesis" 120). Essential to this discussion of mimesis and transformation is the concept of recognition. In art, we recognize the way things are: "there is no doubt that the essence of imitation consists precisely in the recognition of the represented in the representation" (Gadamer, "Art and Imitation" 99). Yes, it is through art that we become more familiar with the world, but part of this improved understanding includes greater mystery. We are not able to completely possess the meaning of an artwork, instead we tarry with the artwork and enter into its depths, always understanding more and better, yet for this very reason pushed to ask more questions as the exact correspondences and relations alter and adapt: "a work of art, thanks to its formal aspect, has something to say to us either through the question it awakens, or the question it answers" (Gadamer, Gadamer in Conversation 71).

This entire discussion of dialogue hinges on the idea that language and meaning have their origin in conversation. Before there was ever such a thing as a text or an artwork, there were two people, each in the presence of the other, using gesture, facial cues, and, most importantly, language to communicate. Before any words are uttered, neither partner knows what exactly he or she wants to communicate: language blooms as each encounters the other. We are oriented to language, to meaning, and we cannot do otherwise. This model is decisive - precisely because it allows for question and response. Every utterance is spoken within a definite context and it is the role of the conversation 
partner to clarify, ask questions, and place it within a broader horizon, so that its meaning is more relatable and ultimately clearer:

"Now every single statement that we make acquires its ultimate meaning (that is, what it says to someone) from the question to which it supplies an answer. This is what I call the hermeneutic character of speech: when we speak to one another we do not so much transmit well-defined facts, as place our own aspirations and knowledge into a broader and richer horizon through dialogue with the other" (Gadamer, "On the Contribution of Poetry to the Search for Truth" 106).

We have everything to gain by using language and participating in conversation. In conversation we engage our very understanding of the world: our horizon shifts as the dialogue progresses and as we converse with different people. Each time we actually try to say something to someone, the world becomes something else. In point of fact, the hermeneutic character of text and writing relies on this model of conversation: "What characterizes a dialogue, in contrast with the rigid form of statements that demand to be set down in writing, is precisely this: that in dialogue spoken language - in the process of question and answer, giving and taking, talking at cross purposes and seeing each other's point - performs the communication of meaning that, with respect to the written tradition, is the task of hermeneutics" (Gadamer, Truth and Method 361). This dialogical model is so compelling because it places meaning under the rubric of transcendence. Each statement can be clarified and expanded: more can always be said.

In any dialogue there is a loss of subjectivity; the participant's horizon of understanding shapes his or her subjective response. The participant submits to the dialogue and it determines the responses of the participants; however, there is always free will and choice. Instead of trying to fight this loss of subjectivity, the participant can 
make choices to harness this wave of meaning - by asking questions, by enquiring, what, exactly, is happening. Like conversation, texts are also defined by dialogue. Conversation itself guides the reading process. In a conversation the world is shared and further defined: something comes out of it that neither participant can anticipate or predict. Furthermore, the understanding that occurs in a conversation is not purely linguistic: there are extra-linguistic cues that supplement and shape the understanding; the participants have a sense for what is being conveyed but neither is able to exhaust the articulation of this content. For its part, a text encompasses a communicative event in which there is a hermeneutical distance. There is no opportunity for clarification and there are no extra-linguistic cues. A text is pure language, autonomous and timeless. It is the writer's task to acknowledge this aspect of the text: to compose a text in such a way that it communicates itself based on nothing but itself. The writer composes the text in anticipation of its interpretation:

While in living conversation one tries to reach understanding through the give-and-take of discussion, which means that one searches for those words - and accompanies them with intonation and gesture - that one expects will get through to the other, in writing the openness that is implied in seeking the words cannot be communicated because the text is printed. Therefore a 'virtual' horizon of interpretation and understanding must be opened in writing the text itself, one that the reader must fill out (Gadamer, "Text and Interpretation" 34).

This means that it is the writer's responsibility to find and use language that is universal and not idiosyncratic - to use language that represents our general relationship to the world. And in order for a language to be universal it should also be applicable to each 
individual's particular situation. In each application the language acquires greater nuance, meaning and volume.

The text should be understandable in and of itself yet it should also apply to the reader and his or her particular circumstance. Something is understood in the text, but what, exactly, is debatable. The interpreter is trapped in a hermeneutic situation. Because of this, all texts inhere an openness and indeterminacy that is unavoidable; it is the reader's task to account for this indeterminacy by asking questions and developing a dialogue between the reader and the text: "When it is interpreted, written tradition is brought back out of the alienation in which it finds itself and into the living present of conversation, which is always fundamentally realized in question and answer" (Gadamer, Truth and Method 362). In reading, the text becomes alive: the reader reads and transforms the words into meaning. The interpreter, though, wants to respect the text as much as possible and does not want his or her reading to be arbitrary; the text should be understood as it is. But the text as it is depends on its enactment. The reader's goal, then, should be to recognize his or her role in the meaning of the text and to avoid all false anticipations that obstruct the text as it is meant to be: "We who are attempting to understand must ourselves make it speak. But we found that this kind of understanding, 'making the text speak,' is not an arbitrary procedure that we undertake on our own initiative but that, as a question, it is related to the answer that is expected in the text. Anticipating an answer itself presupposes that the question is part of the tradition and regards himself as addressed by it" (Gadamer, Truth and Method 370). A text always constitutes an answer to a question and the reader interprets with this element in mind: he or she anticipates the content of the text based on the question to 
which it is an answer. Above all else, something is understood only because it is shared, as each of us belong to a tradition and a world that is both understandable and mysterious.

More than anything, dialogue represents a chance to acquire experience. As we gain experience the world becomes more discernible, its outline colored in, more nuanced, more textured, more vibrant. Also, part of the nature of experience is that with it we get a sense for what the world is not: "Experience is a process. In fact, this process is essentially negative" (Gadamer, Truth and Method 347). With each experience, we broaden our horizons and the viewfinder becomes more focused; the essential relations of things becomes clearer. Into each experience we bring certain expectations and these anticipations inflect the nature of the event; with each experience certain expectations are thwarted and this means that we are more prepared for further experience and its possible yield; then, with the subsequent undertaking there are fewer distractions and misguided anticipations. The upshot is that with each experience we become more open to-and prepared for-further experiences, encounters that allow for the truth of the subject matter to radiate:

The truth of experience always implies an orientation to new experience. That is why a person who is called experienced has become so not only through experiences but is also open to new experiences. The consummation of his experience, the perfection that we call 'being experienced,' does not consist in the fact that someone already knows everything and knows better than everyone else. Rather, the experienced person proves to be, on the contrary, someone who is radically undogmatic; who, because of the many experiences he has had and the knowledge he has drawn from them, is particularly well equipped to have new experiences and learn from them. The dialect of experience has its proper fulfillment not in 
definitive knowledge but in the openness to experience that is made possible by experience itself (Gadamer, Truth and Method 350).

The experienced person is someone who knows what the world is not and because of this has a better sense for what it is. What it is, of course, varies and belongs to each new experience. And the experienced person seeks out experiences because he or she knows that is his or horizon is limited and so is his or her knowledge; each new experience is a chance to gain greater insight, so that further experiences are even more fruitful: "Insight is more than the knowledge of this or that situation. It always involves an escape from something that had deceived us and held us captive. Thus insight always involves an element of self-knowledge and constitutes a necessary side of what we called experience in the proper sense. Insight is something we come to. It too is ultimately part of the vocation of man-i.e., to be discerning and insightful" (Gadamer, Truth and Method 35).

Through dialogue we acquire experience and through experience we become discerning and insightful. Dialogue constitutes an experience because through it we get a sense for our mistaken notions - because the dialogical partners must find common ground and this means that the shared and the true are the valid. The result is a greater openness to experience, an ability to share and recognize those elements that are binding while still remaining receptive to potential meaning. Engagement with tradition is an important means of gaining experience:

Hermeneutical experience is concerned with Tradition. This is what is to be experienced. But tradition is not simply a process that experience teaches us to know and govern; it is language-i.e., it expresses itself like a Thou.

A thou is not an object; it relates itself to us. [...T]he relationship to the Thou and the meaning of experience implicit in that relation must be capable of teaching us 
something about hermeneutical experience. For tradition is a genuine partner in dialogue, and we belong to it, as does the I with a Thou (Gadamer, Truth and Method 352).

One gains experience when reading a text because one projects his or her world into the text and not all of this world is valid or true. Some of it is mistaken. Until reading the text, though, we do not know the extent to which our world includes falsehood. It is only by reading the text and adhering to the text, by respecting the text and interpreting it correctly - to allow it to be what it is at its most fully - that we come to realize the error of our notions and the limitedness of our horizon; the text places its own demands and refutes our expectations when they do not align with the text. All one can do is listen intently and ask questions: "One intends to understand the text itself. But this means that the interpreter's own thoughts too have gone into re-awakening the text's meaning. In this the interpreter's own horizon is decisive, yet not as a personal standpoint that he maintains or enforces, but more as an opinion and a possibility that one brings into play and puts at risk, and that helps one truly to make one's own what the text says" (Gadamer, Truth and Method 390). It is the text itself that determines the validity and truth of one's horizon. Some of it is legitimate, but it is never perfect. It can be improved, though, by engaging with the text and allowing the text to be the arbiter of validity — as we put the text into our own words, it is the text itself that determines the legitimacy of those words, forcing us to renounce certain expectations and include others that had been previously ignored.

All that has been said about the text and dialogue also applies to the relationship between the interpreter and the literary text, but the literary text belongs to its own special category, for the literary text mines human being's linguisticality and orientation to 
meaning; literature is, in fact, defined by our orientation to language. We grow up with language and this unconscious acquisition determines the nature of what we understand. Furthermore, each life is its own sort of whole, one that is coherent but still in search of meaning and definition. Language is the means of confronting this entirety: each time we use language, each word is only understandable in the context of the whole and the context of the whole is understandable because of each word. It is a never-ending dynamic process. However, the literary text represents a chance to engage with a coherent unity that does not change. As is the case with life, the literary text is made up of words, but these words are eminently coherent—each one links with the other-and these words depend on nothing but themselves — each word discloses, presenting a web of relationships and meaning that guarantees its truth. In life we are oriented to a whole that is incomplete, a need for fulfillment that is made up of language; meanwhile, a literary text allows us to engage with this language, but in this case the language is complete in itself, able to constitute a meaningful unity, each word depending on the other. A literary text represents self-fulfillment: "A poetic text is not like a sentence in the ongoing flux of speech, but rather it is like something whole which lifts itself out of the stream of speech that is flowing past" (Gadamer, "The Eminent Text and Its Truth" 6). As the literary text is a unity that depends on nothing but language, it places unique demands on the reader. The reader, too, has language but the interpreter's language and circumstance is necessarily different than that of the text. It is the reader's challenge to allow the literary text to be what it is by adapting it to his or her present situation. With each reading, we want the text to be at its most coherent, so that it truly does fulfill itself, but, at the same time, the interpreter must constantly adapt for this to happen. With each 
new moment, the interpreter understands differently: "No work of art addresses us always in the same way. The result is that we must answer differently each time we encounter it. Other susceptibilities, other attentivenesses, other openness in ourselves permit that one, unique, single, and self-same unity of artistic assertion, to generate an inexhaustible multiplicity of answers" (Gadamer, "Reflections On My Philosophical Journey" 44). The artwork presents a challenge to the interpreter-one of revision and adaptation. It is a fluid procedure: as each word combines it is a matter of looking forwards and backwards, always seeking coherence, always forcing the reader to ask questions, never static. In fact, the literary text includes the potential reader within itself, includes difference within itself: "the literary text $[\ldots]$ is simply accompanied by the interpreter's constant cospeaking” (Gadamer, "Text and Interpretation” 46).

The interpreter is able to participate in the meaning of the literary text because of the nature of language: the word says something - it has something to say. There is no such thing as a word that does not say anything. The literary text, for its part, taps into this aspect of language and takes full advantage. Instead of using language to describe a verifiable state of affairs, it harnesses language to create its own world, its own truth. Based on what each word says, every other word must cohere: "In literary texts the word attains its highest coherence with the whole of the text (Gadamer, "On the Truth of the Word" 149). In a literary text the words acquire extra value because they are corroborated. Each word fulfills itself, depending on nothing but every other word: "The word is true in the sense that it discloses, producing this self-fulfillment. The poetic word suspends the positive and the posited as that which might serve to verify whether our statement corresponds with what lies outside it" (Gadamer, "On the Contribution of 
Poetry to the Search for Truth" 112). In this case, in the context of dialogue and interpretation, it is up to the reader to participate in this self-fulfillment, an act of completion that includes the reader's own linguisticality, a need to complete the text so that it is what it is meant to be, an effort in which the language resounds even if there is no final resolution.

The reader is a participant and it is up to the reader for the text to be itself. A text is not a text unless it is meant to be read. This reading process, though, is variable and dynamic. And it is precisely because of its variability that a text—and, in our case, a literary text—represents such a tremendous opportunity. A literary text is always the same, yet it includes within itself an infinite possibility of different interpretations. However, there are good interpretations and bad ones too. It is the reader's task to understand what is there. But what is there depends on the reader, changing with each reader and each moment. In order for an interpretation to be more correct, the reader has no choice but to recognize and include his or her role in the active construction of meaning. Each interpreter belongs to the meaning of that which he or she interprets:

There cannot, therefore, be any single interpretation that is correct 'in itself,' precisely because every interpretation is concerned with the text itself. The historical life of a tradition depends on constantly being assimilated and interpreted. An interpretation that was correct in itself would be a foolish ideal that mistook the nature of tradition. Every interpretation has to adapt itself to the hermeneutical situation to which it belongs (Gadamer, "On the Contribution of Poetry to the Search for Truth" 112).

A text only means anything based on its overall context; this matrix of sense, however, is mobile, twisting and widening, subject to unforeseeable contortions. The reader belongs to this context and so does the text. It is up to the reader to identify where there is 
overlap, to recognize that the text belongs to an overall meaning that is shared. But it is also the case that we do not know what we know, for everything we know is prior toand determines — everything we think we know. As a way of understanding better and further and more, we read texts. In doing so we strive to interpret the text correctly: thereby we discard misguided notions and falsehood. For a text represents a completed whole, language at its most coherent and stable. We strive to enact this fulfillment and in this act we recognize our own false presuppositions, for they do not accord with the prescription of the text - that it fulfills itself:

The hermeneutical experience also has its own rigor: that of uninterrupted listening. A thing does not present itself to the hermeneutical experience without an effort special to it, namely that of 'being negative toward itself.' A person who is trying to understand a text has to keep something at a distance - namely everything that suggests itself, on the basis of his own prejudices, as the meaning expected-as soon as it is rejected by the sense of the text itself (Gadamer, Truth and Method 460).

It is the reader's responsibility to listen intently because it is the text's identity to achieve maximum coherence; this completeness, though, depends on the reader recognizing how the words mesh; this only happens when they are not distorted by the reader's false expectations; the reader senses that these anticipations are false when they do not gel with the overall meaning of the text.

The reader occupies a situation and a text too. A literary text is identifiable and stable but also productive of an endless quantity of interpretations. Each interpretation is more correct when the reader recognizes his or her role in interpretation, that the text depends on assimilation in order for it to be itself. But how does the reader avoid arbitrary fancies? How does he or she secure the interpretive act? Here, it is up to the 
reader to accept that there is a fusion between the reader and the text and probe what this means. The meaning of a text belongs to a context that includes the reader. To recognize this context and identify it is part of the reader's responsibility. This context, though, is an open question, different for every reader. The only way that the reader can get a sense for how and why the text means anything at all is to ask questions. In point of fact, in the act of reading a literary text, the dialectic of question and answer never comes to a stop. Every answer is motivated by the question to which it is an answer and every question includes an answer within the confines of the question. A question is only a question when it accepts certain givens while trying to open them up in a new direction: "Posing a question implies openness but also limitation. It implies the explicit establishing of presupossitions, in terms of which can be seen what still remains open" (Gadamer, Truth and Method 357). Questions are absolutely vital because the world cannot be everything. By asking questions one limits and defines the subject matter while opening it up for the new. This nature of the question is applicable, of course, to the act of reading. A text only has meaning because we anticipate its meaning. One is only able to anticipate meaning by recognizing the specific subject matter of the text; the text does not concern everything. And it is only as an answer to a question that the text resounds; the text belongs to a context and it is within this context that the text makes sense. It is also true that this act of anticipation leads to further questions. The text means something but it can always mean more. By asking questions the reader gets a better sense for his or her role in the act of meaning - the manner in which the reader belongs to the text and also a technique for excluding false anticipations; the context for which a text has meaning is forever open: 
Thus a person who wants to understand must question what lies behind what is said. He must understand it as an answer to a question. If we go back behind what is said, then we inevitably ask questions beyond what is said. We understand the sense of the text only by acquiring the horizon of the question - a horizon that, as such, necessarily includes other possible answers. Thus the meaning of a sentence is relative to the question to which it is a reply, but that implies that its meaning necessarily exceeds what is said in it (Gadamer, Truth and Method 363).

If a reader understands a text as answer to a question then it follows that there are an infinite number of possible answers to the question. The reader and the text play an equal part in providing possible answers to the question. Furthermore, a question only has meaning if we understand the presuppositions of the question. In order to determine the presuppositions of the question, the reader then asks even more questions, so that its meaning is contextualized. This act of contextualization does not cease because the overall meaning is never rigid; the interaction between the reader and the text necessarily remains open because of the unbridgeable distance between the two: "Understanding the word of tradition always requires that the reconstructed question be set within the openness of its questionableness-i.e., that it merge with the question that tradition is for us" (Gadamer, Truth and Method 367). A text only has meaning because it addresses our own experience; an experience that belongs to tradition but is also new and different.

We are able to understand a text because we belong to the same world as the text; we try to enact the text at it most authentic and this act includes assimilating the text to our own particular situation; this effort necessarily includes anticipating the content and relating it to our own world; however, when the text does not align with our own experiences and expectations, then our primary recourse is to ask questions. "The 
negativity of experience implies a question. In fact we have experiences when we are shocked by things that do not accord with our expectations. Thus questioning too is more a passion than an action. A question presses itself on us; we can no longer avoid it and persist in our accustomed opinion" (Gadamer, Truth and Method 360). Indeed, we cannot help but ask questions, but the questions only sprout when we are engaged with the text. It is our desire to bring the text to its original authenticity and this means that we ask questions; we do so because our world is both the same and different as that of the text and it is our aim to highlight this mediation —so that, instead of distortion, we achieve communion. For when we read a literary text, when we have a hermeneutic experience, we interrogate because our horizon has altered - the text is now seen from a new angle and we want to understand the implications of this shift. By asking questions, then, we further define the world and come closer to the truth. For each question already includes true presuppositions and is an attempt to further sort out the true ones from the false: "All dialectical negativity contains an adumbration of what is true" (Gadamer, Truth and Method 460). We interpret as a result of our engagement with the text, as a means of placing the text in the context of our interaction with it; it is a matter of having the right expectations, of confirming certain anticipations and refuting others. In point of fact, all meaning includes interpretation because all meaning is necessarily open, for all that is said only has meaning as it relates to what might be said: "Nothing that is said has its truth simply in itself, but refers instead backwards and forward to what is unsaid" (Gadamer, "Man and Language" 67). Undoubtedly, we have no choice but to interpret, but in asking questions we might further secure our interpretation; we might even inch a little closer towards the truth of the world. 


\section{CHAPTER 5}

\section{MRS. DALLOWAY}

Tracing the rhythms of the day, Mrs. Dalloway highlights the variety of ways that people experience one moment to the next. Illuminating the manner in which people are oriented to understanding and fulfillment, this novel presents characters whose perceptions and outlook are shaped by the need for resolution. Each character in the novel has undergone a series of experiences that define his or her world: now, in the midst of another day, these characters confront a sequence of moments in which they are drawn to resolve the past with the present as it looks toward the future. Each character in this novel has lived his or her particular story, one in which he or she developed binding connections: first, with a mother and father, with family, and then, with the surrounding community. Gadamer advises us that to interpret literature we recognize that the characters' first experiences of love and commonality are not conscious, but they determine their orientation to the world. In this manner these characters learn to speak and use language; the world begins to take shape. At the same time, when the world seems to acquire its lasting appearance things continue to shift and change. Nevertheless, there is something in these characters' understanding that recognizes the possibility of communion, of living in a world that belongs to them and to which they belong. At this

point, they turn to the people who matter most in their lives - those very people who were 
decisive in forming the world as it has become, those who inspire the very language that shapes understanding — and remember that it is through them that the world becomes meaningful; that it is at its most true when it is shared.

Mrs. Dalloway emphasizes the productive, unfathomable nature of relationships and human interaction: the outcome of all dialogue, of all human interaction can never be predicted. This interaction provides the impetus for language, meaning, and greater understanding. It forces one to reassess and acknowledge one's blind spots, to notice those aspects of one's horizon that that are mistaken. Mrs. Dalloway stresses that all knowledge should be tempered with the knowledge that one does not know; more can always be said and knowledge is limited. These, in fact, are central concerns of Gadamer's philosophical hermeneutics. In many ways, these ideas resonate with much of the critical effort to interpret this novel, but they also undermine and transcend much of the critique. For example, DiBattista correctly argues that concepts such as truth and reality are elusive in Mrs. Dalloway: "The imaginative center, where truth and beauty, life and death coexist as terms in the transparent equation of reality, eludes, as Mrs. Dalloway dramatizes, the spirit's grasp" (24). DiBattista's analysis is appropriate-truth and reality are, to a certain degree, elusive — but she fails to appreciate how, and in what manner, they are accessible. For life is not entirely mysterious; there are moments of truth and understanding too. Mrs. Dalloway explores this tension. In it are characters who seek truth and make an effort to reach it. Although not always successful, the possibility is still decisive. The actions and thoughts of these characters are oriented toward approaching truth and understanding reality: these characters seek out interactions that will contribute to this effort, interactions that determine truth and reality, terms that are dependent on 
engagement and participation. For his part, Ruotolo echoes this idea that the dynamic of human relationships is decisive: "Typically for Woolf, human intercourse occurs on the boundary of the mind's knowledge, some obscure communion deeper than ideology and more fundamental than sex" (114). Ruotolo is on the right track, but his analysis does not fully consider the ontological consequences and implications of this "obscure communion." This concept of human connection is decisive, productive of meaning and language, the very world of each character. Human relationships may be shrouded in darkness, but they are still one's primary avenue towards improved meaning and understanding.

In Mrs. Dalloway we encounter characters who are entangled in time's web: to a considerable extent, each has already developed his or her outlook, his or her worldview, but this day is a new day and, like any other, it presents its own particular set of challenges. As each individual moves about the world, as each encounters strangers and friends, the world becomes something else. For these characters, the world has already become what it is, but, with every new experience, each has no choice but to synthesize these new experiences, to accommodate these new experiences so that they square with the past. This, in fact, is the nature of hermeneutical experience:

[I]n the utilization of the linguistic interpretation of the world that finally comes about, something of the productivity of our beginnings remains alive. [...] What I am describing is the mode of the whole human experience of the world. I call this experience hermeneutical, for the process we are describing is repeated continually throughout our familiar experience. There is always a world already interpreted, already organized in its basic relations, into which experience steps as something new, upsetting what has led our expectations and undergoing 
reorganization itself in the upheaval (Gadamer, "The Universality of the Hermeneutical Problem" 15).

Mrs. Dalloway is the story of a June day in London and the different characters who populate the city. Clarissa Dalloway is at the center of the narrative. A middle-aged socialite, she is hardly the obvious candidate for transcendent meaning (she is just a housewife, neither an artist nor an intellectual), yet she experiences thoughts and feelings that do matter, that do represent a willingness to go deeper; she too wonders about the meaning of life and her role in its drama. Set right after the end of World War I, the meaning and impact of this novel hinges on the particular concerns of its time and place. Certainly, the author and her English compatriots were still reeling from the savagery of this conflict. In many ways, this novel is a response to this schism-producing world event. For the war was a symptom of a larger problem, of social and historical trends that culminated in outright conflict. To a considerable extent, this war was the result of modernization, of blind faith in science and technology, industrialization and imperialism. Certainly, the era preceding the War was one of rapid change. For many, there was a sense of unidirectional progress: with science and technology, the world was becoming more understandable and so was the ability to control and distribute its objects and resources. People moved to cities en masse, hoping for an easier life: cities promised technological infrastructure, jobs in industry and a resultant source of steady food and reliable housing. With this movement, though, there was a growing sense of inequality (as those with capital exploited those without), of increased competitiveness, and an alienation stemming from the loss of home and place. This industrialization and faith in progress could not be stopped. Indeed, the European powers embraced science, 
technology and industry. Soon their goal was to amass resources, control markets and develop technology that would aid in these efforts. To this end, the competitive instinct was primary: all technology, all industry was necessarily good as long as they promoted their sense of progress. But competition, technology, and industry are not necessarily good. For these countries became increasingly competitive in the race for resources and markets. Rivalries grew, eventually metastasizing into bloody conflict.

For its part, the artistic, intellectual, and philosophical movement known as Modernism is a response to these trends. For, with all of this blind faith in science and progress, there was a pushback to open one's eyes and see the limitations of science, to identify its proper place within human understanding. For science gives the impression of objectivity and promotes the idea that there is one way to see the world and one objective truth. This sense of objectivity led the European powers to believe that their way was the right way — that they were closer to truth than anybody else — and that this way of thinking should be exported and promoted around the world. Under the guise of science, there is a devaluing of individuality, an obfuscation of one's interpretive and creative nature: people become tools, cogs in a machine. The artists, philosophers and intellectuals commonly associated with Modernism retorted by asserting the primacy of creativity and the relativity of science. Science was recognized as "one of the possible orders of understanding rather than $[\ldots]$ the ultimate form of truth statement" (Bell 11). For all scientific conclusions depend on an observer, somebody who determines the parameters of the experiment and the research questions that shape the conclusions. All in all, "the underlying notion of observation was increasingly problematic" (Bell 11). These thinkers came to conclude that "science is a reflection of the human mind before it is a 
reflection of the world" (Bell 11). If science is a reflection of the human mind, then what is the human mind and how does it work? Many of these thinkers recognized the concurrence between the human mind and the world: the two are inseparable. These thinkers saw "the human world as self-created", dependent on one's interaction with it (Bell 14). Language was seen to be the primary means of this interaction: "rather than describing or reflecting the world, language was now seen to form it" (Bell 16). The most important and most relevant of these thinkers to relativize science and recognize the importance of interpretation and language in human understanding was Martin Heidegger. He, in fact, was a relative contemporary of Virginia Woolf. Born seven years later, he belonged to a similar historical milieu as Virginia Woolf. Certainly, the two engaged similar questions; as such, it is no surprise that there is resonance between Woolf's concerns and Gadamer's, for Gadamer was a student of Heidegger's. Heidegger emphasized "human involvement in language as resistant to technical or external analysis" (Bell 17). In other words, any attempt to describe language already takes place in language: language is concurrent with one's embeddedness in the world. As language and the meaning of the world cannot be parsed, the relative status of each individual came to be affirmed: "the relative status of the human was a central recognition of Modernism itself' (Bell 13).

As the world for each individual is different because of his or her interaction with it, many artists began to explore the dynamics of this interaction, to promote this sense of interpretive responsibility and awareness. In the field of painting, for example, Claude Monet's 1874 painting, Impression-Sunrise, is considered by many to be the first Modern painting (Fiero, 6: 114). According to Fiero, "the painting says more about how one sees 
than about what one sees" (6: 114). This painting emphasizes the primacy of the perceiving individual — that perception varies depending on who sees and what that person chooses to highlight. As the $19^{\text {th }}$ Century came to a close and the $20^{\text {th }}$ gained steam, there was a gradual moving away from realistic representation and a moving toward formal innovation and abstraction, an attempt to represent the world as the artist sees it. Certainly, Virginia Woolf paid attention to these changes in art, as when she declares that human character changed forever in 1910, the year of the first PostImpressionist exhibit in England (Schwarz 26-7). In these paintings, one can notice an emphasis on individuality, perception, and personal vision: "These painters demonstrated that artists could create their own order in a chaotic world. Thus they intentionally neglect some details, while they simplify, distort, exaggerate, and stress others to express their emotions, solve problems of pictorial space and create effects, In a sense, the artist's temperament and perspective become the subject" (Schwarz 27).

Modernist novelists adopted a similar project of highlighting perception, of showing that each individual belongs to his or her own world. According to Schwarz, these authors "realized that each person perceives a different reality and lives in $[\ldots]$ a "closed circle"" (19). At the same time, the world of each individual is influenced by and influences the worlds of others. Much of Modernist literature focuses on this interaction between individuals. To capture the Modernist mode of perception, Woolf creates characters that embody this Modern trope. For its part, the characters in Mrs. Dalloway represent unique individuals who have been shaped by his or her upbringing and circumstance, characters who interpret their place in the world, who are shaped - and shape - as each interacts with others. These characters belong to a world that is 
changing - some believe in God, others do not - a world that is in crisis, one in which the stale precepts of the past are inevitably questioned. Like many who lived at the time, most of these characters do not purport to have the final answer or to understand absolutely. Instead they live in an atmosphere of questioning and wondering, of uncertainty. Certainly, in Clarissa we get a sense for her outlook: she wonders about the meaning of things and accepts that she will never reach an absolute conclusion, but she also does not despair, willing to test and explore, aware that she might find clues as she interacts with people and shares in the meaning of the world. This aspect of Clarissa's personality is highlighted when she is out in the street, pondering life and its mystery: "She knew nothing; no language, no history; she scarcely read a book now, except memoirs in bed; and yet to her it was absolutely absorbing" (Woolf, Mrs. Dalloway 8). It is "absolutely absorbing" because of her engagement with people, as the narrative immediately stresses: "Her only gift was knowing people almost by instinct" (Woolf, Mrs Dalloway 9).

Undoubtedly, Woolf presents Clarissa as a character who tries to understand. She makes an effort, but she is also presented as someone who recognizes the limitations of her effort. A part of her is aware that no matter her intent, understanding and meaning cannot be forced. Nevertheless, much of the critical reception has chosen to focus on Clarissa's subjectivity. Hussey, for example, argues that "Clarissa is engaged in what may be seen as a search for her ownmost identity: her recollections of childhood and an unresolved early love affair often prevent her from having a sense of continuity in her being" (25). Of course, Clarissa's identity is important, but my argument is that Woolf 
stresses those experiences of meaning that lie beyond subjectivity, situations in which meaning springs forth, the result of an unconscious interaction with people and language.

As Clarissa goes through her day, her many experiences, perceptions and sensations are filtered through the lens of her past, her relationships, and a potential future that she yearns to optimize. Each scent or sight triggers memories and thoughts that shape her mood; the very identity of these sensations and perceptions depend on her past experiences. In her case, the world turns out to be the result of her interaction with the people who know her best. In this context, Gadamer's words resonate: "It belongs to the nature of familiarity with the world that whenever we exchange words with one another, we share the world" ("On the Contribution of Poetry to the Search for Truth" 115). Somehow, she senses that each relationship, each encounter, is of the utmost importance, at the heart of any to attempt to understand or find fulfillment. According to Gadamer, dialogue and relationships are, in fact, one's main source of fulfillment:

The basic constitution of the game, to be filled with its spirit - the spirit of buoyancy, freedom and the joy of success - and to fulfill him who is playing, is structurally related to the constitution of the dialogue in which language is a reality. When one enters into dialogue with another person and then is carried along further by the dialogue, it is no longer the will of the individual person, holding itself back or exposing itself, that is determinative. Rather, the law of the subject matter is at issue in the dialogue and elicits statement and counterstatement and in the end plays them into each other. Hence, when a dialogue has succeeded, one is subsequently fulfilled by it ("Man and Language" 66).

Indeed, Clarissa has a sense for this nature of dialogue as she tends her relationshipsthat they shape who she is, that they are her primary means of finding fulfillment. She knows that there is something indefinably productive about relationships: their yield is 
always more and different than one anticipates — with each encounter, insight, reassurance and provocation. And when the relationship is at its most productive, when the participants find commonalities and a shared world, then each acquires a sense for what the world might be at its most true; each feels more at home, less alienated, the world more understandable because it has been corroborated. Certainly, Clarissa recognizes the value and productivity of her interactions with others: she knows that each meeting represents a tremendous opportunity; that this very person presents a chance to approach the world as it truly is; that this moment of unconscious congeniality shapes one's horizon and how one understands at all. Clarissa is reminded of the potential of her interpersonal encounters when she recalls how she has failed her husband; she knows she has failed him because there have been moments when she has sensed the potential and power and possible insight — the intense feeling of communion and completeness —of her interactions:

Only for a moment; but it was enough. It was a sudden revelation, a tinge like a blush which one tried to check and then, as it spread, one yielded to its expansion, and rushed to the farthest verge and there quivered and felt the world come closer, swollen with some astonishing significance, some pressure of rapture, which split its thin skin and gushed and poured with an extraordinary alleviation over the cracks and sores! Then, for that moment, she had seen an illumination; a match burning in a crocus; an inner meaning almost expressed. But the close withdrew; the hard softened. It was over- the moment (Woolf, Mrs. Dalloway 32).

Each encounter and each relationship are, to a certain extent, indefinable: within each there is an unquantifiable emotional and sexual undercurrent. Clarissa recognizes that there is something that occurs between two people that is decisive yet uncontrollable: the 
ways in which two people connect cannot be intellectualized. Clarissa is content with her decision to marry Richard, yet she also knows that their connection is imperfect - with Richard there is not intense passion nor is there transcendent meaning; however, Clarissa is fully aware that such experiences are possible when two people come together. When two people enter into a dialogue and confront the world there are moments when the passion of the interaction is decisive. Both parties submit to the dialogue and it is the subject matter that gains ascendency. Now, the topic of the dialogue could be absolutely anything, but the possible subject matter is only available within the world horizon of each participant; each particular is only understandable as it relates to the entire context. Each participant brings his or her self into the dialogue, a self that is oriented to the whole, of everything that might be understood, of everything that might be at all: "We are ourselves encompassed by the whole, which we are and which is in us; but not encompassed in such a manner that the whole would be present for us as the whole. We encounter it rather as the totality and vastness, wherein everything is, only through adhering to what has been allotted us, ie., the nómos, whatever it may be" (Gadamer, Hans-Georg Gadamer on Education, Poetry, and History 91). When people share the world in conversation, there is always the possibility that one might glimpse this whole and gain an improved sense for one's place in it; the world and its meaning - one's very perceptions - are confirmed. So, "the world come[s] closer" and is at its most meaningful for Clarissa when she is most connected with someone.

Clarissa has a sense for the potential of people. She knows that every individual, when combined with the right person, might gain a firmer footing and feel more complete. She herself has experienced such moments of communion. She has lived such 
moments and they shape how she experiences her day. She knows that each day carries within it tremendous potential—she feels an "exquisite suspense" from one moment to the next, aware that one cannot force moments of understanding and unity (Woolf, Mrs. Dalloway 30). It is only within the context of time that one might commune with the world. Every moment is new: a particular challenge and a particular opportunity. Sometimes one feels good, sometimes one feels bad; sometimes one feels inspired and at others stumped. But these opportunities only come about as time passes. The number of moments that one might seize are limited. With each passing hour, opportunities become fewer. At the same time, these opportunities evolve as one grows and changes: the manner in which one harnesses a moment depends on past experiences and how one has been shaped. With the right experiences and a refined ability to process those experiences, every new experience acquires greater meaning and more impact.

The action of this narrative takes place within the space of one day. And from the very beginning we get a sense for its narrative arc: Clarissa will be hosting a party in the evening; she needs to prepare for this party. This event is essential because it is a chance for people to come together: for each and every guest, the party represents an opportunity for the world to become something else - more understandable, more vibrant. For Clarissa too: it is a chance to make a connection that could change her life. By means of her party, she might "kindle and illuminate" (Woolf, Mrs. Dalloway 5). In this example, Woolf utilizes the metaphor of fire to highlight the manner in which two people interact: when people come together, something comes to be that neither can anticipate, an interaction of passion, the result new and unexpected. 
It is within the context of the looming party that Clarissa lives her day. In many ways, this day is special because people will come together who might not otherwise; that people will come together at all is of special importance — each encounter is necessarily a unique opportunity. In other ways, this day is entirely ordinary: one wakes up at the beginning and goes to bed at the end, the sun rises and sets, and the birds still chirp. So too, Big Ben booms with the passing of each hour. With each vibration, Woolf highlights the thematics of this novel: meaning and truth are only accessible within the context of time. Each new moment is different and it is up to each character to face this difference; time is incontrovertible and seeps into each and every little crevice; time will end but until then all one has is each moment; the past has been and the future will be, each impinging on the present. Certainly, this is Clarissa's feeling as she contemplates her present circumstance: "She was not old yet. She had just broken into her fifty-second year. Months and months of it were still untouched. June, July, August! Each still remained almost whole, and as if to catch the falling drop, Clarissa (crossing to the dressing table) plunged into the heart of the moment, transfixed it, there - the moment of this June morning on which was the pressure of all the other mornings" (Woolf, Mrs. Dalloway 36-7). It is important for Clarissa to digest the moment, to assess and orient herself, to determine who she really is, in spite of distractions, in spite of change, to ground herself, so that she might become more as a result of the party instead of scattered or confused. By "plunging into the very heart of the moment", Clarissa prepares herself for what may come. This is, in fact, something we all might do if we hope to understand: "In all human knowing of the world and in all orientation within the world the nature of the moment of understanding has to be worked out" (Gadamer, "Reflections on My 
Philosophical Journey" 28). For each moment is different, a synthesis of the past and one's expectations, and it is worthwhile to confront its nature, to understand it for what it is so that one might approach coherence.

This particular approach to understanding is characteristic of Modernism in and of itself. In Modernism one encounters a special emphasis on the subject and the uniqueness of the individual. In part, each individual is different because of his or her experiences and background. In this novel and in Gadamer's philosophical approach one can easily notice this accent on individuality and personal history. Part of understanding includes understanding one's place in the moment—-how it relates to the past and its possible impact on the future: "Memory enables us to integrate experience in a series of ongoing syntheses which become understandable as we interpret the past and future in a changing present" (Kern 45). With the importance of memory in mind - the manner in which it informs understanding and the human subject—many Modernist thinkers came to recognize the value of confronting and accounting for one's personal past: "the personal past began to attract a variety of prominent thinkers who scrutinized it with unprecedented care and insisted that an understanding of it was essential to a healthy and authentic life" (Kern 61).

This day is new and fresh, an opportunity and a challenge. Its success depends on what has happened before and what might happen in the future, but there is still a feeling of personal responsibility: within the confines of the possible, one makes choices. And certainly there is a feeling that the meaning and value of the day depends on one's approach to it: each day, each moment represents an opportunity to live in a world of one's own creation, as participants in its meaning. Clarissa recognizes this aspect of the 
world - that it depends on her to create it, that she is responsible: "Heaven only knows why one loves it so, how one sees it so, making it up, building it round one, tumbling it, creating every moment afresh" (Woolf, Mrs. Dalloway 4). Every moment is new and it depends on each and every one of us to interpret these moments. Here, though, interpretation is not something that happens after the experience, but is instead part of one's perception of the world: "Pure seeing and pure hearing are dogmatic abstractions that artificially reduce phenomena. Perception always includes meaning" (Gadamer, Truth and Method 80). Indeed, the meaning of the world depends on the approach to it; interaction with the world, ability to describe it, and expectations actually determines meaning: "We are simply following an internal necessity of the thing itself if we go beyond the idea of the object and the objectivity of understanding toward the idea that subject and object belong together" (Gadamer, Truth and Method 457). Of course, this creative opportunity and responsibility depends on one's past experiences and how the moment fits into what remains. And it is the case that Clarissa will be hosting a party that evening; her experiences are filtered through the lens of what is to come.

Furthermore, her old friend, the man she almost married, Peter Walsh, remains foremost on her mind. From the very beginning of the novel her sensations and experiences trigger memories of Peter; to a certain degree he is the arbiter and fulcrum of Clarissa's world: "For they might be parted for hundreds of years, she and Peter; she never wrote a letter and his were dry sticks; but suddenly it would come over her, If he were with me now what would he say?" (Woolf, Mrs. Dalloway 7). For Clarissa, it is because of Peter that the world has acquired its present shape and color-her perception of it, its very significance. 
So, too, Clarissa remains a central figure in Peter's world: "no one understood him, felt with him, as Clarissa did" (Woolf, Mrs. Dalloway 46). For both, underlying their relationship is a spring of overwhelming emotion and feeling. Between them there is and was an undeniable connection that molded their worlds. Because of the complicated reality of love and feeling, they did not marry each other, yet neither can deny that there was and is love, that their connection determined who they became: "She had influenced him more than any person he had ever known" (Woolf, Mrs. Dalloway 153). For Clarissa, too, Peter is decisive: "He made her see herself" (Woolf, Mrs. Dalloway 168). This novel culminates with Clarissa's party and at this party Peter fixates on Clarissa. Recently returned to London from India, Peter yearns to reconnect with Clarissa. Despite their problems and complications, he knows that she remains a central figure in his life. Any subsequent love or happiness that he might have found after their separation still hinges on his initial relationship with Clarissa. For Peter, his bond with Clarissa represented the apex of emotion and feeling. As a result, any subsequent relationships are forever skewed, any emotion or feeling never fully understandable: "He had not found life simple, Peter said. His relations with Clarissa had not been simple. It had spoilt his life" (Woolf, Mrs. Dalloway 192). So, when Peter talks to his and Clarissa's mutual friend, Sally Seton, they discuss what matters most. Sally states her position plainly: "For she had come to feel that it was the only thing worth saying — what one felt. Cleverness was silly. One must say simply what one felt" (Woolf, Mrs. Dalloway 191). Peter wishes he could say what he feels, for then he might actually understand his emotions. Bereft of words, Peter flounders; for, until he is able to articulate his emotions, they remain mysterious: "'But I do not know [...] what I feel”” (Woolf, Mrs. Dalloway 191). Indeed, 
Peter wishes he could verbalize his feelings so that they might be understandable; we all need language if we hope to understand: "To come into language does not mean that a second being is acquired. Rather, what something presents itself as belongs to its own being" (Gadamer, Truth and Method 457). Peter struggles to pin down his emotions, but he recognizes that Clarissa still influences any feeling that he might have; he senses that, maybe, she can help him rediscover his feelings and their true nature. Maybe Clarissa can prompt the language that might calm his emotional turmoil. When, in the end, he finally sees Clarissa again at the party, he thinks to himself: "What is this terror? what is this ecstasy? [...] What is it that fills me with extraordinary excitement?" (Woolf, Mrs. Dalloway 194). She is still the potential source of a world that might reach fulfillment and this potential is both scary and exciting - terrifying because he has so much to lose; thrilling because he has so much to gain.

Now, my consideration of this relationship between Clarissa and Peter - and the marriage between Clarissa and her husband Richard-is somewhat complicated by societal and historical strictures. Certainly, the general concept of love, marriage, and friendship between men and women has evolved and changed over time: the ways that men and women interact is very different now than it was then. To a certain degree, it is unavoidable that I will project my sense of this interaction between men and women as it has taken shape in the beginnings of the Twenty-first century, but, at the same time, an acute and highly developed historical consciousness belongs to the present moment also. I cannot help but affirm that the world was different then than it is now. Certainly, traditionally, women have been second-class citizens, often seen as property, and bereft of agency. The Modern period was a time of rapid change and this movement 
comprehends the status of women. It was during this time that the suffrage movement began, culminating in Great Britain in 1918 when women won the right to vote. This right was one step in the direction towards equality, but undoubtedly there was much left to rectify. As one might expect, Virginia Woolf was part of this conversation. In general, she focused on "equal opportunity for education and economic advantage" (Fiero, 6: 110). She also argued for "psychological independence from men" (Fiero, 6: 110). Now, in order to win the right to vote and to rally for a more equal status, women had to unite as a group and, to a certain extent, affirm their status as different from men. However, Woolf took issue with this grouping of women, as if all women were the same or shared similar characteristics. Instead, Woolf aimed to transcend this concept of gender difference and to promote a notion of women as people, with similar interests, desires and needs as men. Her aim was to affirm the "value of human life itself in its natural freedom" (Payne, 2). All in all, the point was that people should be allowed to become who they might be, that each might become the best version of his or her self. And it is this theme that stands out in Mrs. Dalloway. A middle-aged socialite and housewife, Clarissa hardly represents radicality, but it is exactly within this atmosphere of tradition that Clarissa might transcend traditional gender norms. In her relationships with Peter and Richard, there is a general tension between tradition and transcendence. Belonging to their time and place, there is no doubt that their relationships were shaped by societal expectations. At the same time, they grew up and matured in a time of rapid change. While seeking a sense of fulfillment that could only come to fruition as something that takes place within society, these characters also interact in a way that undermines these 
expectations. In their interactions there is this sense that the most important thing is to encourage one's individual freedom so that he or she might reach fulfillment.

Woolf indicates in her novelistic characterization that Peter and Clarissa are essential to each other and how each understands the world. Clarissa, for her part, is acutely aware of the mystery of people and of life; people are inscrutable and so is life, each capable of the unexpected: "She would not say of any one in the world now that they were this or that" (Woolf, Mrs. Dalloway 8). It is impossible to know people as they truly are, she thinks, but we do make judgments and conclusions, even when one knows that these opinions might not be entirely accurate; that is, each attempt to know someone should be tempered with the recognition that people are unknowable and surprising. Clarissa herself wrestles with this tension between revealment and concealment, surface and depth. On one end of things, to a certain degree Clarissa can accurately judge people just by being in the same room with them: "Her only gift was knowing people almost by instinct" (Woolf, Mrs. Dalloway 9). On the other end: "she would not say of Peter, she would not say of herself, I am this, I am that" (Woolf, Mrs. Dalloway 8-9). Clarissa is fully aware of the paradox of judging others: people contain within them an infinite depth, yet they necessarily assert themselves. In one's interactions with others there is something identifiably there. With this in mind, Gadamer's philosophy resounds: "Being is visible not only as the one but also, and just as originally, as the other and as the multiplicity of differences, and as the identity and difference that comes into language" ("Towards a Phenomenology of Ritual and Language" 44). In many ways, these considerations are part and parcel of the historical climate in which Woolf wrote and Gadamer philosophized. The world was in crisis and many were seeking an alternative to 
the mindset that had led Western civilization into war: there was a "widespread belief that Western civilization had lost its course" (Matthews and Platt 589). Objective certainty was a central component of Western civilization and its unidirectional notion of progress and many thinkers decided that it was necessary to dismantle this notion. So, instead of certainty, these thinkers preferred uncertainty — as the individual relates to the world and as one tries to understand the world: "a questioning mood became the normative way of looking at the world, replacing the certainty of previous centuries" (Matthews and Platt 589).

Certainly, Clarissa feels like she is capable of unexpected surprises — and the people she meets too. This too is Clarissa's feeling as she lives her day: each day should be approached with radical wonder; anything can happen; she is part of the world yet outside of it; each moment is a gift and a burden; she could die at any moment: "She sliced like a knife through everything; at the same time was outside, looking on. She had a perpetual sense, as she watched the taxi cabs, of being out, out, far out to sea and alone; she always had the feeling that it was very, very dangerous to live even one day" (Woolf, Mrs. Dalloway 8). Clarissa accepts that life is fleeting, that it is both comprehensible and incomprehensible, that it exhilarates as it frustrates. And it is within this context that Clarissa lives her life: she will die and everything will end; her access and opportunity are limited - all she has is the moment. Willing to look death in the face, Clarissa confronts her finitude: "Did it matter then, she asked herself, walking towards Bond Street, did it matter that she must inevitably cease completely; all this must go on without her; did she resent it; or did it not become consoling to believe that she ended absolutely?" (Woolf, Mrs. Dalloway 9). Woolf suggests by this passage that Clarissa 
recognizes that no one knows what happens when we die, but we all know that it will happen and that when it does all of this striving and needing and wanting and wondering will cease.

And it is this notion of death that tinges much of the novel. Death is always there and it is always an option. Clarissa never dies in the narrative nor does she contemplate suicide, but death still remains a central motif. In point of fact, it is famously known that Woolf initially intended for Clarissa to commit suicide; death is at the center of this narrative. Considering the mass carnage of World War I, it is no surprise that death would play such a prominent role in this fictional account. The specter of death was everywhere, seemingly inevitable. Although many considered Western civilization to be on a track of progress, part and parcel of this progress was the potential for mass annihilation: "The same science, technology, and medicine that extended and improved life produced weapons that made it easier for modern armies to annihilate each other" (Winks and Neuberger 289). This potential for annihilation hovered over everyone, requiring all to look death in the face. So, at Clarissa's party, death takes center stage, offering a clear juxtaposition between the joviality and mirth of the party and the stark finality of death. This story culminates with Clarissa's party, a time when people can come together and celebrate and feel unity, a time when people can forget about their worries and frustrations, yet even an event like a party cannot gloss over life's ultimate truth: "Oh! thought Clarissa, in the middle of my party, here's death" (Woolf, Mrs. Dalloway 183). Septimus Warren Smith has committed suicide. He is a topic of conversation because Doctor Bradshaw is at the gathering, having treated Septimus just that day. Septimus is a stranger to Clarissa, yet his life and death affect her deeply: he is a 
reminder that life is short and temporary. In contemplating his death, Clarissa understands the truth of life: "A thing there was that mattered; a thing, wreathed about with chatter, defaced, obscured in her own life, let drop in corruption, lies, chatter. This he had preserved. Death was defiance. Death was an attempt to communicate; people feeling the impossibility of reaching the centre which, mystically, evaded them; closeness drew apart; rapture faded, one was alone. There was an embrace in death" (Woolf, Mrs. Dalloway 184). Certainly, for Clarissa (and people in general) in one's daily life one very rarely feels like one has a handle on everything; there are always distractions and circumstances that bend meaning; but in death there is no longer this anguish and anxiety of wanting to know but never reaching a final conclusion; finally, in death, one communes with the world and the circle is complete, consciousness no longer striving for unity.

Septimus' suicide serves as a point of contrast for Clarissa: she is still alive and the world remains vibrant, but she knows that she has an option-she can die if she chooses; it is possible. And it is Septimus' suicide that reminds Clarissa that each moment is a gift, that it is up to her to choose how to live: "But what an extraordinary night! She felt somehow very like him — the young man who had killed himself. She felt glad that he had done it; thrown it away. The clock was striking. The leaden circles dissolved in the air. He made her feel the beauty; made her feel the fun" (Woolf, Mrs. Dalloway 186). Clarissa reacts to Septimus' suicide positively because his death helps clarify the true nature of life; death itself is like a frame that allows the viewer to see what is and what is not; life is limited and mysterious but it is all there is. 
This particular day concludes with Clarissa's party, an event in which people might celebrate community, commonality, and solidarity. But this party is not all joy; Septimus' suicide intrudes. Woolf chooses to include Septimus as a central character because his plight sheds light on the ravages of war and the vicious character of humanity. Of course, not everyone experiences the brutality of war to such a heightened degree nor does everyone feel the cutting edge of one's fellow being, but, undoubtedly, Septimus' outlook and world has been warped by war. Sensitive by nature, he entered the war enthusiastic about literature, as someone who acutely felt the benefits of community and solidarity. But the war changed him; it was inevitable. Forced to participate in the downfall of others, Septimus had no choice but to shut down and snuff out his affective capacity, his ability to empathize, all feeling and emotion. In her article, "Trauma and Recovery in Virginia Woolf's Mrs Dalloway," Karen DeMeester echoes this notion: "During combat, indifference is a survival tool that protects the psyche from being overwhelmed by the horror received through the senses" (658). Furthermore, within this environment of heightened stress, Septimus developed a close friendship with his commanding officer, Evans. But Evans did not survive the war and Septimus had even further reason to despair and retreat into himself: "when Evans was killed, just before the Armistice, in Italy, Septimus, far from showing any emotion or recognizing that here was the end of a friendship, congratulated himself upon feeling very little and very reasonably. The War had taught him. It was sublime" (Woolf, Mrs. Dalloway 86). When Septimus returns from the war, he begins to realize that the war has changed him and he starts to panic; he fears that he will not lead a normal life, that he is no longer able to share or love: "When peace came he was in Milan, billeted in the house of an innkeeper 
with a courtyard, flowers in tubs, little tables in the open, daughters making hats, and to Lucrezia, the younger daughter, he became engaged one evening when the panic was on him— that he could not feel" (Woolf, Mrs. Dalloway 86).

As readers, we do not first learn of Septimus at Clarissa's party. He is introduced much earlier, at the beginning of the day, when Clarissa is out buying flowers for her party. Clarissa is out in public, among the masses of people who happen to be in London that very day. Everyone becomes mesmerized by a car that may or may not include the Prime Minister or the Queen of England. Septimus is one of those people being mesmerized: he too is captivated. But Septimus is not only enthralled by the car, he is lost in reverie because his perceptions and sensations demand an explanation; terrible things have happened to Septimus; he has been chosen to suffer; this pain, though, must have some benefit—there must be some unique meaning attached to his experiences:

And there the motor car stood, with drawn blinds, and upon them a curious pattern like a tree, Septimus thought, and this gradual drawing together of everything to one centre before his eyes, as if some horror had come almost to the surface and was about to burst into flames, terrified him. The world wavered and quivered and threatened to burst into flames. It is I who am blocking the way, he thought. Was he not being looked at and pointed at; was he not weighted there, rooted to the pavement, for a purpose? But for what purpose? (Woolf, Mrs. Dalloway 15).

There must be some special significance linked to Septimus' tribulations. His perceptions are supercharged because he has witnessed extreme cruelty and suffering; he knows what people are capable of and this knowledge tinges his perceptions - they are endowed with need; his pain must be useful in some way; the world and its appearance must be meaningful, harmonious; surely, resolution and unity are possible: 
But they beckoned; leaves were alive; trees were alive. And the leaves being connected by millions of fibres with his own body, there on the seat, fanned it up and down; when the branch stretched he, too, made that statement. The sparrows fluttering, rising, and falling in jagged fountains were part of the pattern; the white and blue, barred with black branches. Sounds made harmonies with premeditation; the spaces between them were as significant as the sounds. A child cried. Rightly far away a horn sounded. All taken together meant the birth of a new religion (Woolf, Mrs. Dalloway 22-3).

Septimus is particularly equipped to comprehend the scope of existence because he has witnessed the underbelly of human nature (degradation, cruelty) and the truth of the world is only available in this context - as something that must be meaningful, harmonious and understandable despite — or because of - the way people treat one another. At the same time, Septimus' perceptions are distorted because he has not been able to link his pre-war existence with his post-war life. He is stuck in his own head, unable to overcome his trauma. As DeMeester contends, “The survivor's traumatized mind apprehends the traumatic event as ever-present, and his memories of the event often exist in the present consciousness as encapsulated images and fragments of thought that are juxtaposed against other nontraumatic memories but do not relate to them sequentially or chronologically" (651). To recover from his trauma, he "must escape the prespeech chaos of his traumatized psyche and form his fragments of thought into a coherent, communicable narrative" (DeMeester 652). But Septimus is unable to form a coherent narrative; he lacks a sympathetic interlocutor, an outlet for his thoughts and emotions, somebody who might understand his plight.

Woolf includes the character of Septimus in her novel because he represents what might happen when the world is turned upside down by war; instead of propping each 
other up, people chop each other down; when each is obligated to renounce the value and dignity of others; when each witnesses and participates in carnage. These experiences could not but change Septimus. As a response, in a last-gasp attempt to regain normalcy, Septimus chooses to marry Lucrezia. But this marriage to Lucrezia did not rescue Septimus. He remained bereft, alone, solitary—on an island. And Lucrezia suffers as a result. She too ends up feeling alone, disconnected from Septimus, each unable to understand the other. Lucrezia yearns for a connection with Septimus; she longs to be able to communicate with him; she wants to understand him and him to understand her. But they inhabit different worlds. Septimus is pre-occupied with working out the consequences of the War: he feels that he is uniquely qualified to interpret truth and meaning. He has approached the limits of human cruelty, of feeling, of life; he has walked to the edge and looked over the precipice: "He lay back in his chair, exhausted but upheld. He lay resting, waiting, before he again interpreted, with effort, with agony, to mankind" (Woolf, Mrs. Dalloway 68). Septimus feels the need to interpret because he senses that his background uniquely qualifies him to understand the true nature of things. Septimus acknowledges and trumpets the value of interpretation-his very need to interpret—-because his familiarity with the world has been destabilized. One may not recognize the value of interpretation - and one's need for it - but it is something that occurs regardless: "interpretation seems to be a genuine determination of existence rather than an activity or intention" (Gadamer, "Text and Interpretation" 71). Septimus thinks that his experiences must include a secret meaning, that there must be an explanation for his pain, that his primary duty and challenge is to interpret this meaning. But, unfortunately, Septimus struggles to articulate the profound insights that he is uniquely 
equipped to share; precisely because they are so important, because they are so deep,

Septimus becomes frustrated; these insights are of such importance that any flaw, any gap between his need and the realization of this need becomes glaring:

$[\mathrm{H}] \mathrm{e}$, Septimus, was alone, called forth in advance of the mass of men to hear the truth, to learn the meaning, which now at last, after all the toils of civilization-Greeks, Romans, Shakespeare, Darwin, and now himself - was to be given whole to... 'To whom?' he asked aloud. 'To the Prime Minister,' the voices which rustled above his head replied. The supreme secret must be told to the Cabinet; first that trees are alive; next there is no crime; next love, universal love, he muttered, gasping, trembling, painfully drawing out these profound truths which needed, so deep were they, so difficult, an immense effort to speak out, but the world was entirely changed by them for ever (Woolf, Mrs. Dalloway 67).

Here, Septimus recalls civilization and its accomplishments: people like Shakespeare or Darwin, people who themselves interpreted the world, shared their interpretation with others, and challenged people to participate in this interpretive effort. To interpret, to approach truth, Septimus fully appreciates the value of this effort-but precisely because of his need (its immensity, its complexity), Septimus despairs. In the character of Septimus one notices an emphasis on interpretation and this emphasis reflects one of Modernism's primary tenets - that each person is different and interpretation should be adjusted based on this difference. This variability of personality and experience became a central concern of many artists and intellectuals of the time: "They sought to depict a new kind of realism, situated in the subjective rather than the objective realm" (Winks and Neuberger 310). The character of Septimus is particularly appropriate for a consideration of the subjective because of the uniqueness and intensity of his experiences and consciousness. The unique subjectivity of Septimus reflects one of Modernism's 
principal tropes: "Culture had a new function for the modernists: not to represent, explore, analyze, or catalog objective reality, but to turn inward and explore under the surface of things, to express the subjective experience unique to each individual, including contradictory feelings, drives, energies at the very heart of life" (Winks and Neuberger 310).

Septimus is obsessed with his need for understanding, but the world that he endeavors to interpret is very different than that of Lucrezia. The two struggle to communicate, to connect, each on a different wavelength. The reference of the language of each is utterly dissimilar. As DeMeester puts it, "Communication between a trauma survivor and an untraumatized listener is diminished by a gap in meaning that to an extent exists in all attempts to communicate. Though the listener recognizes the words the traumatized person uses, she cannot comprehend the reality these words represent; there is an irreconcilable gap between the intensity of experience and emotion the veteran wishes to convey and the experience and emotion the listener can imagine and feel" (654). His concerns are different than hers and vice versa. As a result, Lucrezia also feels alone, abandoned even. Unable to communicate with the most important person in her life, the world loses its color, becomes indiscernible and murky with shadows. So, when Lucrezia comments to her husband that he should see the Milan gardens, she feels that the words do not reach Septimus, obsessed as he is with his own predicament:

There was nobody. Her words faded. So a rocket fades. Its sparks, having grazed their way into the night, surrender to it, dark descends, pours over the outlines of houses and towers; bleak hillsides soften and fall in. But though they are gone, the night is full of them; robbed of colour, blank of windows, they exist more ponderously, give out what the frank daylight fails to transmit - the trouble and suspense 
of things conglomerated there in the darkness; huddled together in the darkness; reft of the relief which dawn brings when, washing the walls white and grey, spotting each windowpane, lifting the mist from the fields, showing the red-brown cows peacefully grazing, all is once more decked out to the eye; exists again. I am alone; I am alone! (Woolf, Mrs. Dalloway 23-4).

Lucrezia is unable to communicate with Septimus because their concerns are entirely separate; without this communication, the world lacks meaning, becomes incomprehensible, as if the world were bathed in darkness: "The light that causes everything to emerge in such a way that it is evident and comprehensible in itself is the light of the word" (Gadamer, Truth and Method 478). In the same way that the world is indistinguishable when completely dark, Lucrezia's world is imperceptible because she has no one to share it with; instead of reaching their destination and illuminating their shared existence, her words are duds, unable to reach self-fulfillment, launched towards their target but never reaching it—instead of enlightenment, darkness.

Septimus enters the novel when he is out with his wife; later, he visits Doctor Bradshaw's office; then he commits suicide; and finally he resurfaces at Clarissa's party, when she learns of his fatal act. We get a sense for the arc of his day and how he might make that final decision - his mindset and all that it implies. For Septimus, the pain of the day accumulates precipitously, so much so that he feels compelled to end his life. Now, Septimus is included in this novel because he represents one possible direction that a day might take. In the character of Septimus one sees a contrast between his dejection and Clarissa's approach to her day. Clarissa is not a perfect person and she too sometimes struggles and sometimes despairs, but she has also been lucky, having lived a life in which she was nurtured and loved. Clarissa is thankful for her lot in life, but she also 
knows that she has contributed significantly to her own happiness and success; she has made an effort. Clarissa is fully aware that with each day and each moment anything can happen, that time itself brims with danger and opportunity. With each instant she might understand and feel more or she might fail, cowed by the mystery and challenge of existence. However it may be, she knows that every day presents tremendous opportunity, within each a series of moments that could change her life: so that she might be who she wants to be and the world might be what it should be. But time is running out for Clarissa: she has lived more years than remain; her opportunities are becoming less and less abundant; her burden, her need, is becoming more and more acute. Now she feels a growing sense of urgency to embrace each moment:

she feared time itself, $[. .$.$] the dwindling of life; how year$ by year her share was sliced; how little the margin that remained was capable any longer of stretching, of absorbing, as in the youthful years, the colours, salts, tones of existence, so that she filled the room she entered, and felt often as she stood hesitating one moment on the threshold of her drawing-room, an exquisite suspense, such as might stay a diver before plunging while the sea darkens and brightens beneath him, and the waves which threaten to break, but only gently split their surface, roll and conceal and encrust as they just turn over the weeds with pearl (Woolf, Mrs. Dalloway 30).

Clarissa experiences such an intense feeling of suspense because she knows that her opportunities are becoming scarcer; her experiences are shaped by her sense of the future, a future that is dwindling, intensifying the importance of the present moment, one that may or may not prove decisive.

As Clarissa prepares for the party, as she moves about her house and muses, her thoughts return to Peter; she cannot help but do so, as he occupies such a central role in 
her story. She recalls that her outlook in life, her very vocabulary has been shaped by Peter: "She owed him words: 'sentimental,' 'civilized'; they started up every day of her life as if he guarded her" (Woolf, Mrs. Dalloway 36). She then wonders when Peter would be back from India and he appears at her house. His visit affects her deeply: his influence in her life is so important, his role in her past so central, that his presence challenges Clarissa, reminding her of where she is and what she has become. His presence prompts her to evaluate the entirety of her life:

'Do you remember the lake?' she said, in an abrupt voice, under the pressure of an emotion which caught her heart, made the muscles of her throat stiff, and contracted her lips in a spasm as she said 'lake.' For she was a child, throwing bread to the ducks, between her parents, and at the same time a grown woman coming to her parents who stood by the lake, holding her life in her arms which, as she neared them, grew larger and larger in her arms, until it became a whole life, a complete life, which she put down by them and said, 'This is what I have made of it! This!' And what had she made of it? What, indeed? sitting there sewing this morning with Peter (Woolf, Mrs. Dalloway 43).

Here we might return to Gadamer's notion that we are oriented towards unity, that we are a whole and that the whole is in us. Clarissa recalls her parents because they were more influential and more present than anyone else when she began her life. Now that she is beginning to near her end, she remembers her parents because they are especially qualified to assess the continuity of her life, how all of the parts fit together, the extent to which she has fulfilled her potential. This sense of continuity constitutes a vital aspect of Modernist thought. The Modernists placed an emphasis on subjectivity and the uniqueness of the individual; a vital part of this subjectivity and particularity is one's memory; for its part, memory is one's primary means towards attaining continuity- 
without memory each moment would be discrete and disconnected. Many Modernist thinkers contemplated the importance of memory, with Bergson commonly considered to be the most important: "For Bergson, memory was all-important as the condition of our free will: it is through memory, he argued, that our actions transcend predictable mechanical responses to the extent that we bring our accumulated experiences to bear on a given situation. Consciousness or 'duration', in which the present is swollen with the past is the essential feature of our humanity" (Fernihough 69).

And, of course, in the same way that Peter mediates Clarissa's life, Clarissa is also the arbiter and reference for Peter. Peter even depends on Clarissa to approve his current love-interest. Peter wants Clarissa to acknowledge and endorse his new life, his new love, for it is because of Clarissa that Peter has become who he is; it is because of her that he has fallen in love once again:

There they are! he thought. Do what you like with them, Clarissa! There they are! And second by second it seemed to him that the wife of the Major in the Indian Army (his Daisy) and her two small children became more and more lovely as Clarissa looked at them; as if he had set light to a grey pellet on a plate and there had risen up a lovely tree in the brisk sea-salted air of their intimacy (for in some ways no one understood him, felt with him, as Clarissa did) their exquisite intimacy (Woolf, Mrs. Dalloway 45-6).

This intimacy between Peter and Clarissa is so decisive that it determines how each feels about life and the people in their lives. It is, in fact, because of Clarissa that Peter became who he was, that he ended up choosing to marry Daisy at all.

This day happens to be Peter's first day back in London after several years spent in India. Back in London to consult with lawyers about divorce and marriage, Peter finds himself with several idle hours to pass while waiting for his next appointment. Having 
visited with Clarissa, he chooses to wander about London, contemplating his life and the changes that have taken place in London during his time away. At this moment, Peter feels detached, without anchor, as if the usual distractions and concerns have melted away, as if his circumstance was completely new, as if he were freed to confront his life with a renewed outlook and fresh eyes, the world and its meaning supremely mysterious, yet there to be confronted as it truly is: "And just because nobody yet knew he was in London, except Clarissa, and the earth, after the voyage, still seemed an island to him, the strangeness of standing alone, alive, unknown, at half-past eleven in Trafalgar Square overcame him. What is it? Where am I? And why, after all, does one do it?" (Woolf, Mrs. Dalloway 52). These are questions without a direct answer, questions that seep into anything and everything humans do, part of an undercurrent that sweeps people along, always there, belonging to every statement or answer that is given. These questions belong to an essential orientation to the world:

How is understanding possible? [...U]nderstanding is not just one of the various possible behaviors of the subject but the mode of being of Dasein itself. It is in this sense that the term 'hermeneutics' has been used here. It denotes the basic being-in-motion of Dasein that constitutes its finitude, and hence embraces the whole of its experience of the world. Not caprice, nor even an elaboration of a single aspect, but the nature of the thing itself makes the movement of understanding comprehensive and universal (Gadamer, Truth and Method xxvii).

Gadamer notes that people are oriented to understanding and this orientation is decisive; everything one does or thinks depends on one's understanding of the world, but people rarely recognize or confront this orientation; one normally contemplates particulars and concrete situations, but rarely questions those factors and elements that contribute to the 
nature of the situation and one's understanding of it. Moreover, this novel implies that by confronting one's orientation one might readjust it so that one approaches life with clearer vision.

In Woolf's novel Peter feels liberated to confront his life with fresh eyes, to ask questions that normally remain in the background, to challenge his presuppositions, orientation, outlook and horizon, as Gadamer claims is necessary for understanding. Peter knows that, in doing so, there is supreme reward. For he knows that his life and its yield depends on his participation - its meaning depends on his attitude and approach: "one makes up the better part of life" (Woolf, Mrs. Dalloway 54). That life and its meaning depends on one's participation is a common Modernist trope. Life is unique for each and every person: there is an "infinite variation in the ways each individual perceives reality" (Winks and Neuberger 310). One participates in meaning, and this significance depends on one's past and one's relationships - all that has determined one's vocabulary and horizon. As a result, Woolf has Peter return to Clarissa so that he might contemplate their relationship: it is because of her that he is who he is. Peter accepts that Clarissa is an individual, with her own idiosyncracies and unique traits; like everyone else, she is of infinite depth and richness. Because she is so particular and special, Peter still wrestles with understanding her, defining her, parsing her personality. In Clarissa, Peter notes a strange juxtaposition: she is both extremely friendly and open to others, while forever withholding her interior, her essence, sedulous of her privacy, unwilling to share everything —or, at least, that which is most important. Nevertheless, there is something about Clarissa that directly confronts Peter and burrows into his core-perhaps it is her private depth: "That was the devilish part of her-this coldness, this woodenness, 
something very profound in her, which he had felt again talking to her; an impenetrability. Yet heaven knows he loved her. She had some queer power of fiddling on one's nerves, turning one's nerves to fiddle strings, yes" (Woolf, Mrs. Dalloway 61). That Clarissa guards her most profound depths so diligently appeals to Peter; her interior and the manner in which she safeguards it represents an alternative for Peter and a challenge.

Peter cannot and should not dismiss Clarissa. For Peter, Clarissa has a presence that is undeniable and exhilarating. She is far from a perfect person, with no special talents or skills, yet her very being exudes dignity and humanity. Among people, her generosity, humility and acceptance stand out: the world is harsh enough and challenging enough already — as an antidote, people should accept each other, embrace each other, support each other. Instead of criticizing and analyzing, one might embrace the world for all it has to offer: Clarissa had "that extraordinary gift, that woman's gift, of making a world of her own wherever she happened to be. She came into a room; she stood, as he had often seen her, in a doorway with lots of people round her. But it was Clarissa one remembered. Not that she was striking; not beautiful at all; there was nothing picturesque about her; she never said anything specially clever; there she was, however; there she was" (Woolf, Mrs. Dalloway 76). For Peter, Clarissa's presence is enough. In her bearing, her appearance, her gestures and looks, Clarissa's value is undeniable: embedded in the world, Clarissa accepts her place and does her best to improve it, all the while doing the same for others (Woolf, Mrs. Dalloway 76).

Clarissa remains central to Peter's narrative, a sequence that remains unfinished and continues to unfold. A middle-aged man, Peter finds himself taking stock, assessing 
everything that has happened in life and everything that might yet happen. Fortunate in many ways, Peter has been lucky enough to live a full life, to fall in love, to travel, to persevere, to withstand and overcome the vicissitudes of existence. As a young man, Peter was passionate, filled with verve and exuberance; he was someone who embraced his instincts and impulses. But, in youth, it is hard to fully understand the meaning and importance of one's choices and experiences — one's context is limited. Grown older, Peter accepts that his future may no longer be expansive, but he also acknowledges that his experiences are now more understandable and belong to a wider context—everything means more: "The compensation of growing old, Peter Walsh thought, coming out of Regent's Park, and holding his hat in hand, was simply this; that the passions remain as strong as ever, but one has gained — at last! The power which adds the supreme flavour to existence, - - the power of taking hold of experience, of turning it round, slowly, in the light" (Woolf, Mrs. Dalloway 79). The benefits of age and experience emerge in this character. With them, he is better prepared to understand the meaning of new experiences, their significance understandable within a wider frame of reference;

furthermore, with experience he knows to discard certain concerns and avoid certain distractions, so that the truth of the experience might flower, so that understanding is more focused. This aspect of experience is a central concern of Gadamer:

The truth of experience always implies an orientation to new experience. That is why a person who is called experienced has become so not only through experiences but is also open to new experiences. The consummation of this experience, the perfection that we call 'being experienced,' does not consist in the fact that someone already knows everything and knows better than everyone else. Rather, the experienced person proves to be, on the contrary, someone who is radically undogmatic; who, 
because of the many experiences he has had and the knowledge he has drawn from them, is particularly well equipped to have new experiences and learn from them. The dialect of experience has its proper fulfillment not in definitive knowledge but in the openness to experience that is made possible by experience itself (Gadamer, Truth and Method 350).

Peter acknowledges the value of experience; he appreciates that the world is more understandable with more context; he embraces the idea that he is more discerning, less distracted by the superfluous or the irrelevant. The manner in which the past effects the present and its degree of influence were important considerations for the Modernists; the background and experiences of each individual shapes meaning and perception. In her article, "Consciousness as a Stream", Fernihough quotes the Modernist novelist Dorothy Richardson, who analyzed the personal past and its influence on the present in similar terms to that of Bergson: "In actual experience it is more like an agglomeration, a vital process of crystallization grouped in and about the human consciousness, confirming and enriching individual experience" (69).

With age, Peter has gained a better sense for life and the meaning of his experiences. However, he remains fully aware that life remains mysterious: it is, in fact, so compelling because it can never be fully understood. It is incomprehensible, yet there are moments of communion and correspondence, moments in which truth asserts itself, when its impact cannot be denied: for example, moments of beauty. When Peter experiences the beautiful, he is often overwhelmed, feeling, at least in the moment, an exhilarating clarity, as if he were given access to the true nature of things. This clarity prompts an emotional response: however clear and understandable, however potent, Peter's impressions of things will never fully be understood or communicated. So, when 
Peter tries to explain to himself why he is prone to uncontrollable bouts of emotion, he signals the weight of beauty and understanding, the challenge they present:

in privacy one may do as one chooses. One might weep if no one saw. It had been his undoing - this susceptibilityin Anglo-Indian society; not weeping at the right time, or laughing either. I have that in me, he thought standing by the pillar-box, which could now dissolve in tears. Why, heaven knows. Beauty of some sort, and the weight of the day, which beginning with that visit to Clarissa had exhausted him with its heat, its intensity, and the drip, drip, of one impression after another down into the cellar where they stood, deep, dark, and no one would ever know. Partly for that reason, its secrecy, complete and inviolable, he had found life like an unknown garden, full of turns and corners, surprising, yes; really it took one's breath away, these moments; there coming to him by the pillar-box opposite the British museum one of them, a moment, in which things came together; this ambulance; and life and death (Woolf, Mrs. Dalloway 152).

For Peter then, life is secretive yet open; in it he encounters something that is identifiably there and understandable, yet this identity includes difference and change within itself. Gadamer's philosophical approach can be applied here to Peter's experience:

"Hermeneutics has the task of revealing a totality of meanings in all its relations. The individuality of the sense intended corresponds to the totality of definitions" (Gadamer, Truth and Method 467).

Peter had visited Clarissa earlier that day and their meeting had impacted him deeply; to see his old friend after several years, to see the woman he had loved, to revisit his passion and heartache—all of this affects him to the core. For Peter could not escape Clarissa's influence: despite their sharp edge, his encounters with Clarissa were consistently fruitful; although she might challenge him, her particular manner of being would always provoke Peter, push him to expand his world: 
Brief, broken, often painful as their actual meetings had been what with his absences and interruptions [...] the effect of them on his life was immeasurable. There was a mystery about it. You were given a sharp, acute, uncomfortable grain - the actual meeting; horribly painful as often as not; yet in absence, in the most unlikely places, it would flower out, open, shed its scent, let you touch, taste, look about you, get the whole feel of it and understanding, after years of lying lost. Thus she had come to him; on board ship, in the Himalayas; suggested by the oddest things [...]. She had influenced him more than any person he had ever known (Woolf, Mrs. Dalloway 153).

Their relationship is so intense, their encounters so powerful, that Clarissa remains in Peter's mind even when she is not there. There is something about Clarissa that provokes Peter; her outlook, her words, and her very bearing demand an explanation; something about her may provide an answer; their conversations comprehend their situation, who they are; because of their conversations the world is understood more completely. In point of fact, this is the nature of dialogue and conversation; by way of the other, one's vision becomes clearer: "Self-understanding always occurs through understanding something other than the self, and includes the unity and integrity of the other" (Gadamer, Truth and Method 83).

This self-reflective, productive element of dialogue is illustrated when Peter contemplates attending Clarissa's party: Peter braces himself for the gathering, fully aware that he will undergo, once again, one of these painful yet exhilarating encounters with Clarissa. He is also mindful that he will be among scores of people, at a party, an environment in which individuals come together to celebrate togetherness and community. Peter is not a naturally social person, but he recognizes that parties have their value and worth. A light and mirthful event, one in which people have no obligations and 
feel no pressure, people might alight on topics that would not otherwise be approached; furthermore, it is a chance for people to meet who would not meet otherwise: a party's value is often surprising and unexpected; it is common to be inspired by this mixing, this jumbling together of personalities and differences. Frequently, one does not even know what one knows nor does one even make an effort to overcome mystery until enlightened or provoked by the right person: "For this is the truth about our soul, he thought, our self, who fish-like inhabits deeps seas and plies among obscurities threading her way between the boles of giant weeds, over sun-flickered spaces and on and on into the surface and sports on the wind-wrinkled waves; that is, has a positive need to brush, scrape, kindle herself, gossiping" (Woolf, Mrs. Dalloway 161). There is something about meeting different personalities and individuals that pushes one to go in entirely new and different directions; one feels the need to account for the other person and in doing so acquires a better sense for who one is; one also feels provoked to assert one's particular stance, to compare and contrast, to test one's horizon.

Peter recognizes the appeal of parties and he intuits that this party will matter, that he will have an experience. It is not just the possibility of seeing Clarissa that compels Peter, he also anticipates that he will experience beauty; but not just beauty, life in its entirety: people, space, eccentricities, sounds, all combining somehow, in harmony somehow, related somehow. All of it is significant, yet Peter also knows that this significance is incomplete - there, interesting, real, meaningful but forever questionable:

It was not beauty pure and simple-Bedford place leading into Russell Square. It was straightness and emptiness of course; the symmetry of a corridor; but it was also windows lit up, a piano, a gramophone sounding; a sense of pleasuremaking hidden, but now and again emerging when, through 
the uncurtained window, the window left open, one saw parties sitting over tables, young people slowly circling, conversations between men and women, maids idly looking out (a strange comment theirs, when work was done), stockings drying on top ledges, a parrot, a few plants. Absorbing, mysterious, of infinite richness, this life (Woolf, Mrs. Dalloway 163).

Peter wrestles with these contrasting impressions of life, aims to balance them: life is meaningful, harmonious, and symmetrical, yet within this order there is variability and difference; the understood itself branches into questions.

Like Clarissa, Peter contemplates the depth of life-its meaning and its mystery. He knows that there are no final answers but still believes that life is worth exploring and interrogating, that it might be more understandable if he participates in its meaning. But Peter is less tolerant than Clarissa, more exacting. As an emblem of his personality, Peter consistently brandishes his pocket knife and fiddles with it: "What an extraordinary habit that was, Clarissa thought; always playing with a knife. Always making one feel, too, frivolous; empty-minded; a mere silly chatterbox as he used" (Woolf, Mrs. Dalloway 44). As this habit would suggest, for Peter all of life's intricacies are worth exploring and this effort should be precisely executed; one should confront life's challenges with open eyes and controlled movements; one should be unrelenting and focused.

At times Peter can irritate Clarissa. He demands too much, needs too much. Despite his imperfections, Clarissa almost chose to marry Peter; she still wonders, even, if maybe she should have married him. As she weighs the positives and negatives of her life-decisions, Clarissa generally concludes that she was right to marry Richard instead of Peter. With Peter, she might have been happy but she almost might have been cowed by the more flinty elements of his personality_-his exactingness, his demands. With 
Richard, however, Clarissa feels that her life has turned out much smoother, easier, less dramatic; perhaps she might not experience as many moments of bliss as with Peter, but she also may have avoided innumerable moments of despair and frustration. For Richard encourages Clarissa to be herself, to do as she pleases, and to think as she chooses; he accepts her as she is, someone who prefers privacy, someone who recognizes that some things cannot or should not be shared: "And there is a dignity in people; a solitude; even between husband and wife a gulf; and that one must respect, thought Clarissa, watching him open the door; for one would not part with it oneself, or take it, against his will, from one's husband, without losing one's independence, one's self-respect—something, after all, priceless" (Woolf, Mrs. Dalloway 120). Although Peter might be essential to Clarissa's world and her horizon, his and Clarissa's interaction is not entirely positive; he might expand Clarissa's world, but, to a certain extent, he also distorts it. For his part, Richard might not inspire Clarissa to the same degree, but he is also more accepting and encouraging.

Certainly, Richard does respect and understand Clarissa's need for privacy, but it is also true that he, like Peter, does not entirely understand Clarissa's motivation for throwing parties. In the case of Richard, he worries about Clarissa's health, the toll the parties take, and, in Peter's case, he thinks that she cares more about rank and status, that she hosts parties to promote Richard's station and, by proxy, Clarissa's. This criticism rankles Clarissa and she feels the need to defend herself. She searches herself, attempting to understand why, exactly, she feels compelled to throw parties. First, she tells herself: "What she liked was simply life" (Woolf, Mrs. Dalloway 121). Then she elaborates: “They're an offering" (Woolf, Mrs. Dalloway 121). Now, Clarissa equates parties with 
life because these get-togethers represent a chance for people to share and communicate, to simply be among one another. When people gather, no one can anticipate the outcome. She throws parties as an offering to her friends and acquaintances, a gift to life itself, so that all might experience an increase in being. At a party, each attendee has an opportunity to renew or develop his or her bond with others, so that the world might be more understandable, so that each might feel more at peace:

But to go deeper, beneath what people said (and these judgments, how superficial, how fragmentary they are!) in her own mind now, what did it mean to her, this thing she called life? Oh, it was very queer. Here was So-and-so in South Kensington; some one up in Bayswater; and somebody else, say, in Mayfair. And she felt quite continuously a sense of their existence; and she felt what a waste; and she felt what a pity; and she felt if only they could be brought together; so she did it. And it was an offering; to combine, to create; but to whom? (Woolf, Mrs. Dalloway 122).

Woolf portrays Clarissa as a character with an acute sense for the essential dignity of her fellow beings. She recognizes that each has a special value, has something to offer. But Clarissa's friends and acquaintances are all submerged in his or her life, his or her world, working, eating, moving forward; and it is not easy to rouse oneself, to take time to connect, to visit with one's friends, to do something different, to break with routine. Clarissa feels moved to do her part to battle complacency by giving parties; in doing so she might spark her friends to go further, to connect with strangers or long-lost-friends, to consider what is or might be, to grow and evolve.

Clarissa feels the need to bring people together, to combine, to create; but what exactly is she creating? She is building a venue, an arena for people to learn from one another. Of course, people do not go to a party with the express intent of learning, but it 
is an implied aspect of all conversation. At a party, people very often feel liberated, freed to discuss topics that might not be considered otherwise, compelled to flit around, test and wonder. Frequently people wear special clothing to parties and find themselves in unusual situations with unusual people; such events are an escape from the routine and the mundane: "Every time she gave a party she had this feeling of being something not herself, and that every one was unreal in one way; much more real in another. It was, she thought, partly their clothes, partly being taken out of their ordinary ways, partly the background, it was possible to say things you couldn't say anyhow else, things that needed an effort; possible to go much deeper" (Woolf, Mrs. Dalloway 171). Liberated from one's daily routine, now in a situation where one might discuss questions that normally do not seem relevant, unexpected topics suddenly become important—at a new setting, with different people, the world suddenly seems different—and one feels the need to confront this difference.

Clarissa brings people together because each individual contains within him or her an infinite depth, a unique perspective that never becomes depleted. And when people share each becomes more. But even as one becomes more, one never entirely gains a firm handle on meaning; no matter how much one knows, there is something about the moment that destabilizes and unsettles; one's perception necessarily includes meaning, cannot help but find meaning, but this meaning does not blot out mystery; difference will never be entirely overcome - the world is always in motion, people always inscrutable: "that's the miracle, that's the mystery; that old lady, she meant, whom she could see going from chest of drawers to dressing-table. She could still see her. And the supreme mystery $[\ldots]$ was simply this: here was one room; there another. Did religion solve that, 
or love?" (Woolf, Mrs. Dalloway 127). No matter how much one understands or knows, one's concerns and circumstances determine meaning; something is understood, but the thing itself resists mastery, its implications infinite, belonging to the perception itself: "Is the given not in fact the result of an interpretation? It is interpretation that performs the never fully complete mediation between man and world, and to this extent the fact that we understand something as something is the sole actual immediacy and givenness" (Gadamer, "Text and Interpretation" 30). One inherits a world and it is based on this inheritance that one slowly adapts to its nature; it is up to each person to participate in its meaning and to nurture an understanding that recognizes the challenge and opportunity that one faces; if one embraces the opportunity then one might live in a world that inspires and vibrates with potential, the possibility of unity right there, within one's reach, even if it necessarily slips out of one's grasp. 


\section{CHAPTER 6}

\section{TO THE LIGHTHOUSE}

The story of the Ramsay family on vacation at their summer home and their houseguests, To the Lighthouse explores the sometimes-porous, sometimesinsurmountable borders that exist between individuals, the difference and affinity that represents both a challenge and an opportunity for understanding and growth. For in these characters we encounter individuals who are drawn to share their lives in community; who, despite their need to share, maintain their uniqueness, aware that their particular stake in the world is of special value. Each has his or her or own particular story and special way of seeing and understanding; when together, though, each becomes more; in sharing the world each might refine his or her viewpoint and discard his or her idiosyncrasies, those unexamined assumptions that inhibit understanding; furthermore, in sharing one might confirm and reinforce those assumptions—one's very horizon—-that promote truth and understanding. The principle characters of this novel are Lilly Briscoe, an amateur painter and houseguest of the family, and the matriarch and patriarch of the family, Mr. and Mrs. Ramsay, the father and mother of eight children, a philosopher and his generous-hearted, socially-attuned wife. Lilly, for her part, is infatuated with this family and all that it represents—in particular, she is obsessed with Mrs. Ramsay—her beauty, her instincts, her general way of being. In Lilly's mind, Mrs. Ramsay is a clue in her effort to understand, a central piece in the puzzle of meaning. As a central component 
in her effort to interpret, Lilly paints a portrait of Mrs. Ramsay as she reads to her son James: her aim is to represent in pictorial form the balance and unity within the family, a harmony that exists because its members directly confront and account for their differences. In producing her painting, Lilly's goal is to impose a form and structure on her understanding of this family and the world. In her attempt to paint, Lilly necessarily engages her perceptions and her sense of meaning; the painting only means anything as it relates to this family and the world, a collection of individuals who are willing to face the world with open eyes and participate in its creation. In particular, in Mr. and Mrs. Ramsay we encounter two characters who emphasize participation, who recognize the value of effort and engagement. A philosopher, Mr. Ramsay directly confronts the nature of reality and the meaningfulness of the world — he is someone who attempts to identify the mechanisms of each individual's interaction with the world and the implications therein. For her part, Mrs. Ramsay possesses a highly refined social instinct: she stresses the importance and value of one's interpersonal relationships — by way of these relationships one might approach a more refined notion of truth and understanding.

Undoubtedly, Mr. and Mrs. Ramsay are individuals with their own particular characteristics and interests. In the case of Mrs. Ramsay, she privileges those experiences where she connects and interacts with others. In this connection, and in this interaction, truth and improved understanding become more accessible: "Understanding or its failure is like an event that happens to us. Thus we can say that something was a good conversation or that it was ill-fated. All this shows that a conversation has a spirit of its own, and that the language in which it is conducted bears its own truth within it-i.e., that it allows something to 'emerge' which henceforth exists" (Gadamer, Truth and 
Method 385). In this instance, neither member of the interaction knows what it will yield, but that it will produce something valuable is the important point. As for Mr. Ramsay, his personality prefers isolation, concentration and interrogation. His aim is to understand the world for what it is, to abstract those factors and elements that belong to perception and meaning. This, of course, is central to his vocation — he is willing to plumb the depths, to question and consider; he might not reach a final answer, but in the effort he might contribute to improved understanding. Though Mr. Ramsay chooses to shoulder this burden, this responsibility belongs to everyone:

It is the world itself which is communicatively experienced and continuously entrusted (Traditur) to us as an infinitely open task. It is never the world as it was on its first day but as it has come down to us. Always present when we experience something, when unfamiliarity is overcome, where enlightenment, insight, and appropriation succeed, the hermeneutic process takes place in bringing something into words and into the common consciousness" (Gadamer, "Reflections on My Philosophical Journey" 29).

Indeed, Mr. and Mrs. Ramsay are central to the meaning of this novel. In the character of each and in the way that they mesh, one gleans that each depends on the other and the world becomes more understandable as a result of the other. But not all critics agree with this stance. For example, A.O. Frank argues that the two occupy a "basically binary scheme" (24). She contends that, on one end, lies Mr. Ramsay, aligned with professional philosophy, and, on the other, is Mrs. Ramsay, aligned with social instinct and creativity. To Frank, this binary is related to "the question of truth" (27). Frank goes on to flesh out her position: "The opposing claims come from professional philosophy on the one hand, and some at least quasi-artistic type of knowledge on the other. Thus it is Woolf who sets up an opposition between philosophy and art, dropping 
early hints that truth dwells in the latter and not the former, but this refers to one particular type of philosophy only" (27). In this case, the kind of philosophy Frank is referencing has to do with the type of philosophy that presents the world as an object and one reaches the truth of the object by way of method, a circumstance in which the subject discounts his or her role in the interpretation, so convinced of his or her sovereign subjectivity that he or she believes it can be entirely accounted for and included in one's understanding. But the reader does not know the specifics of Mr. Ramsay's philosophical stance. Sure, Mr. Ramsay may practice a type of philosophical thought that clashes with art, the social, and the personal, but that does not mean that he is completely alienated from truth or interpersonal fulfillment. Just because he is wrong in some ways, does not mean that he is wrong in all ways. That he is willing at all to question and probe the transaction between human being and the world is commendable and of value. Mrs. Ramsay loves and appreciates Mr. Ramsay for this particular characteristic, and Mr. Ramsay has the same feeling about his wife and her particular approach to life. Frank goes on to consider the philosophical implications of this binary and how they manifest themselves in the novel: "What we can know, how we know it and what are the conditions under which we live and know are the concern [of To the Lighthouse]. [...T] he question of knowledge is tied in with the question regarding the structure of the world or reality" (33). In this instance, I do not disagree with Frank, but I would argue that her binary scheme distorts and undermines the manner in which the novel enacts these considerations. To my mind, the entire novel hinges on the harmony and resonance - the accommodation of identity and difference - that takes place as the couple 
interacts; the world is more understandable and meaningful as the result of this interaction.

Divided into a tripartite structure, the action of this novel takes place within the space of two days, each divided by an interlude of ten years. During the first day, the family prepares to visit the lighthouse. This potential journey is important to the Ramsays' son James; only six years old, it represents an excursion into the possible, into the unknown, the light house right there, but still in the distance. For James, his very perception is filtered through his anticipation-whether or not they will go to the lighthouse. But they never reach the lighthouse, the weather prohibitive. Other events take place also: Mrs. Ramsay reads to her son James while Lilly paints a picture of the scene, and everyone gathers around the dinner table to share a meal. Then the day ends, and ten years pass. In this section, titled "Time Passes", the impersonality, power and savagery of time is highlighted; several members of the Ramsay family do not survive: Mrs. Ramsay, Prue (giving birth), and Andrew (in the war). Then, in the final section, the family and several of the same houseguests return to the vacation home, a place that reminds them of their loss, a place where they might heal, a means of resolving the past with the present. Furthermore, Mr. Ramsay and two of his children, his son James and his daughter Cam, decide to, at last, visit the lighthouse. In its structure, the first section (that day in which Lilly begins her painting, everyone shares a meal, and the trip to the lighthouse is still a possibility) frames the final section, another day ten years later, one that is very different because Mrs. Ramsay is no longer alive, nor James, nor Prue. On this day Lilly Briscoe finishes her painting and reaches resolution; Mr. Ramsay and James also reach their goal—-they successfully land at the lighthouse. 
These central characters attain resolution within the framework of time; so too their actions and thoughts take place within a world that is historically conditioned. Generally considered to be a high watermark of Modernism, To the Lighthouse directly addresses and reflects the concerns of its time and place (early twentieth Century Europe). Though it plays a mostly peripheral role, World War I is the historical event that is most decisive for understanding the context of this novel, as it was a symptom of larger historical, and societal conditions. For Hussey, in fact, Woolf's work is an attempt to expose the links between the personal and society at large: "all Woolf's work is deeply concerned with war; that it helps redefine our understanding of the nature of war; and that from her earliest to her final work she sought to explore and make clear the connections between private and public violence, between the domestic and the civic effects of patriarchal society, between male supremacy and the absence of peace, and between ethics and aesthetics" ("Living in a War Zone" 3). Overall, it is Woolf's aim to subvert the dominant paradigm of univocal objectivity and progress that led to war in the first place. For, in war, there is a deliberate elision of human dignity and value; people are seen as tools and instruments; the depth and significance of each individual is discounted. In her novels and, in particular, To the Lighthouse, Woolf succeeds in highlighting the supreme worth of each individual — the individual's unique and valuable purchase on the world. Furthermore, she suggests that it is through interacting and engaging with others that the world becomes more understandable and meaningful; that shared experience is an avenue to truth, that truth itself is a matter of engagement with the world and each other. So, it is Woolf's contention that every individual is unique and particular and this uniqueness is of special importance; through the combination of different individuals and 
personalities one might gain insight and the world might be more understandable.

According to Matthews and Platt, To the Lighthouse emphasizes the "differing senses of reality experienced by the characters" (570). Yes, this novel trumpets the potential and value contained within each person, an interpretive opportunity that is in direct opposition with the objectivity necessary for science and technology: "Inner domains modernism explores could sustain values and desires imperiled by the 'progress' of modernity and the recent war, obviously restoring, in particular, depth and significance to a sense of self much imperiled in a new machine age" (Stevenson 154). In each character, one does notice depth and significance, in each a sense of meaning that is variable and in movement as they combine and interact.

One such character is Lilly Briscoe, someone who is committed to understanding and truth. Toward this end, Lilly chooses to paint. Lilly's vocation as a painter also belongs to a larger historical context. At the time, art and painting were in the midst of a revolution: "Although there were many trends within this revolution, in painting and sculpture it generally meant a shift from an art that reflected the natural world to one rooted in the artist's inner vision, from an art based on representational or naturalistic images to one devoted to nonrepresentational or nonobjective forms, and from an art focused on content to one dedicated to the process of creation itself' (Matthews and Platt 542). Certainly, in her painting Lilly aims to represent her inner vision and she does so in a way that is nonrepresentational. For its part, Lilly's painting is an attempt to transfer into visual form her understanding of this family, this place, this moment—all as they relate to her understanding of the world, her very perceptions. In particular, Lilly fixates on Mrs. Ramsay. As Lilly attempts to finish her painting, she is inundated with emotion 
and feeling; Mrs. Ramsay's absence a spur, Lilly aims to comprehend her friend-her importance, her weight, her value. In many ways this painting is a tribute to Mrs. Ramsay. Mrs. Ramsay is so important to Lilly because her very presence and personality prompted Lilly to understand more and differently, to see the world with improved clarity; Lilly senses something very truthful about Mrs. Ramsay in the way she interacts with the world and those around her. For example, as Lilly attempts to complete her painting, she recalls a particular scene in which she, Mrs. Ramsay and Charles Tansley share an experience on the beach, a scene of unity and connection. Charles Tansley, for his part, is a difficult person who has endured a difficult life. So, as Lilly tries to paint, she recalls this particular moment on the beach, when she and Charles played together, skipping stones on the water, and Mrs. Ramsay watched them and wrote letters. Because Lilly and Charles were fond of Mrs. Ramsay, they were able to overcome their differences and share a moment that stayed in her memory, an instant when life seemed good and honest. To Lilly, it was as if the presence of Mrs. Ramsay had united Charles and herself, as if her presence made the world less complicated. To Lilly, this recollection, and the role played by Mrs. Ramsay, might be compared to a work of art:

That woman sitting there writing under the rock resolved everything into simplicity; made these angers, irritations fall off like old rags; she brought together this and that and then this, and so made out of that miserable silliness and spite (she and Charles squabbling, sparring, had been silly and spiteful) something - this scene on the beach, for example, this moment of friendship and liking - which survived, after all these years complete, so that she dipped into it to re-fashion her memory of him, and there it stayed in the mind affecting one almost like a work of art (Woolf, To the Lighthouse 160). 
Lilly equates this particular scene on the beach, this memory of her and Charles, with a work of art—and this comparison is vital. A work of art is something essential, something illuminating. It is deep and unfathomable. It is a means of insight. It is coherent, complete and entire, yet provocative. This moment and memory is like a work of art because in it there is a clue to understanding, insight and meaning. According to Gadamer, art is an essential means of self-confrontation, an opportunity to see in new and different ways:

Language signifies memory. Mnemosyne is, however, the mother of all the muses and so the patron of art. Artwhether picture, word, sound, song, or whatever its origin was or its present social function may be-means, in the final analysis, a way of confronting ourselves in which we become mindful of ourselves. In word as in picture, in petroglyph as in the song, and still in the refined and mediated forms of later literature, the world as a wholethe whole of our world experience- - has become present. And even the most silent forms of modern painting, which radiate a brooding silence, evoke in us the 'you are that.' Such an experience of the whole, in which we confront ourselves, occurs through the continual new-awakening of the echoing of art. In this lies the actual distinguishing characteristic of humans (Hans-Georg Gadamer on Education, Poetry, and History 90).

Somehow, she and Charles were able to enjoy each other's company on that day; something about that day and their interaction is exhilarating and meaningful, so much so that it is compared to a work of art. Despite their differences, despite their antagonism and antipathies, Lilly and Charles were able to connect, enjoy — this day, and the antipathy overcome, is of special value to Lilly. For once they were able to enjoy each other's company: people can find common ground after all. Mrs. Ramsay played a vital 
role: her presence and its significance united them. They were able to enjoy the day, share, learn, and grow, all because of Mrs. Ramsay.

Now, these thoughts occur to Lilly as she herself is painting, as she remembers Mrs. Ramsay, as she tries to understand why this woman is so important-how her absence is such an important presence. Mrs. Ramsay is gone, but her legacy remains strong, hovering over Lilly and the Ramsay family, as ubiquitous as oxygen. Someone who had an acute sense for the value of each individual, someone who recognized that people have much to offer, Mrs. Ramsay promoted tolerance, generosity, openness: people should be accepted as they are - it is worthwhile to share with each other, talk with each other - much can be gleaned. It is this stance, this attitude that Lilly particularly appreciates as she remembers Mrs. Ramsay and that specific memory of them on the beach: life should be enjoyed, appreciated - all one can do is what one can; to try, to accept mystery and challenge but still take the necessary step and leap forward. When Lilly remembers Mrs. Ramsay and her ability to resolve difference into acceptance, she compares this memory to a work of art and this thought leads Lilly into an even more general consideration: what is the meaning of life? With Mrs. Ramsay's absence so present, with this recollection of her and Charles in harmony despite their antagonisms, with this painting in front of her, Lilly is drawn towards this most general of all questions. It is a relevant question as she paints, as she considers the subject matter and how to express it visually. It is an applicable query as she tries to pin down Mrs. Ramsay, as she strives to understand who this woman was and why she means so much:

What is the meaning of life? That was all-a simple question; one that tended to close in on one with years. The great revelation had never come. The great revelation 
perhaps never did come. Instead there were daily little miracles, illuminations, matches struck unexpectedly in the dark; here was one. This, that, and the other; herself and Charles Tansley and the breaking wave; Mrs. Ramsay bringing them together; Mrs. Ramsay saying, 'Life stand still here'; Mrs. Ramsay making of the moment something permanent (as in another sphere Lilly herself tried to make of the moment something permanent) - this was of the nature of a revelation. In the midst of chaos there was shape; this eternal passing and flowing (she looked at the clouds going and the leaves shaking) was struck into stability (Woolf, To the Lighthouse 161).

Simply put, there is no final answer to Lilly's question, as each variant plays off each other, leading to further considerations, more caveats, more explanations, mystery surging forth as more is said. Yet there are moments when life seems understandable, when there is harmony and balance, when the different components fit the one with the other. In this instance, Lilly points toward shared experience as an essential clue: this scene on the beach when she felt at harmony with Charles Tansley and Mrs. Ramsay; that Mrs. Ramsay was able to resolve Lilly and Charles' differences, that her presence could be so impactful and powerful. To Lilly, there was something about Mrs. Ramsay that simplified the world; Mrs. Ramsay was cognizant of the value and meaning and opportunity of just such a moment — that a simple day and a simple activity such as relaxing on the beach could be so impactful; perhaps the inescapable mystery and eternal flux of existence includes understanding within itself, an access point, one that derives from shared experience and personal connection: "The nature of the hermeneutical experience is not that something is outside and desires admission. Rather, we are possessed by something and precisely by means of it we are opened up for the new, the different, the true" (Gadamer, "The Universality of the Hermeneutical Problem" 9). 
People are oriented to understanding and this orientation is decisive for all interaction: truth emerges as something unexpected; identity and difference blend together.

As Lilly attempts to paint her portrait of Mrs. Ramsay and James, she considers the Ramsay family and their friends. In many ways, this painting frames the entire novel. This novel is about the space between people, how this space is crucial to the nature of understanding and meaning: this painting comprehends these considerations also. So, as Lilly attempts to finish her painting, she does so with Mrs. Ramsay in mind, with meaning in mind. There is something in Lilly that recognizes the importance and value of these people and their interconnectedness: each is different, yet each is more because of their interactions, their undeniable connection. Lilly acknowledges that this connection is a source of understanding and fulfillment. It is her aim to mine this connection and present it in her artwork, to present it so that it is seen for what it is. This, according to Gadamer, is one of the primary functions of art: "In it we can see without any doubt that a picture is not a copy of a copied being, but is in ontological communion with what is copied. It is clear from this example that art, as a whole and in a universal sense, increases the picturability of being. Word and image are not mere imitative illustrations but allow what they present to be for the first time fully what it is" (Truth and Method 137). Lilly senses that within this family there is a feeling of completeness and it is this unity that she aims to represent in pictorial form: "She seemed to be standing up to her lips in some substance, to move and float and sink in it, yes, for these waters were unfathomably deep. Into them had spilled so many lives. The Ramsays'; the childrens'; and all sorts of waifs and strays of things besides. A washer-woman with her basket; a rook; a red-hot poker; the purples and grey-greens of flowers: some common feeling held 
the whole" (Woolf, To the Lighthouse 192). This family represents a model of love and feeling, of undeniable connection. Each makes an effort and does so in a way that acknowledges the provisionality of this effort; although one might misstep, each can rely on the knowledge that there below lies a safety net of affection and support; one might be uncertain, but not about these feelings: here is verification and corroboration, a sense that all uncertainty is shared, the world itself meaningful and uncertain all at once.

For it is this feeling of connection, of shared experience, that attracts Lilly. She recognizes that love and family and togetherness promote a sense of completeness: "It was some such feeling of completeness perhaps which, ten years ago, standing almost where she stood now, had made her say that she must be in love with the place" (Woolf, To the Lighthouse 192). It is this feeling of coherence and unity that Lilly aims to represent in her painting: "And as she dipped into the blue paint, she dipped too in the past there" (Woolf, To the Lighthouse 172). It is, of course, a nearly impossible task to represent this family — and Lilly's feeling about them — in her painting. But Lilly does have an idea of what she is trying to accomplish. She is attempting to represent completeness, harmony and balance. Also, too, the primary subject matter of her painting is Mrs. Ramsay as she reads to her son James. But Lilly does not attempt to represent mother and son realistically, instead she focuses on line and color-how they signify and represent balance. When Lilly explains to Mr. Bankes her artistic decisions, we get a better sense for her mission: "It was Mrs. Ramsay reading to James, she said. She knew his objection - that no one could tell it for a human shape. But she had made no attempt at likeness, she said. For what reason had she introduced them then? he asked. Why indeed? - except that if there, in that corner, it was bright, here, in this, she felt the need 
of darkness" (Woolf, To the Lighthouse 52). As Lilly engages with her painting she engages with balance and harmony: an order and unity that Lilly is drawn to and strives towards. For this reason Lilly chooses to paint: to engage her perception of the world and its meaningfulness. In transforming her perceptions into a meaningful structure, they might become more understandable and truthful: "Thus the concept of transformation characterizes the independent and superior mode of being of what we called structure. From this viewpoint 'reality' is defined as what is untransformed, and art as the raising up (Aufhebung) of this reality into its truth" (Gadamer, Truth and Method 112).Yes, by means of her painting, Lilly's perceptions are transformed into a meaningful structure and this structure comprehends unity and order: "art is present whenever a work succeeds in elevating what it is or represents to a new configuration, a new world of its own in miniature, a new order of unity in tension" (Gadamer, "Art and Imitation" 103). In point of fact, this emphasis on the meaningfulness of art and its ability to order the world and one's understanding of it constitutes an important attribute of Modernism as it responded to the trends of its time. At the time, there was a prevailing "mood of uncertainty produced by $[\ldots]$ the outbreak of World War I" (Fiero, 6: 30). With this uncertainty in mind, art was seen as an especially vital means of ordering and understanding the world: "Modernism is viewed as a kind of aesthetic heroism, which in the face of the chaos of the modern world (very much a 'fallen' world) sees art as the only dependable reality and as an ordering principle of a quasi-religious kind. The unity of art is supposedly a salvation from the shattered order of modern reality" (Eysteinsson 9).

Now, Lilly does not finish her painting during the first section of the novel, the first day, but it remains in her mind during the ten years that divide the novel. There is 
something about the painting that is so essential, so important and meaningful, that it stays with her as she participates in her day-to-day existence, jostling her, still a matter to be resolved:

There was something (she stood screwing up her little Chinese eyes in her small puckered face), something she remembered in the relation of those lines cutting across, slicing down, and in the mass of the hedge with its green cave of blues and browns, which had stayed in her mind; which had tied a knot in her mind so that at odds and ends of time, involuntarily, as she walked along the Brampton road, as she brushed her hair, she found herself painting that picture, passing her eye over it, and untying the knot in her imagination. But there was all the difference in the world between this planning airily away from the canvas, and actually taking her brush and making the first mark (Woolf, To the Lighthouse 157).

By means of this painting, Lilly might understand herself, how her personal narrative might be unified; she might approach coherence and continuity:

Self-understanding always occurs through understanding something other than the self, and includes the unity and integrity of the other. Since we meet the artwork in the world and encounter a world in the individual artwork, the work of art is not some alien universe in which we are magically transported for a time. Rather, we learn to understand ourselves in and through it, and this means that we sublate (aufheben) the discontinuity and atomism of isolated experiences in the continuity of our own existence (Gadamer, Truth and Method 83).

This painting, though, is a challenge that is rather indefinable, no true way to know when the painting has really been completed, when this knot has truly been untied. Nevertheless, Lilly is unwilling to ignore the mystery and uncertainty, the challenge of the painting; it is there, it remains, and no one but Lilly will finish it. It is her responsibility. In completing her painting, Lilly has the feeling that she will approach 
greater understanding, that she and the world will be closer together. This, according to Gadamer, is one of the primary functions of art - to recognize the world for what it is:

When I recognize someone or something, what I see is freed from the contingency of this or that moment of time. It is part of the process of recognition that we see things in terms of what is permanent and essential in them, unencumbered by the contingent circumstances in which they were seen before and are seen again. This is what constitutes recognition and contributes to the joy we take in imitation. For what imitation reveals is precisely the real essence of the thing" ("Art and Imitation" 99).

This painting represents a challenge to be confronted, one that is part of Lilly's very marrow, her essence, one that relates to any and all of her activities. But now, when it is time to finish, Lilly also recognizes the high stakes, the practical realities. For one might have a general sense of what needs to be done, but when it comes time to do the actual painting, the practicalities become overwhelming; there are so many possibilities; in the doing, though, the limitations become more noticeable too. Lilly cannot instantaneously change who she is: she already has a style, a way of being, which determines what appears on the canvas. It is Lilly's task to fully harness the positives of her style and personality, to use them to her advantage — instead of obstacles, aids. All Lilly can do is make the leap, participate:

For a moment it stayed trembling in a painful but exciting ecstasy in the air. Where to begin? - that was the question at what point to make the first mark? One line placed on the canvas committed her to innumerable risks, to frequent and irrevocable decisions. All that in idea seemed simple became in practice immediately complex; as the waves shape themselves symmetrically from the cliff top, but to the swimmer among them are divided by steep gulfs, and foaming crests. Still the risk must be run; the mark made (Woolf, To the Lighthouse 157). 
Lilly is fully aware that each decision, each brushstroke changes the nature of the entire picture, that possibility becomes something else as she paints, that the success of her painting requires her to respond and react, to revise and amend as she moves forward. In this effort, of course, there is a distinct parallel between the sense of possibility inherent in both art and life: there are nothing but decisions and actions and, once done, there is no turning back. At this point all one can do is incorporate and account for these decisions and move forward, to do so in a way that unifies. In all cases, there is no escaping one's situation and circumstance, yet within each person there is a sense of limitless possibility—art is a means of engaging this tension:

Amidst the variety of art, this same message of the whole addresses us over and over again. Indeed, this seems to provide a more precise answer concerning the significance of art and beauty. This means that in any encounter with art, it is not the particular, but rather the totality of the experienceable world, man's ontological place in it, and above all his finitude before that which transcends him, that is brought to experience (Gadamer, The Relevance of the Beautiful 32-3).

In participating in art one is attempting to identify and share in generalities and universalities: everyone perceives and this perception is meaningful; by means of participation in art one might resolve and unify and share in what one sees. It is an effort to discover essence, to achieve balance and unity, to represent the world for what it is: "The concept of imitation can be used to describe the play of art only if one keeps in mind the cognitive import of imitation. The thing presented is there (Das Dargestellte ist da). That is the situation basic to imitation. When a person imitates something, he allows what he knows to exist and to exist in the way that he knows it" (Gadamer, Truth and Method 113). This is Lilly's aim, to represent the world in a way that reveals its 
underlying structure, those shared experiences of perception that undergird the meaning of the world:

She took up once more her old painting position with the dim eyes and the absent-minded manner, subduing all her impressions as a woman to something much more general; becoming once more under the power of that vision which she had seen so clearly once and must now grope for among hedges and houses and mothers and children-her picture. It was a question, she remembered, how to connect this mass on the right hand with that on the left. She might do it by bringing the line of the branch across so; or break the vacancy in the foreground by an object (James perhaps) so. But the danger was that by doing that the unity of the whole might be broken (Woolf, To the Lighthouse 53).

As Lilly attempts to represent the world as she knows it to be, it is an attempt that does not allow for verification. Instead it is the structural whole that is decisive, the one and only criteria that matters. As one takes action to balance out the painting - or life - then that very act changes the nature of the whole; a response is required to unify - and then another-and then another.

Overall, it is Lilly's mission to commune with the world, to represent her impression, her perception of the world and its visual meaning. For Lilly appreciates the meaning and mystery of what she sees. Perception includes meaning but Lilly also knows that this meaning is incomplete, that it depends on her to flesh out its body and identity. In doing so she might approach a closer correspondence between her perception of a thing and its meaning in her life: "What was the problem then? She must try to get hold of something that evaded her. It evaded her when she thought of Mrs. Ramsay; it evaded her when she thought of her picture. Phrases came. Visions came. Beautiful pictures. Beautiful phrases. But what she wished to get hold of was that very jar on the nerves, the 
thing itself before it has been made anything" (Woolf, To the Lighthouse 193). The thing itself, of course, depends on the perceiver; each thing is different based on the person who sees it. Lilly, for her part, accepts the provocative thrust of the world as what it is: the world means infinitely and variously; its meaning belongs to her interaction with it. It is Lilly's aim to plumb this interaction, to mine her feelings and impressions so that the world is represented as she feels it, to represent the world as she has experienced it. This accent on perception, in fact, is a predominant characteristic of Modernism. According to Eysteinsson, "Modernism is felt to signal a radical 'inward turn"” (26). This turn to subjectivity constituted "a revolt against the traditional relation of the subject to the outside world" (Eysteinsson 28). Traditionally, this relation to the outside world accepted that the world was the same for everyone and it was up to the individual to discover its essence, its eternal truth. The Modernists responded by demonstrating the variability of the subject and the moment, with truth itself contingent on this variability.

For it is Lilly's goal to bring her world to appearance, so that she understands it for what it is and so that it might be shared. Visually, the world is nothing but a series of appearances, but these appearances include an infinite depth and meaningfulness. That is, the meaning of each appearance is infinite and variable, yet these appearances are communicable and subject to dialogue, the meaning there to be chiseled even as it resists total mastery: "The play of art as appearance is played out between us. The one takes the creation simply as a creation, just as the other does. Communication takes place when the other person takes part in what is imparted to him — and in such a way that he does not, as it were, only receive in part what is communicated to him, but shares in this knowledge of the whole matter that is fully possessed by both of them" (Gadamer, "The Play of Art" 
128). These appearances are meaningful, but it is not until one engages with this meaningfulness that they acquire a more definite identity and understandability. In painting, one engages with these appearances and by doing so one approaches essence, the manner in which the meaningfulness of the visual is shared and understood. It is this shared visual experience that Lilly mines: "Here she was again, she thought, stepping back to look at it, drawn out of gossip, out of living, out of community with people into the presence of this formidable enemy of hers-this other thing, this truth, this reality, which suddenly laid hands on her, emerged stark at the back of appearances and commanded her attention" (Woolf, To the Lighthouse 158). For Lilly, painting is an avenue to truth, in that she engages with her perception of the world and this perception becomes something definite and real, something that demands that she account for absolutely everything, something that makes perception itself both more meaningful and understandable.

Lilly is vital to the meaning of this narrative, but she is not the only character who lies at its heart. Mrs. Ramsay is central too. Lilly's painting concerns Mrs. Ramsay—her huge presence in the first section, her gaping absence in the final section. The mother of eight children and the wife of a philosopher, Mrs. Ramsay has chosen to nest in the heart of life. Beautiful, she is used to people wanting her and needing her and praising her, offering her tributes; she is used to people listening to what she says and obeying what she says. Her beauty and heartfelt personality gives her access to the intimate concerns of her friends and loved ones—-she is convincing in her charm and grace, her straightforward simplicity. People are drawn to trust her and need her. For her part, Mrs. Ramsay is drawn to share with and influence those around her: it is in her nature to help 
and care. More than just being helpful, Mrs. Ramsay's transaction with the world is truthful and honest - it is her instinct to understand the plight of those around her and to acknowledge that it is something universal, a burden that might be eased when shared. For example, the reader gets a sense for Mrs. Ramsay's character when the narrative discusses her ability to empathize with "stories of great passion, of love foiled, of ambition thwarted" (Woolf, To the Lighthouse 29). Although she might not have undergone these experiences to the same degree of intensity, she is still able to identify with and understand them, at home with people and the vicissitudes of life. Part of Mrs. Ramsay's character is an awareness of the difficulty and challenge inherent in living: part of life is disappointment - it is unavoidable. To grow up, to learn and have experiences also means that one's horizon and expectations are refuted: "Every experience worthy of the name thwarts an expectation" (Gadamer, Truth and Method 350). It is her ability to comprehend people's shared plight that endears her to others: "She knew then-she knew without having learnt. Her simplicity fathomed what clever people falsified. Her singleness of mind made her drop plumb like a stone, alight exact as a bird, gave her, naturally, this swoop and fall of upon truth which delighted, eased, sustained-falsely perhaps" (Woolf, To the Lighthouse 29). Mrs. Ramsay is so simple and capable of understanding the world as it is because she trusts her instincts - that, when shared, the world is more understandable.

It is Mrs. Ramsay's nature to share with others; so too it is her nature to act, to do. Instead of just talking about the need to help others, she acts. In this action she is at home, comfortable, where she belongs. When helping, when sharing, she is most herself: "She never talked of it - she went punctually, directly. It was her instinct to go, an 
instinct like the swallows for the south, the artichokes for the sun, turning her infallibly to the human race, making her nest in its heart" (Woolf, To the Lighthouse 196). This instinct, for its part, is Mrs. Ramsay's primary tool for understanding. It is an approach to life that is foreign to Lilly but one that she appreciates. Lilly has her own personality and approach—one that starkly contrasts with Mrs. Ramsay—but Lilly sees that Mrs. Ramsay is successful, that her approach allows her to know the world as it is: "did she lock up within her some secret which certainly Lilly believed people must have for the world to go on at all? Everyone could not be as helter skelter, hand to mouth as she was. But if they knew, could they tell one what they knew?" (Woolf, To the Lighthouse 57). Lilly senses that Mrs. Ramsay has figured things out. Of course, no one ever fully understands everything, but Lilly feels that Mrs. Ramsay has come closer to truth, that she understands better than most. However, this sort of knowledge is difficult to relay: a secret, it is something that is so central, so vital, that one is not aware of it—something that shapes who and what somebody understands and who and what somebody is. Sure, one can try to communicate the identity of one's platform, one's horizon, but the words are bound to miss the mark, the width and depth and simultaneity always outpacing one's ability to express it. This concept that one can never truly know oneself or express all that one knows resonates with the concerns of Modernism. The Modernists acknowledged that this aspect of the self was decisive and decided to explore its contours: "As writers lost confidence in their perception and grasp of things outside man's consciousnessfeeling that they hardly knew themselves, much less anything outside themselves - they inevitably turned inward to that consciousness for their subject matter" (Beja 47). In the characterization of Mrs. Ramsay and Lilly's desire to unlock her friend's interior, one can 
notice this highlighting of the self, this stress on what and how one understands, whether it be one's limitations or one's possibilities.

Lilly is drawn to Mrs. Ramsay. Mrs. Ramsay's sense for truth attracts Lilly; when Lilly is attempting to finish her painting, she returns again and again to Mrs. Ramsay. She recalls several scenes in which she and Mrs. Ramsay are together. In one, Lilly has her arms around Mrs. Ramsay's knees, to get as "close as she could get" (Woolf, To the Lighthouse 50). Lilly wishes she could truly understand Mrs. Ramsay: "she imagined how in the chambers of the mind and heart of the woman who was, physically, touching her, were stood, like the treasures in the tombs of the kings, tablets bearing sacred inscriptions, which if one could spell them out, would teach one everything, but they would never be offered openly, never made public" (Woolf, To the Lighthouse 51). Lilly intuits that Mrs. Ramsay holds a key to understanding and that if she could possess it then she would understand. But complete understanding cannot be shared nor gained, the intricacies too knotted, the view too one-sided. However, one can refine one's understanding and improve. Through dialogue, one can expand one's horizon, approach the world with improved clarity: "when we speak to one another we do not so much transmit well-defined facts, as place our own aspirations and knowledge into a broader and richer horizon through dialogue with the other" (Gadamer, "On the Contribution of Poetry to the Search for Truth" 106). In this context, the emotional component of this interaction should not be discounted: caring for someone is a crucial step towards understanding. Strong feelings are commonly a fount of inspiration —one is suddenly able to see from the other's point of view and the world is both unified and corroborated: "Could loving, as people called it, make her and Mrs. Ramsay one? for it was not 
knowledge but unity that she desired, not inscriptions on tablets, nothing that could be written in any language known to men, but intimacy itself, which is knowledge, she had thought, leaning her head on Mrs. Ramsay's knee" (Woolf, To the Lighthouse 51). In the relationship between Mrs. Ramsay and Lilly we get a sense for the value and importance of closeness, of intimacy. Together, close, ready to share, the two seek something that can only be found in the interaction. Neither pursues something specific; instead each flowers when in the presence of the other-narrowness and bias, one's self-doubt- these evaporate in this intimacy. Despite individual particularities and differences, each has a world and it is this shared experience that shapes the dialogue, allowing it to illuminate truth and refute falsehood: "Most astonishing about the essence of language and conversation is that I myself am not restricted by what I believe when I speak with others about something, that no one of us embraces the whole truth within his beliefs but that the whole truth can, however, embrace us both in our individual beliefs" (Gadamer, "What is Truth?" 46). It is an interaction that pushes the individual to account for the presence of the other; it is a dynamic that is neither conscious nor difficult: the world glows, backlit from within, effortlessly illuminated. Stabilized by this platform of intimacy and feeling, one might take risks, experiment, always aware that this platform will cradle and support. Furthermore, because of this connection, one is pushed to explore: the difference of the other a spark that flames into language, into understanding. Indeed, Lilly recognizes the value of sharing, of intimacy and human connection, and so does Mrs. Ramsay. It is this feeling of community that Mrs. Ramsay promotes above all others. The dinner scene is a good example of this effort. More will be said about this scene, but, for the moment, Mrs. Ramsay's contribution to the success of this 
dinner is most relevant. She is the heartbeat of this summer home and everyone connected to it. Her social instinct, her sense for the value and importance of human individuality — and connection — means that she is the social and emotional puppet master. In many respects, she is the thread that connects everyone: "Nothing seemed to have merged. They all sat separate. And the whole of the effort of merging and flowing and creating rested on her" (Woolf, To the Lighthouse 83). It is not an easy task, but it is her identity to bring people together. This characteristic helps explain why she is so valued, why she is viewed as exceptional, supremely wise, at home with truth and understanding, a willing participant in the meaning of the world. And it is this reputation that enables her to influence her friends and family so noticeably: they trust her instincts, her sense for truth, her implicit knowledge that she knows the right path, the right decision. And it is Mrs. Ramsay's influence that persuades Paul Rayley and Minta Doyle to marry. Mrs. Ramsay does not openly persuade them to marry, but her very personality embodies the argument without saying a word; in Mrs. Ramsay they cannot but notice the value of marriage and human connection. For Minta and Paul, Mrs. Ramsay is a model to emulate; her very presence suggests that marriage and love are possible and even appealing: "They would, she thought, going on again, however long they lived, come back to this night; this moon; this wind; this house: and to her too. It flattered her, where she was most susceptible of flattery, to think how, wound about their hearts, however long they lived she would be woven" (Woolf, To the Lighthouse 113).

For her part, Mrs. Ramsay is neither a poet nor a philosopher. It is not her life's task to engage with — understand and interpret — the primordial phenomena of the world. But she does not completely ignore the value of intellectual and creative engagement. She 
is not a laser beam of focus and intensity, but she is still drawn to language, to textuality, to the rhythm and musicality, the mystery and disclosure of poetry. As when, after dinner, she alights in the study, joins her husband, and picks a book of poetry randomly, opens it randomly, and reads what is there. There is something about the balance, the rhythm, the capacity to evoke, the imaging of the world, that settles Mrs. Ramsay: the world can be understandable and ordered — it can be beautiful and complete. Although her life is filled with frayed edges and unanswerable questions, it can be corralled and contained; mystery can be accounted for, included, part of the very meaning; life can be put into language and made understandable. For Mrs. Ramsay reads a sonnet and in this reading acquires a feeling of completeness; a sensation that stems from her participation, a unity that is her responsibility: "So reading she was ascending, she felt, on to the top, on to the summit. How satisfying! How restful! All the odds and ends of the day stuck to this magnet; her mind felt swept, felt clean. And then there it was, suddenly entire; she held it in her hand, beautiful and reasonable, clear and complete, the essence sucked out of life and held rounded here- - the sonnet" (Woolf, To the Lighthouse 121). The words of the sonnet are only understandable as they relate to Mrs. Ramsay's perceptions; in the reading she is reminded of what she sees and understands; but, instead of a series of fragmented impressions, in the sonnet she discovers order and balance, a feeling of resolution that is transferred to her life and all that it might be. In Gadamer's philosophical outlook poetry is a means of confronting one's familiarity with the world:

When we grow up in a language, the world is brought close to us and comes to acquire a certain stability. Language always furnishes the fundamental articulations that guide our understanding of the world. It belongs to the nature of familiarity with the world that whenever we exchange 
words with one another, we share the world. The word of the poet does not simply continue this process of

Einhausung, or 'making ourselves at home.' Instead it stands over against this process like a mirror held up to it. But what appears in the mirror is not the world, nor this or that thing in the world, but rather this nearness or familiarity in which we stand for a while. This standing and this nearness find permanence in the language of literature and, most perfectly, in the poem ("On the Contribution of Poetry to the Search for Truth" 115).

In engaging with a poem, one has the opportunity to enact order and meaning, as all the words belong and relate to a meaningful whole. One gains insight and understanding because one relates the unity of the poem to the potential unity of life. The Modernists, for their part, were particularly enamored with art and literature's ability to provide order where otherwise there was chaos: "the modernists were convinced that they could impose an order on the seeming randomness, and meaninglessness of human of human existence” (Matthews and Platt 570).

In addition to Lilly and Mrs. Ramsay, Mr. Ramsay is vital to the meaning of this novel. A philosopher, he is intensely engaged with meaning, the transaction that occurs between the individual and the world. For its part, Mr. Ramsay's philosophical engagement also belongs to a historical moment, a philosophical climate that was rapidly changing. This change might be described as "a late nineteenth-century turn in philosophy from describing the world to an investigation of its 'conditions of possibility, to 'formulating an experience of the world, a contact with the world which precedes all thought about the world"” (Hussey, "Woolf: After Lives" 20). Though his philosophical position is never outlined, it is within this climate that Mr. Ramsay philosophizes. His task is to question and probe, to consider all of those factors that contribute to meaning, 
an amalgamation of factors that elude and morph as they mesh and combine. For his part, Mr. Ramsay is defined by the intensity of this effort: to approach life and all of its complexities; to discover what is common, what we all share- this is his responsibility and it is very difficult, a supreme challenge. But this is his life's work and he is committed. Certainly the weight and challenge of his effort renders him surly and frustrated, the answer never entirely clear, the complexity too knotted. In all, though, the effort is worthwhile: despite the ever-extending horizon, his work does contribute to improved understanding; the texture becomes stronger, the weave tighter; illusion and false understanding are sidestepped and truth embraced. In point of fact, to a considerable degree, Mr. Ramsay's concerns resonate with the subject matter of this very project: he too considers "Subject and object and the nature of reality" (Woolf, To the Lighthouse 23). In Gadamer's case, he argues for the indivisibility between the world as it is perceived and named and the world as it is: "We are simply following an internal necessity of the thing itself if we go beyond the idea of the object and objectivity of understanding toward the idea that subject and object belong together" (Truth and Method 457). Now, these considerations are foreign to the other characters of this novel, but they sense that his work matters. Lilly, for example, acknowledges his contribution: that the ephemeral, multi-colored world might be reduced to essence, the extraneous and superfluous discarded. As an emblem of his work, Lilly is told to think of a kitchen table when she is not there. Lilly marvels that Mr. Ramsay is able to reduce perception to something so bare and geometric. She notices that he is exceptional, different: "Naturally, if one's days were passed in this seeing of angular essences, this reducing of lovely evenings, with all of their flamingo clouds and blue and silver to a white deal four-legged 
table (and it was a mark of the finest minds so to do), naturally one could not be judged like an ordinary person" (Woolf, To the Lighthouse 23). Undoubtedly, Mr. Ramsay is different than most, a man who is willing to approach life's most difficult questions, a man who doggedly hunts for truth and abhors falsehood.

But Mr. Ramsay's outlook and effort includes collateral damage. His instinct for the thoughts and feelings of others is stunted. His primary concern is truth, never mind the consequences. He is blunt to a fault, even with his children. At the opening of this novel, the reader gets a sense for Mr. Ramsay's heartlessness. At this point, husband and wife discuss with their son James if he will be able to go to the lighthouse tomorrow. Mrs. Ramsay says that it might be possible - the weather could be mild. Mr. Ramsay says that it definitely will not be possible, a storm on the horizon. Both are right in their own way. For Mrs. Ramsay, the weather could change, necessarily unpredictable; for Mr. Ramsay, meteorology is a science, objectively predictable. To Mr. Ramsay, planning for a trip that will surely not happen is silly and foolhardy, a bad example for his son. For Mrs. Ramsay, the possibility of the trip should be maintained, James' very mood dependent on the prospect of this trip. Mrs. Ramsay would like to encourage James' sense of hope and possibility: the trip, after all, might happen. But Mr. Ramsay would prefer James to confront life as it is, harsh and uncompromising: "What he said was true. It was always true. He was incapable of untruth; never tampered with a fact; never altered a disagreeable word to suit the pleasure or convenience of any mortal being, least of all his own children, who, sprung from his loins, should be aware from childhood that life is difficult; facts uncompromising" (Woolf, To the Lighthouse 4). Yes, "life is difficult", but, as readers, we get a sense that Mr. Ramsay is too rigid in his principles; sure, parents 
should prepare their children for the challenges of the world; at the same time, however, parents should encourage their children, protect and promote their sense of hope and wonder. When the world is presented so bleakly, children might not feel motivated to participate, might feel overwhelmed and choose to withdraw. Furthermore, in his absolutism we see a lack of consideration for context and audience. To seek truth with such intensity is honorable, but to do so in a manner that is rigid or inflexible could also obscure truth, too unreceptive to the nuances of the moment and its demands. The importance of this adaptability is one of Gadamer's primary concerns: "Every interpretation has to adapt itself to the hermeneutical situation to which it belongs" ("On the Contribution of Poetry to the Search for Truth" 112).

Regarding Mr. Ramsay's character, the novel seems to maintain an attitude of ambivalence. On one side, he should be commended for his effort and his willingness to confront life's most difficult and challenging questions; he wants nothing more than to understand. On the other, his consideration of these questions seems to discount the moment, the context, and the participation of the individual, as if one could arrive at a final answer that explains everything. Too often Mr. Ramsay fails to include his own participation in the thing being understood; this inclusion is one of Gadamer's primary directives: "In all understanding an application occurs, such that the person who is understanding is himself or herself right there in the understood meaning. He or she belongs to the subject matter that he or she is understanding" (Gadamer in Conversation 47). Because he seems to view the world as something that can be objectively understood, Mr. Ramsay seems to believe that he can arrive at a final answer. This is his ultimate goal and he is willing to strain himself to the utmost in order to reach it. As an 
emblem of his effort, the novel presents his philosophical thought as if it were sequential—once one problem is solved then on to the next, until there are no more problems, the world fully mapped — as if each problem was like a letter of the alphabetif one can recite all of the letters then one has conquered the entirety of mystery. In this scheme, Mr. Ramsay has reached Q, has gone farther than most everyone else. Now he is on to $\mathrm{R}$, but is unable to nail it down. It is his life's goal, his supreme priority, willing to work himself until nothing is left: "Qualities that would have saved a ship's company exposed on a broiling sea with six biscuits and a flask of water-endurance and justice, foresight, devotion, skill, came to his help. R is then—what is R?" (Woolf, To the Lighthouse 34). Mr. Ramsay is committed, willing to endure discomfort and pain, prepared to sacrifice for his goal. But no matter how much he tries, he cannot overcome his limitations - life remains mysterious, the world a question. According to Gadamer, the world will forever remain questionable, as all understanding is limited and more can always be said: "Nothing that is said has its truth simply in itself, but refers instead backwards and forward to what is unsaid" (Man and Language 67). But Mr. Ramsay should be commended for his effort: despite his shortcomings, he is willing to try, to take on the responsibility of understanding, of contemplating something that is bound to frustrate, cannot but frustrate.

For this effort requires a willingness to go deep, to discard irrelevancies, to concentrate one's thought to the point of essence, to recognize scope, to place oneself and others in proper context. To do so, of course, is to acknowledge one's smallness, the world and understanding ultimately unfathomable; to accept one's place, to account for it and to consider the implications - these are his concerns. Overall, his aim is to confront 
understanding: "It was his power, his gift, suddenly to shed all superfluities, to shrink and diminish so that he looked barer and felt sparer, even physically, yet lost none of his intensity of mind, and so to stand on this little ledge facing the dark of human ignorance, how we know nothing and the sea eats away the ground we stand on - that was his fate, his gift" (Woolf, To the Lighthouse 44). Mr. Ramsay only wants to think about those transactions between the individual and the world that are most essential, transactions that are necessarily limited but, at the same time, are most potent because of these limitations. This notion that human understanding and human reason are limited are characteristic of Modernism. It was a time when many began to refute "the precept that human reason governs human behavior" (Fiero, 6: 27). It was also an era when there was "a loss of confidence in moral absolutes" (Fiero, 6: 69). The subject was no longer seen to be in control of his or her self, subject to contradictory thoughts and feelings, and there was no certainty about good or bad either; the limitations of the human subject began to acquire greater weight — how to account for them and incorporate them into one's understanding.

However ambitious Mr. Ramsay might be, however willing to pursue the most difficult challenges, he is able to do so because he has the support of his wife. She is his beacon of light should he lose his way. It is because she believes in him that he is able to take risks; it is because she loves him that the world is worth exploring: "If he put implicit faith in her, nothing should hurt him; however deep he buried himself or climbed high, not for a second should he find himself without her" (Woolf, To the Lighthouse 38). Mrs. Ramsay is willing to sacrifice for her husband, to spend her energy in a way that sustains and nourishes him. But their relationship is not a one-way street either. Mr. 
Ramsay also sustains and nourishes Mrs. Ramsay. During the dinner scene, for example, the group discusses fishermen and their wages and Mrs. Ramsay yearns for her husband to comment on the topic. To her, he is wise and knowledgeable, capable of illuminating the topic in a way that makes it both interesting and important: "One word, she said to herself. For if he said a thing, it would make all the difference. He went to the heart of things. He cared about fishermen and their wages. He could not sleep for thinking of them. It was altogether different when he spoke; one did not feel then, pray heaven you don't see how little I care, because one did care" (Woolf, To the Lighthouse 95). The two, then, are a team, each giving something to the other, something missing but needed.

Mr. and Mrs. Ramsay are very different, but, when combined, create something new that is better than the sum of its parts, each depending on the other, each inspiring the other. Each compensates for the limitations of the other, as when Mr. Ramsay needs reassurance and love or Mrs. Ramsay needs precision and accuracy—upon interacting, they produce "successful creation", their relationship so alive it has a pulse: "Every throb of this pulse seemed, as he walked away, to enclose her and her husband, and to give to each that solace which two different notes, one high, one low, struck together, seem to give to each other as they combine" (Woolf, To the Lighthouse 38-9). In the interaction, in the other, there is balm and relief, a resonance that soothes. In the marriage the two become more; in the particular character of the other, each a feeling of corroboration and a challenge. In general, there is a sense of shared perception, of looking at the same thing: "So that is marriage, Lilly thought, a man and a woman looking at a girl throwing a ball" (Woolf, To the Lighthouse 72). Marriage represents a chance to share, to belong to the 
same world, to partake in the meaningfulness of perception. No matter their differences, this sharing fulfills, sustains, allows each to be more confident in his or her individuality. In marriage the world is shared and in this sharing there is a chance to transcend one's individuality and limitedness; one's partner sees what one does not see, one's blind spots become more visible. In the interaction, one becomes more, but part of this interaction includes friction, an immitigable difference; this difference can never be truly overcome: "it was painful to be reminded of the inadequacy of human relationships, that the most perfect was flawed" (Woolf, To the Lighthouse 40). All human relationships are imperfect because of the primacy of individuality — the differences are patent: "To be this and not that constitutes the determinacy of all beings" (Gadamer, Truth and Method 442). Differences can never entirely be overcome. Each person sees and understands from a particular horizon: "The infinite perfectibility of the human experience of the world means that, whatever language we use, we never succeed in seeing anything but an ever more extended aspect, a 'view' of the world" (Gadamer, Truth and Method 444). The particularities are ingrained, but one can choose to be generous, one can choose to give. Instead of fixating on the differences as something to be overcome, they can be celebrated, they can be seen as an opportunity. In the case of the Ramsays, there are certainly many differences, yet each chooses to embrace the other without hesitation; love is intangible, inexpressible, something that occurs between two people in a way that is entirely unique and unrepeatable; every moment, every instance, every interaction has its own identity, requiring its own particular approach. So, when Mr. and Mrs. Ramsay find themselves together at the end of the day, the two discuss the day, the dinner, and two of their houseguests, the newly engaged couple, Paul Rayley and Minta Doyle. This 
engagement leads the Ramsays to think about their own marriage - its nature, what each means the one to the other. At this moment Mr. Ramsay wants his wife to tell him that she loves him, something - the book hints — that he requests rather often. But Mrs. Ramsay distrusts the verbalization of her feelings, scared that the words will not capture her true feelings, preferring to express her feelings with action. But between them there is a concord, a sense for the thoughts and feelings for the other without them ever being said. This concord is unique to their marriage and to their history: they are able to communicate wordlessly, in their own nonverbal language. So, Mrs. Ramsay chooses not to express her love with words, yet she successfully relays the message — she loves him so much that she does not even need to say it: "And she looked at him smiling. For she had triumphed again. She had not said: yet he knew" (Woolf, To the Lighthouse 124). Their love is unique: a shared feeling that is indecipherable to anyone but the couple, an interaction with its own special language, reliant on nobody else, vindicated by the only people that matter.

In addition to Lilly and the Ramsay couple, the Ramsay children are vital to the impact and meaning of this novel. In particular, James and Cam stand out. After all, the two, along with their father, finally reach the lighthouse, ten years after their initial effort. We first meet James and Cam when they are six and seven years old respectively. Fresh and new to life, James hinges all of his hopes and dreams on this trip to the lighthouse. To him, somehow, it represents a daring expedition, a chance to explore the unknown and reach a far-away goal. This failed trip stays in James' mind, a symbol for life: one sets a goal and one is thwarted. It is no one's fault, but disappointment and pain are inevitable. James imagines a particular scene to illustrate this thought: "Suppose then that as a child 
sitting helpless in a perambulator, or on some one's knee, he had seen a wagon crush ignorantly and innocently, some one's foot? Suppose he had seen the foot first, in the grass, smooth, and whole; then the wheel; and the same foot, purple, crushed. But the wheel was innocent" (Woolf, To the Lighthouse 185). One is bound to be disappointed, overcome, stymied, and it is no one's fault. Part of what it means to live is to suffer: "What a man has to learn through suffering is not this or that particular thing, but insight into the limitations of humanity" (Gadamer, Truth and Method 351). All one can do is accept this reality, live with it, move forward, respond and react accordingly.

James was disappointed as a child and this disappointment informs his outlook as an adolescent. In the end, he does reach the lighthouse, even if he is no longer enthusiastic about the prospect. Nevertheless, in this long-delayed trip he is compelled to revisit the seeds of his pessimism and gloominess. Back when he was a child, the lighthouse represented possibility, mystery; ten years later it is something material, practical. James realizes that the lighthouse represents many things: "For nothing was simply one thing" (Woolf, To the Lighthouse 186). When, in the end, James finally alights at the lighthouse, he describes it as "stark" and "bare" (Woolf, To the Lighthouse 203). He compares it to his own life: "It confirmed some obscure feeling of his about his own character" (Woolf, To the Lighthouse 203). Having finally made it the lighthouse, James accepts and confronts life as it is: it brims with adversity and challenges; though alone and bereft, one stands tall, endures, and cherishes those moments of joy that are even more special because nothing is guaranteed.

Aside from James, Cam and Nancy also play an important role in the narrative. To a considerable degree, both represent adolescence - the link between adolescence and 
possibility. Nancy appears most prominently in the first section of the novel, when she is out hiking with Paul Rayley and Minta Doyle. During this trip, Paul is on the cusp of proposing marriage to Minta. He feels nervous and so does Minta—both are uncertain about their future. It is one of the most important decisions that the two will make, a fork in the road, two distinct futures. Based on this choice, the future of each will completely transform; but nothing is certain, verification impossible — one can only leap. So, there comes a point when Minta grasps Nancy's hand, releases it, takes it again, lets it go, and so on: Nancy senses why Minta is so nervous—-she will make a decision that will shape her entire life. For, it is true, deep profound connection determines meaning, the world a potential source of inspiration, fulfillment in the distance but visible. Nancy registers this dynamic, that love and marriage could be hers, all of its possibility, all of its potential disappointment: "When Minta took her hand and held it, Nancy, reluctantly, saw the whole world spread out beneath her" (Woolf, To the Lighthouse 73). Nancy instantly intuits that the world itself is shaped by one's decisions and one's relationships; options and choices are inevitable. Each path is bound to be misshapen in some way, flawed and limited. Furthermore, these potentialities are rarely one-sided: something might be gained, but something is also lost. So, when Minta loses her brooch and cries, Nancy feels that Minta is not only lamenting her lost brooch; Minta is emotional because she is growing up and decisions are on the horizon, because her elections are likely flawed, bound to lose even as she gains: "It might be true that she minded losing her brooch, but she wasn't crying only for that. She was crying for something else. We might all sit down and cry, she felt. But she did not know what for" (Woolf, To the Lighthouse 77). No matter her decision, Minta will suffer dissapointment. All relationships are imperfect- 
here tension, there conflict, the differences insuperable. Or-perhaps better, perhaps worse - one is alone, in charge of one's destiny, but uncertain about its meaning and importance, no one there to support or challenge it.

Cam, for her part, hardly appears in the first section of the novel, but figures more prominently in the final section, when she, James, and their father travel to the lighthouse. During this trip her adolescent mindset appears in bold relief: the world awaits, almost anything possible. During this trip she daydreams, released from habit, out on the water, on an adventure, her sensations new and special: "It was the sense of adventure and escape that she wanted [...] From her hand [...] there spurted up a fountain of joy $[\ldots]$. And the drops falling from this sudden and unthinking fountain of joy fell here and there on the dark, the slumbrous shapes in her mind; shapes of a world not realized but turning in there darkness, catching here and there, a spark of light; Greece, Rome, Constantinople" (Woolf, To the Lighthouse 189). For Cam, there is an entire world that remains to be realized, awaiting her, at its most powerful when she chooses to engage with it, only possible if she becomes what she might be. To know the world and belong to the world is a primary concern for everyone: how to make it happen? What steps should be taken? There is no direct answer, but the possibility of self-fulfillment is undeniable.

The members of the Ramsay family are the primary characters of this novel, but the houseguests are also critical. Much has already been said about Lilly, but it is also worth discussing the guests as a group, as members of a community that includes the Ramsays. Overall, that so many different and unique personalities have gathered together is of special note. Because there is friendship, because there is dialogue, the world of 
each might expand. In the interaction, one might grow; furthermore, one might notice one's blind spots, those unexamined assumptions that remain unnoticed until revealed by the presence of another. For example, the trio of Mr. Carmichael, Charles Tansley, and Mrs. Ramsay: each represents an alternative to the other, a reproach and a rebuke, a means of contrast. Each so different, when one sees the world through the eyes of the other, one's entire outlook becomes skewed, strange, wobbly: "Her going was a reproach to them, gave a different twist to the world, so that they were led to protest, seeing their prepossessions disappear, and clutch at them vanishing. Charles Tansley did that too: it was part of the reason why one disliked him. He upset the proportions of one's world" (Woolf, To the Lighthouse 196). Both Mr. Carmichael and Charles Tansley are oriented towards thinking and contemplation, while Mrs. Ramsay is drawn towards action; when they interact, each sees the limitedness of his or her personal outlook and position.

At the same time, in community, in sharing, there is a sense of enlargement. Because of the differences - and in spite of them - the world becomes more. It is a dynamic where the similarities and the differences blend and respond to each other- the outcome now more refined because the similarities push one to highlight priorities and the differences push one to discard irrelevancies. In sharing the world there is a sense of corroboration and refinement, of understanding better and more; that there are differences at all is part of the appeal: "That was his way of looking, different from hers. But looking together united them" (Woolf, To the Lighthouse 97). Mr. Bankes and Mrs. Ramsay are united when the two look at the same thing, the thing now more vibrant and so too Mr. Bankes and Mrs. Ramsay. And it is this sensation of common experience that stands out when the entire house gathers for dinner. The world is filled with infinite possibility, with 
an infinite variety of people, but these people find themselves in this particular house, immersed in this particular dinner, with these particular people; at this moment, the world is something concrete and definite. Instead of anything, they are engaged with something. To have a place, to be with people who matter, who care-in this there is tremendous value, instead of uncertainty, stability and reassurance: "they were all conscious of making a party together in a hollow, on an island; had their common cause against that fluidity out there" (Woolf, To the Lighthouse 97). In this case, this collection of individuals has chosen to share and interact with one another; each responds to the other in a way that accounts for the other, allowing for a suspension of subjectivity and an orientation to the group as a whole that leads to unexpected insight and meaning. According to Gadamer, this is the nature of dialogue - in it there is a loss of subjectivity in which the subject matter itself becomes the decisive factor, shaping all who participate: "Neither partner alone constitutes the determining factor; rather, it is the unified form of movement as a whole that unifies the fluid activity of both. We can formulate this idea as a theoretical generalization by saying that the individual self, including his activity and his understanding of himself, is taken up into a higher determination that is really the decisive factor" ("On the Problem of Self Understanding” 54). The outcome of this grouping is unpredictable - the resultant feelings, conversation, glances and looks, are necessarily spontaneous and of the moment: no one knows if this dinner will be special, if it will lodge itself in the memory of these individuals, if it will, by chance, shift meaning into clearer focus. But this feeling of togetherness is the first step, a loss of self that allows one to see from a different perspective, swept up by the group. 
This sense of potential, that the dinner could be special, memorable and important is most acutely felt by Mrs. Ramsay. She possesses a highly attuned awareness of people and their concerns: she knows that this dinner — and the shared experience that it implies - is both a challenge and an opportunity. She acknowledges that individual differences are hard to overcome, that each has his or her particular priorities; community also comprehends acrimony, bitterness, and resentment. But she also accepts that the challenge is worth confronting. No matter the pain, the reward is worth it. So she links people together, so she insists that everyone dine in unity. At the same time, there is no guarantee that people will get along, that the conversation will soar, that people will feel comfortable. Everyone may be caught up in his or her particular concerns, as when Mrs. Ramsay wonders to herself, "But what have I done with my life?" (Woolf, To the Lighthouse 82). At this point Mrs. Ramsay feels disconnected from her family, her friends, and the world. She feels as if she has done nothing worthwhile, as if nothing matters. Each person is separate, apart from the other other, nothing in common, no unity. Directly, Mrs. Ramsay experiences the urge to merge these disparate personalities, to experience unity —in doing so she might reconnect with her greatest ability and accomplishment, her weightiest responsibility: "Nothing seemed to have merged. They all sat separate. And the whole of the effort of merging and flowing and creating rested on her" (Woolf, To the Lighthouse 83). Mrs. Ramsay binds them together, a source of commonality, each connected to her in some way. She takes on the responsibility because she has the capacity to do so; she knows that the potential reward is worth the sacrifice; everyone might feel as if he or she belongs; each might feel at home, the world suddenly truer and more understandable. 
If they are lucky, the group might amble into a meadow of peace and ease, of comfort, where there is no strain, the feelings completely natural, unforced, where each feels exalted, uplifted. According to Gadamer, this is the nature of dialogue, of play: "It is part of play that the movement is not only without goal or purpose but also without effort. It happens, as it were, by itself. The ease of play—which naturally does not mean that there is any real absence of effort but refers phenomenologically only to the absence of strain - is experienced subjectively as relaxation. The structure of play absorbs the player into itself, and thus frees him from the burden of taking the initiative, which constitutes the actual strain of existence" (Truth and Method 105). Near the end of the dinner, Mrs. Ramsay does feel this way-everyone is together and this togetherness is as it should be:

Everything seemed right. Just now (but this cannot last, she thought, dissociating herself from the moment while they were all talking about boots) just now she had reached security; she hovered like a hawk suspended; like a flag floated in an element of joy which filled every nerve of her body fully and sweetly, not noisily, solemnly rather, for it arose, she thought, looking at them all eating there, from husband and children and friends; all of which rising in this profound stillness (she was helping Mr. Bankes to one very small piece more, and peered in the depths of the earthenware pot) seemed now for no special reason to stay there like a smoke, like a fume rising upwards, holding them safe together (Woolf, To the Lighthouse 104-5).

To Mrs. Ramsay then, this group brought together is its own special entity, one that is of special value precisely because of its uniqueness, because the group is capable of overcoming strife, because, despite the differences, each person means something to the other. To Mrs. Ramsay, this mood of unity and togetherness is what matters most; people do connect, people do depend on each other-these needs are eternal; when people 
experience this connection, it is a moment that lasts, one that is decisive and defines all subsequent experience, all engagement with otherness, all potential growth:

Nothing need be said; nothing could be said. There it was, all round them. It partook, she felt, carefully helping Mr. Bankes to a specially tender piece, of eternity; as she had already felt about something different once before that afternoon; there is a coherence in things, a stability; something, she meant, is immune from change and shines out (she glanced at the window with its ripple of reflected lights) in the face of the flowing, the fleeting, the spectral, like a ruby; so that again tonight she had the feeling she had had once today, already, of peace, of rest. Of such moments, she thought, the thing is made that endures (Woolf, To the Lighthouse 105).

It is only because of moments like these that the world means anything at all. It is only because people bond with one another and begin to care that the world inspires and compels. It is not an act of consciousness; in the moment, one does not know what is happening; instead, it is a matter of attunement to the other, to the subject matter; the world springs forth as something meaningful, as something irrefutable and undeniable while still withholding its innermost meaning.

In the first section of the novel, "The Window", the reader gets a sense for the Ramsay family and their houseguests: their concerns, their values, their goals. In particular, the reader sees that Mrs. Ramsay is at the heart of this group - she is the binding agent that enables and empowers each person to belong and share. But then Mrs. Ramsay dies, ten years pass, and the dynamics change considerably. In this final section, “The Lighthouse", Mr. Ramsay and two of his adolescent children, James and Cam, are en route to the lighthouse. Also, Lilly returns to the summer home and chooses to finish her painting, the very same one she began ten years earlier. In the end, all attain their 
objectives: the Ramsays reach the lighthouse and Lilly completes her painting. The meaningfulness of these goals and their resolution are informed by the first section, when Mrs. Ramsay and all of the Ramsay children were still alive, the War still in the distance; they are also informed by the passage of time and all that it implies. In the dividing section, then, the reader is tasked with directly engaging with time-its identity, its elusiveness.

For Woolf does not present time as something immediately understandable or straightforward; it is, instead, vague and slippery. It is something that envelops, unavoidable, unknowable because its dominion has already been asserted before it has even been recognized. Time does not care; time does not stop; time is impersonal. Certainly, belonging to time and as a part of time, people already understand; the passage of time and the development of meaning are unavoidable; the world and human being necessarily correspond and it is inevitable that this world discloses itself as each person grows and changes. There are, of course, moments in time, when the individual feels that the world's meaningfulness has been revealed, finally understandable— - but this epiphany is only temporary and so too this feeling of completeness - the passage of time will necessarily confound too:

It seemed now as if, touched by human penitence and all its toil, divine goodness had parted the curtain and displayed behind it, single, distinct, the hare erect; the wave falling; the boat rocking, which, did we deserve them, should be ours always. But alas, divine goodness, twitching the cord, draws the curtain; it does not please him; he covers his treasures in a drench of hail, and so breaks them, so confuses them that it seems impossible that their calm should ever return or that we should ever compose from their fragments a perfect whole or read in the littered pieces the clear words of truth. For our penitence deserves a 
glimpse only; our toil respite only (Woolf, To the

Lighthouse 127-8).

Effort, engagement, and humility have their rewards: one might approach the world for what it is. But this reward is only temporary and brings with it corresponding challenges; for once one has finally understood, the world has already swiveled, meaning has already shifted; this understanding still serves as a light in darkness, as a foundation for understanding, but truth remains elusive —-something right there, yet forever one step ahead. No matter how much one wants to understand, no matter how precise and accurate one might be, one cannot fully account for or overcome one's hermeneutical situation; one's limitedness and givenness necessarily lead to interpretation: "It is not only that historical tradition and the natural order of life constitute the unity of the world in which we live as men; the way we experience one another, the way we experience historical traditions, the way we experience the natural givenness of our existence and of our world, constitute a truly hermeneutic universe, in which we are not imprisoned, as if behind insurmountable barriers, but to which we are opened" (Gadamer, Truth and Method xxiii). We are opened to the world and this access point demands adjustment and agility if we hope to approach truth - a correspondence between the individual, the moment, and the world.

The passage of time includes difference and even finality—death: Mrs. Ramsay perishes during this interlude and so too Prue and Andrew (Andrew because of the war and Prue in childbirth). As time passes, events occur and they are mostly a matter of providence, out of one's control—one is bound to be disappointed, to struggle; oftentimes there is no recourse, no answer. Despite the impersonality of time and its ravages, a 
feeling of possibility still remains: one might understand, one might find an answer; despite the confusion and the chaos, the world and one's place in it might be understood, the essential relations of things might be uncovered: "The mystic, the visionary, walking the beach on a fine night, stirring a puddle, looking at a stone, asking themselves 'What am I,' 'What is this?' had suddenly an answer vouchsafed them: (they could not say what it was) so that they were warm in the frost and had comfort in the desert" (Woolf, To the Lighthouse 131). There is always a sense that the answer is one turn around the corner, that this feeling (despite the impossibility of permanently grasping it) is enough; the potential is what comforts, motivating the seeker to continue looking. According to Gadamer, one cannot help but understand and it is time that requires an adjustment to difference, to change, even if the answer always outpaces the question and questioner: "understanding is not just one of the various possible behaviors of the subject but the mode of being of Dasein itself. It is in this sense that the term 'hermeneutics has been used here. It denotes the basic being-in motion of Dasein that constitutes its finitude and historicity, and hence embraces the whole of its experience of the world. Not caprice, or even an elaboration of a single aspect, but the nature of the thing itself makes the movement of understanding comprehensive and universal" (Truth and Method xxvii).

Yes, the ultimate goal is to attain a correspondence between the way the world truly is and the way one sees it. But there is no guarantee; one is bound to be uneasy and uncertain; but one keeps searching; the possibility of an answer is only open to those who seek:

As summer neared, as evenings lengthened, there came to the wakeful, the hopeful, walking the beach, stirring the pool, imaginations of the strangest kind —of flesh turned to 
atoms which drove before the wind, of stars flashing in their hearts, of cliff, sea, cloud, and sky brought purposely together to assemble outwardly the scattered parts of the vision within. In those mirrors, the minds of men, in those pools of uneasy water, in which clouds for ever turn and shadows form, dreams persisted, and it was impossible to resist the strange intimation which every gull, flower, tree, man and woman, and the white earth itself seemed to declare (but if questioned at once to withdraw) that good triumphs, happiness prevails, order rules; or to resist the extraordinary stimulus to range hither and thither in search of some absolute good, some crystal of intensity, remote from the known pleasures and familiar virtues, something alien to the processes of domestic life, single, hard, bright, like a diamond in the sand, which would render the possessor secure (Woolf, To the Lighthouse 131-2).

Yes, in the world, one notices an order and one wishes to be on par with this order;

maybe by paying close attention one can truly understand. Maybe in the world there are hints that help explain how to organize one's very being, how to be at all. One wants an assurance, a means of easing uncertainty.

But there are no final answers. People are limited, flawed; every vision, every view, every answer is bound to disappoint and miss the target; these flaws are patent, unavoidable; the world is bound to be skewed:

Did Nature supplement what man advanced? Did she complete what he began? With equal complacence she saw his misery, his meanness, and his torture. That dream, of sharing, completing, of finding in solitude on the beach an answer, was then but a reflection in a mirror, and the mirror itself was but the surface glassiness which forms in quiescence when the nobler powers sleep beneath? Impatient, despairing yet loth to go (for beauty offers her lures, has her consolations), to pace the beach was impossible; contemplation was unendurable; the mirror was broken (Woolf, To the Lighthouse 134). 
During this section of the novel, the theme of war appears most prominently, as when the narrative describes Andrew's death, or “the silent apparition of an ashen-colored ship for instance, come, gone; there was a purplish stain upon the bland surface of the sea as if something had boiled and bled, invisibly, beneath" (Woolf, To the Lighthouse 133-4). One gets the sense that there is a link between time, understanding, and war. In this scheme, war is a result of misdirected understanding, of people who fail to acknowledge the necessity and importance of interpretation, of people who see the world as an object to be controlled and mastered. If the world is the same for everyone, if it is subject to dominance, then the essential value, worth, and contribution of individuals is minimized: people become expendable, peripheral to truth and meaning. War is the result of the passage of time if people do not adjust to the interpretive demands of difference and change; interpretation includes an acknowledgement of the value and contribution of the other; every attempt to interpret with clarity corresponds to an elevation of meaning and human connection. 


\section{CHAPTER 7}

\section{CONCLUSION}

To sum up, Hans-Georg Gadamer's philosophical hermeneutics and Virginia Woolf's novels highlight and emphasize the interpretive opportunity and responsibility of the individual. This commonality lends itself to an analysis of both Woolf's novels and Gadamer's philophical outlook: by probing Woolf's novels in light of Gadamer's philosophy, one gains an improved understanding of the reference of the words that inhabit her novels, words that have been combined to create a fictional world in which the characters understand better or worse - fail or succeed-based on their willingness to privilege and confront those experiences and situations that shape consciousness, those experiences that determine how and what one understands. By relating Gadamer's philosophy to Woolf's novels, one engages with an enactment and practical instantiation of Gadamer's philosophical approach. Gadamer stresses the link between the literary text and one's interpretation of daily existence. In all cases, the literary text is only understandable as it relates to one's world and one's world becomes more understandable as it interacts with the literary text. Through interrogation of this interaction, one confronts the concept of interpretation and its implications.

Interpretation, for its part, hinges on the indivisibility between language, meaning, and world. Language is necessarily interpretive; the meaning of the world and its appearance in language constitute a non-distinction. That the world meaningfully appears 
in language is of special importance; human being is tuned to engage with the appearance and the meaning of the world and art belongs to this process. An artwork engages one's perceptions of the world and its meaningfulness; by means of art one might gain insight and understand better. In all cases - whenever and wherever the concept of interpretation is involved - the dialogical situation is crucial. All language use, all interpretation, belongs to a concrete situation and this situation determines the understandability and appropriateness of all statements and assertions.

Embedded in their cultural and historical worlds, Woolf's fiction and Gadamer's philosophy arose in response to the encroaching impersonality of scientific objectivity, an objectivity that can be directly linked to World War I, inequality, subjugation, and exploitation. As a riposte to the contention that the world can be objectively understood, Woolf and Gadamer argue that the world is understood uniquely and individually, according to the person who understands. Meaning is in constant evolution, dependent on the level of participation and engagement of the individual. Furthermore, in the interaction with others, with artworks and texts, the world necessarily becomes more understandable, its meaning in clearer focus. This emphasis on the contribution and participation of the individual in the meaningfulness of the world lends itself to a recognition and acknowledgement of the essential dignity, value and worth of the individual; all people should be respected and each person has something to gain through dialogue and personal connection.

Woolf and Gadamer's response to the subject-object dichotomy endemic to scientific method belongs to the larger philosophical, intellectual, and artistic movement known as Modernism. To the Modernists, Western civilization had lost its course, on the 
brink of mass annihilation. Certainly, in the way people treated one another, in the way societies were organized and countries interacted, there was a widespread feeling of malaise and sickness. If civilization were to proceed in the same direction, unchecked, the consequences could be enormously destructive. This potential for mass destruction, this devaluing of human life, has its roots in the levelling process that belongs to scientific objectivity: if the entirety of the world can be objectively understood, then the contribution and the value of the individual is diminished. Furthermore, this objectivity elides the potential for community and solidarity. With people as mere instruments, the potential of shared experience and the consequent insight is discounted. In response, the Modernists stressed the uniqueness of each individual as he or she interacts with the world and the potential insight and expansion of one's world as he or she interacts with others. In addition, interpretation itself took on a special role in Modernism, as interpretation necessarily implies the unique contribution and experience of the individual. To this end, the Modernists stressed the importance and centrality of art, as it necessarily engages one's interpretive faculties, pushing one to think more, differently, and creatively.

Using these concepts as an organizing principle — in particular, the notion that subject and object belong together when the world appears in language- - I chose to interpret Mrs. Dalloway and To the Lighthouse, two novels that highlight the individual's interpretive opportunity and responsibility. Mrs. Dalloway, for its part, is about a June day in London, the war recently ended, still reverberating, and the variety of ways that its inhabitants experience one moment to the next. In this novel, each character has a unique, personal history, with a particular way of understanding and being in the world. It is 
based on this particularity that each individual confronts the fluidity of the day, each in search of resolution and coherence. This notion of particularity, of the uniqueness of the subject is reflective of Modernism. According to the Modernist mindset, each individual was seen to inhabit his or her particular world, and this particularity shaped how each person interpreted and understood the moment in time; it was up to the individual to incorporate and account for this uniqueness instead of approaching the moment with a one-size-fits-all approach. Certainly, in the characters of Clarissa Dalloway, Peter Walsh, and Septimus Warren Smith one notices this emphasis on subjectivity and the interpretive thrust belonging to this subjectivity. In particular, Clarissa and Peter persistently contemplate their personal situation and circumstance, always trying to understand how the present moment fits with their personal past and potential future. Though somewhat estranged, Clarissa and Peter's deep connection and shared past are decisive for how each understands the world. In order to understand the present moment, both consistently return to the other, as both have a sense that this relationship is still imminently influential, still formative of the horizon of each. The two acknowledge that the world is both understandable and mysterious and this recognition informs their approach to understanding; instead of trying to master the moment and the meaning understood, the two place themselves in situations where meaning might spring forth, the result of dialogue and a shared world. Peter and Clarissa privilege experiences of meaning and dialogue because each has a sense that his or her understanding, his or her ability to control what is understood, is limited. This sense that one is not fully in control of one's mind, of one's consciousness, constitutes a Modernist trope. Before one is even aware of it, one's consciousness has been shaped, and this shaping is decisive for understanding. 
Furthermore, scientific objectivity itself hinges on the sovereignty of consciousness and in these characters one notices a subversion of this sovereignty. As for Septimus, he represents what might happen when the present moment fails to cohere with the past and a potential future. Septimus' mindset and outlook is skewed by the war; a witness and participant in bloodshed and carnage, he was forced to disconnect from people, the feelings too intense to process. No longer able to connect with people and estranged from his past, Septimus now lives in a solipsistic world, lacking corroboration and inspiration, inevitably warped. Eventually, Septimus decides to commit suicide, the only means of reaching resolution. In the character of Septimus, then, one notices an extreme example of this Modernist trope of subjectivity—how one's past and experiences can determine meaning, the intense need to square the meaning of the world with one's experience of the world. Overall, the goal of each character is to live in a world that belongs to them and to which they belong, a need reflective of the loss of grounding and the corresponding search for grounding that is characteristic of the modern world. The extent of their success in this endeavor depends on their willingness to privilege personal relationships and their potential yield. In dialogue and in interaction with others, one never knows what the yield will be, but the difference of the other necessarily leads to insight and improved understanding. So these characters seek out experiences that will contribute to interpretive clarity, aware that the meaning of the world depends on their participation.

For its part, To the Lighthouse explores the borders that exist between individuals, the difference and affinity that represent both a challenge and an opportunity. That is, each individual is particular and unique, yet shared experience and meaning belong to 
this individuality. The characters in this novel mediate the polarities of familiarity and strangeness. As the characters interact, their horizons of understanding and meaning expand and refine. As with Mrs. Dalloway, one also notices in this novel a heavy accent on subjectivity, on the uniqueness, depth, and unfathomability of the individual and the manner in which the individual's world shifts and changes. This emphasis on subjectivity constitutes one of Modernism's salient tropes, a direct rebuke to the impersonal objectivity of the modern world. So, the world of each character alters as time passes and each engages with others. In particular, one notices a triangular relationship between Lilly Briscoe, and Mr. and Mrs. Ramsay. In the novel, Lilly paints a scene in which she aims to represent her understanding of this family and how it relates to the meaning of the world. To Lilly, this painting represents an opportunity to understand the world for what it is, as a painting is a meaningful whole in which all of the parts fit together, components that represent one's perception of the world. That art is capable of ordering one's world and providing insight is of special importance. The Modernists, in fact, considered art to be an essential means of order and understanding. With the world—and its objective underpinnings - mired in chaos and destruction, art was considered to be an antidote, a means of engaging one's subjective experience, an experience that directly refutes impersonal objectivity while necessarily involving one's sense of meaning and understanding. For Lilly, this painting is a way to engage with her particular way of understanding and it is also a means of engaging with the unique subjectivity of Mr. and Mrs. Ramsay. In the case of Mr. Ramsay, his life's work consists of interrogating the individual's interaction with the world and he does so with the utmost intensity, concentration, and effort. As for Mrs. Ramsay, she privileges those experiences of 
personal connection, drawn to them, aware that in them the world might appear with greater clarity. In all, these characters participate in the meaning of the world, always aware of the provisionality of this understanding, yet still willing to seek out experiences that will push them to become more, experiences that will yield truth even as the world remains shrouded in mystery.

Overall, then, one's interpretive opportunity and responsibility cannot and should not be denied. Each individual belongs to the world and, before he or she even realizes it, the world and its meaning has already asserted itself. All one can do is accept one's place in the world and respond accordingly. By engaging with others, with artworks and texts, one is afforded the opportunity to confront one's understanding and refine one's understanding. In this confrontation, one might discard falsehood and embrace truth. But it is not a matter of conscious effort; it is a matter of attention and engagement; it is a matter of letting what is to be. But the nature of the thing itself depends on the present moment and situation; to interpret with clarity it is necessary to adapt, to consider all of the contributing factors that determine the thing understood, to include one's very participation in the meaning of the world. This need to adapt, this emphasis on movement, is reflective of the Modernist mindset. The Modernists recognized that the world is different according to the individual, that this subjectivity is primary. Instead of blindly accepting that the subject is master of his or her consciousness, the Modernists stressed that this subjectivity is limited, that this limitation should be incorporated into one's approach to understanding. This subjectivity —in its inherent limitedness and its capacity for change and expansion—directly refutes the impersonality of scientific objectivity, an objectivity that elides the essential value and contribution of one's fellow 
being. Furthermore, Woolf's novels themselves are a refutation of this objectivity, as their very subject matter destabilizes static notions of world, self, and reality. Many critics have chosen to interpret Woolf through a philosophical lens, but they fail to fully appreciate Woolf's radical critique of objectivity, with these interpretations themselves dependent on the stability and permanence of the subject and object. 


\section{REFERENCES}

Auerbach, Eric. "The Brown Stocking." Virginia Woolf: A Collection of Critical Essays. Englewood Cliffs: Prentice Hall, 1993. Print.

Beer, Gillian. Virginia Woolf: The Common Ground. Ann Arbor: The University of Michigan Press, 1996. Print.

Beja, Morris. Epiphany in the Modern Novel. Seattle: University of Washington Press, 1971. Print.

Bell, Michael. "The Metaphysics of Modernism." The Cambridge Companion to Modernism. Ed. Michael H. Levenson. Cambridge: Cambridge UP, 1999. Print

Bruns, Gerald. "The Hermeneutic Anarchist: Phronesis, Rhetoric, and the Experience of Art." Gadamer's Century: Essays in Honor of Hans-Georg Gadamer. Eds. Jeff Malpas, Ulrich Answald, and Jens Kertscher. Cambridge: The MIT Press, 2002. Print.

Davey, Nicholas. "Hans-Georg Gadamer." Key Writers on Art: $20^{\text {th }}$ Century. Ed. Chris Murray. New York: Routledge, 2003. Print.

DeMeester, Karen. “Trauma and Recovery in Virginia Woolf's Mrs. Dalloway.” Modern Fiction Studies 44.3 (1998): 649-67.DiBattista, Maria. Virginia Woolf's Major

Novels: The Fables of Anon. New Haven: Yale UP, 1980. Print.

Duran, Jane. "Virginia Woolf, Time, and the Real." Philosophy and Literature 28.2 (Oct. 
2004): 300-09. Print.

Eysteinsson, Astradur. The Concept of Modernism. Ithaca: Cornell UP, 1990. Print.

Fernihough, Anne. "Consciousness as a Stream." The Cambridge Companion to the Modernist Novel. Ed. Morag Shiach. Cambridge: Cambridge UP, 2007.

Fiero, Gloria K. The Humanistic Tradition. $5^{\text {th }}$ ed. Book 6. New York: McGraw-Hill, 2006. Print.

Figal, Gunter. “The Doing of the Thing Itself: Gadamer's Hermeneutic Ontology of Language." The Cambridge Companion to Gadamer. Ed. Robert J. Dostal. Cambridge: Cambridge UP, 2002. Print.

Frank, A.O. The Philosophy of Virginia Woolf: A Philosophical Reading of the Mature Novels. Budapest: Akademiai Kiado, 2001. Print.

Gadamer, Hans-Georg. "Art and Imitation." The Relevance of the Beautiful and Other Essays. Trans. Nicholas Walker. Ed. Robert Bernasconi. Cambridge: Cambridge UP, 1986. Print.

---. "Boundaries of Language.” Language and Linguisticality in Gadamer's Hermeneutics. Trans. and ed. Lawrence K. Schmidt. Lanham: Lexington Books, 2000. Print.

---. "Culture and the Word.” Praise of Theory: Speeches and Essays. Trans. Chris Dawson. New Haven: Yale UP, 1998.

---. "Composition and Interpretation." The Relevance of the Beautiful and Other Essays. Trans. Nicholas Walker. Ed. Robert Bernasconi. Cambridge: Cambridge UP, 1986. Print. 
---. "The Eminent Text and Its Truth." The Bulletin of the Midwest Language Association 13.1 (Spring 1980): 3-10. Print.

---. "The Expressive Force of Language: On the Function of Rhetoric in Gaining Knowledge." Praise of Theory: Speeches and Essays. Trans. Chris Dawson. New Haven: Yale UP, 1998. Print.

---. Introduction. "From Word to Concept: The Task of Hermeneutics as Philosophy." Gadamer's Repercussions: Reconsidering Philosophical Hermeneutics. Trans. Richard E. Palmer. Ed. Bruce Krajewski. Berkeley: University of California Press, 2004. Print.

---. Gadamer on Celan: 'Who Am I and Who Are You?' and Other Essays. Trans. and Ed. Richard Heinemann and Bruce Krajewski. Albany: SUNY Press, 1997. Print.

---. Gadamer in Conversation: Reflections and Commentary. Trans. and ed. Richard E. Palmer. New Haven: Yale UP, 2001. Print.

---. Hans-Georg Gadamer on Education, Poetry, and History: Applied Hermeneutics. Eds. Dieter Misgeld and Graeme Nicholson. Trans. Lawrence Schmidt and Monica Reuss. Albany: SUNY Press, 1992. Print.

---. "Man and Language." Philosophical Hermeneutics. Ed. and trans. David E. Linge. Berkeley: University of California Press, 1976. Print.

--- "The Nature of Things and the Language of Things." Philosophical Hermeneutics. Ed. and trans. David E. Linge. Berkeley: University of California Press, 1976. Print.

---. "On the Contribution of Poetry to the Search for Truth." The Relevance of the Beautiful and Other Essays. Trans. Nicholas Walker. Ed. Robert Bernasconi. 
Cambridge: Cambridge UP, 1986. Print.

---."On the Problem of Self-Understanding." Philosophical Hermeneutics. Ed. and trans.

David E Linge. Berkely: University of California Press, 1976. Print.

---. "On the Truth of the Word." The Specter of Relativism: Truth, Dialogue, and

Phronesis in Philosophical Hermeneutics. Ed. Lawrence K. Schmidt. Evanston:

Northwestern UP, 1995. Print.

---. Philosophical Hermeneutics. Ed. and trans. David E. Linge. Berkeley: University of

California Press, 1976. Print.

---. "The Play of Art." The Relevance of the Beautiful and Other Essays. Trans. Nicholas

Walker. Ed. Robert Bernasconi. Cambridge: Cambridge UP, 1986. Print.

---. "Poetry and Mimesis." The Relevance of the Beautiful and Other Essays. Trans.

Nicholas Walker. Ed. Robert Bernasconi. Cambridge: Cambridge UP, 1986. Print.

---. Praise of Theory: Speeches and Essays. Trans. Chris Dawson. New Haven: Yale UP, 1998. Print.

---. "Reflections on My Philosophical Journey." The Philosophy of Hans-Georg

Gadamer. Ed. Lewis Edwin Hahn. Trans. Richard E. Palmer. Chicago: Open

Court Publishing, 1997. Print.

---. The Relevance of the Beautiful and Other Essays. Trans. Nicholas Walker. Ed. Robert

Bernasconi. Cambridge: Cambridge UP, 1986. Print.

---. "Text and Interpretation." Dialogue and Deconstruction: The Gadamer-Derrida

Encounter. Eds. Diane P. Michelfelder and Richard E. Palmer. Trans. Dennish J. Schmidt and Richard Palmer. Albany: SUNY Press, 1989. Print.

---. "Towards a Phenomenology of Ritual and Language." Language and Linguisticality 
in Gadamer's Hermeneutics. Trans. and ed. Lawrence K. Schmidt. Lanham:

Lexington Books, 2000. Print.

---. Truth and Method, Second Revised Edition. Trans. Joel Weinsheimer and Donald G.

Marshall. New York: Crossroad Publishing, 1989. Print.

--- "The Truth of the Work of Art." Heidegger's Ways. Trans. John W. Stanley. Albany:

SUNY Press, 1994. Print.

---. "The Universality of the Hermeneutical Problem.” Philosophical Hermeneutics. Ed. and trans. David E. Linge. Berkeley: University of California Press, 1976. Print.

---. "What is Truth?" Hermeneutics and Truth. Ed. Brice. R. Wachterhauser. Evanston: Northwestern UP, 1994. Print.

Grondin, Jean. “Gadamer's Basic Understanding of Understanding." The Cambridge Companion to Gadamer. Ed. Robert J. Dostal. Cambridge: Cambridge UP, 2002. Print.

Hafley, James. "Virginia Woolf's Narrators and the Art of Life." Virginia Woolf: Revaluation and Continuity. Ed. Ralph Freedman. Berkeley: University of California Press, 1980. Print.

Harper, Howard. Between Language and Silence: The Novels of Virginia Woolf. Baton Rouge: Louisiana UP, 1982. Print.

Herrmann, Anne. The Dialogic and Difference: 'An/Other Woman' in Virginia Woolf and Christa Wolf. New York: Columbia UP, 1989. Print.

Hussey, Mark. "Living in a War Zone: An Introduction to Virginia Woolf as a War Novelist." Virginia Woolf and War. Ed. Mark Hussey. Syracuse: Syracuse UP, 1991. Print. 
---. The Singing of the Real World: The Philosophy of Virginia Woolf's Fiction.

Columbus: Ohio State UP, 1986. Print.

---. "Woolf: After Lives." Virginia Woolf in Context. Ed. Bryony Randall and Jane

Goldman. Cambridge: Cambridge UP, 2012. Print.

Ingram, Penelope. “'One Drifts Apart': To The Lighthouse as Art of Response.”

Philosophy and Literature 23.1 (1999): 78-95.

Kern, Stephen. The Culture of Time and Space: 1880-1918. Cambridge: Harvard UP, 2003. Print.

Kertscher, Jens. “'We Understand Differently If We Understand at All': Gadamer's Ontology of Language Reconsidered." Gadamer's Century: Essays in Honor of Hans-Georg Gadamer. Eds. Jeff Malpas, Ulrich Answald, and Jens Kertscher. Cambridge: The MIT Press, 2002. Print.

Levenson, Michael H. Introduction. The Combridge Companion to Modernism. Ed. Michael H. Levenson. Cambridge: Cambridge UP, 1999. Print.

Matthews, Roy T., and F. DeWitt Platt. The Western Humanities. $5^{\text {th }}$ ed. New York: Mcgraw-Hill, 2004. Print.

O'Neill, Linda. “Embodied Hermeneutics: Gadamer meets Woolf in A Room of One's Own." Educational Theory 57.3 (2007): 325-37. Print.

Payne, Michael. "Beyond Gender: The Example of 'Mrs. Dalloway'." College Literature 5.1 (Winter, 1978): 1-11. Print.

Ruotolo, Lucio P. The Interrupted Moment: A View of Virginia Woolf's Novels. Stanford: Stanford UP, 1986. Print.

Sallis, John. "The Hermeneutics of Translation." Language and Linguisticality in 
Gadamer's Hermeneutics. Ed. Lawrence K. Schmidt. Lanham: Lexington Books, 2000. Print.

Schwarz, Daniel R. Reading the Modern British \& Irish Novel 1890-1930. Malden, MA: Blackwell Publishing, 2005. Print.

Stevenson, Randall. "Woolf and Modernity: Crisis and Catoptrics.” Virginia Woolf in Context. Ed. Bryony Randall and Jane Goldman. Cambridge: Cambridge UP, 2012. Print.

Storl, Heidi. "Heidegger In Woolf’s Clothing." Philosophy and Literature 32 (2008): 303-14. Print.

Van Buren Kelley, Alice. To the Lighthouse: The Marriage of Life and Art. Boston: Twayne Publishers, 1987. Print.

Weinsheimer, Joel. Philosophical Hermeneutics and Literary Theory. New Haven: Yale UP, 1991. Print.

Winks, Robin W., and Joan Neuberger. Europe and the Making of Modernity, 1815-1914. Oxford: Oxford UP, 2005. Print

Woolf, Virginia. Mrs. Dalloway. London: Harcourt, 1981. Print.

---. To the Lighthouse. Orlando: Harcourt, 1981. Print. 


\section{CURRICULUM VITA}

NAME: Adam Noland

ADDRESS: Department of Humanities 2301, S. $3^{\text {rd }}$ St.

University of Louisville

Louisville, KY 40208

DOB : Louisville, Kentucky—August 18, 1983

EDUCATION

\& TRAINING : B.A., Spanish

Earlham College, Spring 2005

M.A., Spanish

University of Louisville, December 2007

Ph.D., Interdisciplinary Humanities

University of Louisville,

2008-2015

TEACHING EXPERIENCE: $\quad$ Part-time Lecturer, University of Louisville, August 2008-Present

Basic Spanish program, 2 or 3 courses each semester, 20-25 students per course

\section{TEACHING INTERESTS:}

Philosophical hermeneutics, $20^{\text {th }}$ Century and contemporary literature, philosophy of language, Spanish as a second language, Modernism

\section{CONFERENCE PRESENTATIONS:}

Romance Languages Conference, University of Cincinnati (2008). "La presencia dialéctica de Diego Rivera en Querido Diego, te abraza Quiela de Elena Poniatowska"

Louisville Conference on Literature and Culture since 1900, University of Louisville (2007). "El principio ekfrastico en Impar de Vicente Aleixandre" 